\title{
EVOLUTION AND DEVELOPMENT OF THE PAIRED SPIKELET TRAIT IN MAIZE AND OTHER GRASSES (POACEAE)
}

\author{
A Thesis \\ Presented to \\ The Faculty of the Graduate School \\ At the University of Missouri - Columbia

In Partial Fulfillment
Of the Requirements for the Degree
Master of Arts
by
EDEN A. JOHNSON
Dr. Paula McSteen, Thesis Supervisor \\ May 2017
}


The undersigned, appointed by the dean of the Graduate School, have examined the thesis entitled

\section{EVOLUTION AND DEVELOPMENT OF THE PAIRED SPIKELET TRAIT IN MAIZE AND OTHER GRASSES (POACEAE)}

presented by Eden A. Johnson,

a candidate for the degree of master of arts,

and hereby certify that, in their opinion, it is worthy of acceptance.

Professor Paula McSteen

Professor J. Chris Pires

Professor Melissa Mitchum 
Thank you for the support and love, Mom.

I would like to dedicate this Thesis to my parachute and my partner, William. Before you, I was always looking down at grasses; with you, I am reaching for the sky. 


\section{ACKNOWLEDGMENTS}

I am grateful to my thesis committee, specifically Dr. Melissa Mitchum, Dr. Chris Pires, and Dr. David Braun, for their support, time, and expertise throughout my time at the University of Missouri - Columbia. I would also like to thank the members of the Graduate Education Counsel, Nila Emerich and Lori Eggert, for their pursuit and enthusiasm for whatever makes students in the Division of Biological Sciences thrive.

Thank you to my thesis advisor, Dr. Paula McSteen, for enthusiastically recruiting me to $\mathrm{MU}$, for countless rounds of paper revisions, and for providing me with the opportunity to pursue my Master's degree under your guidance. Thank you also to current and previous members of the McSteen lab. Specifically I would like to thank Katy Guthrie, Diana Roberts Coats, and Micha Matthes for your support and assistance inside and outside of the lab, and for keeping me sane throughout our field seasons. Thank you for the help from a number of undergraduates in the lab, whose dedication to this team is unmatched - Kiley Marshall, Joe Struttmann, Amanda Blythe, and Taylor Smith. Thank you also to the new McSteen lab members, Ashten Kimble and Janlo Robil for listening to countless practice presentations in your first year.

This thesis would not have been possible without the thoughtful insights provided by our collaborators at the Donald Danforth Plant Sciences Center, Toby Kellogg and Mei Zhu. Thank you also to the MU facilities I utilized, including the MU Electron Microscopy Core and the Cytology Core, and for useful troubleshooting by Frank Baker.

Finally, I thank my family for their support and guidance, despite still thinking I study cancer. I will miss the smiles given and received in LSC 3W. 


\section{TABLE OF CONTENTS}

ACKNOWLEDGEMENTS ...............................................................

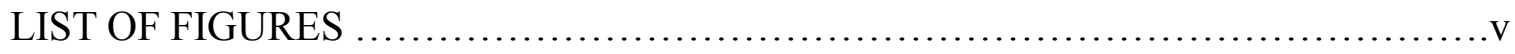

LIST OF TABLES …............................................................... vii

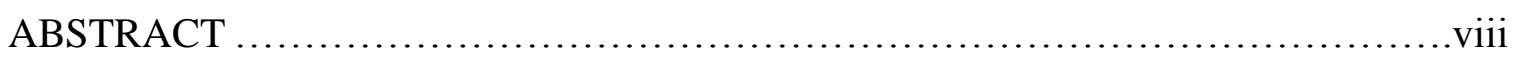

CHAPTER 1 The roles of maintenance and determinacy pathways in meristem initiation and development ................................................... 1

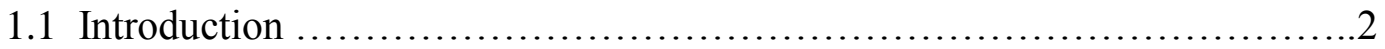

1.1.1 Grass morphology and spikelet traits ...........................2

1.1.2 Meristem types ............................................ 5

1.2 Meristem Maintenance Pathways ....................................... 7

1.2.1 Receptor-kinase signaling pathways regulate meristem maintenance ........................................... 7

1.2.2 Transcription factors and plant hormones contribute to meristem homeostasis .............................................10

1.2.3 Integration of signaling pathways occurs at many levels for normal meristem patterning ........................................14

1.3 Meristem Identity and Determinacy ................................... 17

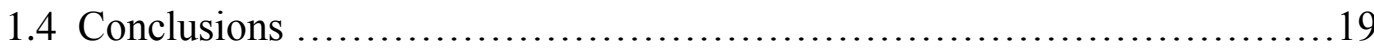

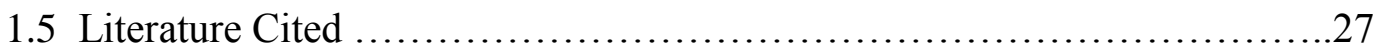

CHAPTER 2 Genetic interaction of Suppressor of sessile spikelet1 (Sos 1) with meristem mutants in the CLAVATA signaling pathway ...............................36

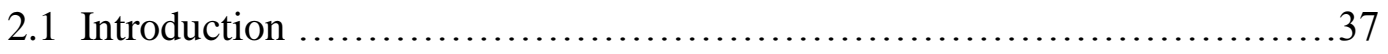

2.1.1 The role of the CLAVATA signaling pathway in meristem maintenance .................................................... 37

2.1.2 Sos 1 may function in the CLAVATA signaling pathway ............40

2.2 Materials and Methods .................................................45

2.2.1 Generating double mutants .................................45

2.2.2 Tassel quantification ........................................46

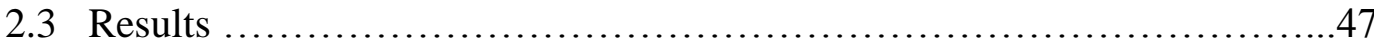

2.3.1 Sos 1 mutants develop additional single spikelets ................47

2.3.2 Double mutant analyses indicate that $t d l$ is epistatic to $\operatorname{Sos} 1$......48

2.3.3 Sos $I$ and $c t 2$ interact additively .............................50

2.3.4 Compensation from other $C L V$ receptors may cause the Sos 1;fea2 double mutant phenotype ..................................51

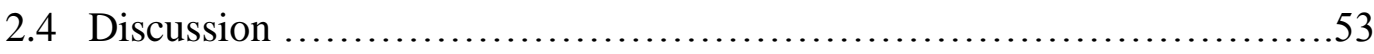

2.4.1 Sos 1 interacts with known orthologs of the CLAVATA signaling

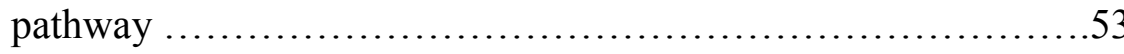


2.4.2 Model for CLAVATA signaling complexes in maize ............55

2.4.3 Reasoning for single spikelets ................................58

2.4.4 Possible function of Sos 1 in meristem determinacy .............60

2.5 Literature Cited ................................................... 78

CHAPTER 3 Elucidating the origin of the paired spikelet trait in the grasses (Poaceae).82

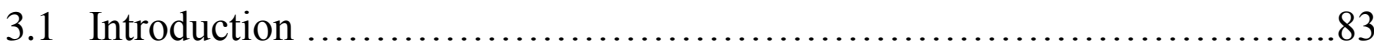

3.1.1 Overview of spikelet development ........................85

3.2 Methods and Results ................................................ 86

3.3 Discussion ......................................................... 91

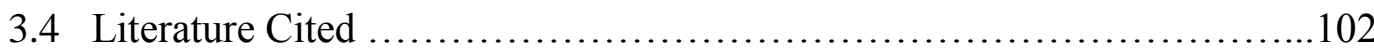

CHAPTER 4 Conclusions and future directions ............................... 106

4.1 Discussion and Conclusions .......................................... 107

4.2 Directions for future research ...................................... 113

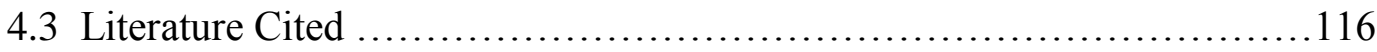

APPENDIX Additional data on the characterization of double mutants between Sos 1 and components of the maize CLAVATA signaling pathway ................118

A.1 Introduction ...................................................... 119

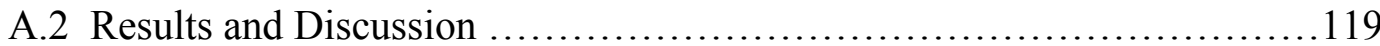

A.2.1 Additional measurements of Sos $1 ; t d 1$ double mutants ...........119

A.2.2 Additional measurements of Sos1;fea2 double mutants .........120

A.2.3 Additional measurements of Sos 1;ct2 double mutants ...........121

A.2.4 Analysis of Sos 1;ct2 double mutants revealed a possible "HET effect" 


\section{LIST OF FIGURES}

Figure 1-1: Phylogeny of the grasses showing the occurrence of single versus paired spikelets

Figure 1-2: Differences in inflorescence morphology between grass species .........22

Figure 1-3: Meristematic zones within an Arabidopsis shoot apical meristem .........23

Figure 1-4: Meristem development occurs in a gradient along the inflorescence ......24

Figure 1-5: CLAVATA signaling components in Arabidopsis and maize .............25

Figure 1-6: Gene regulatory network integrating hormone regulation and signaling

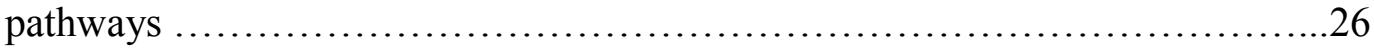

Figure 2-1: CLAVATA signaling components in Arabidopsis and maize .............62

Figure 2-2: $\quad$ Suppressor of sessile spikeletl (Sos 1) phenotype …..................63

Figure 2-3: Analysis of Sos $1 ; t d 1$ double mutant phenotypes ......................64

Figure 2-4: Analysis of Sosl; ct2 double mutant phenotypes ......................65

Figure 2-5: $\quad$ Ear phenotype in Sos1;ct2 double mutant ...........................66

Figure 2-6: Analysis of Sosl;fea2 double mutant phenotypes .....................67

Figure 2-7: $\quad$ Model of proposed receptor complexes .............................68

Figure 3-1: Phylogeny of the grasses showing the occurrence of paired spikelets within three grass tribes ............................................... 97

Figure 3-2: Mesquite ancestral character state reconstruction ......................98

Figure 3-3: Spikelet character mapping onto an expanded phylogeny of the

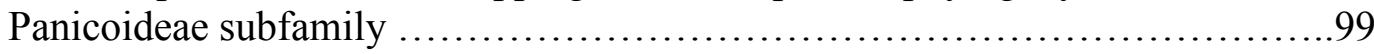

Figure 4-4: Phylogeny of the grass subfamilies indicating that paired spikelets exist outside of the Panicoideae .................................................... 101

Figure A-1: Analysis of branch number in Sos 1;td1 double mutants ...............124

Figure A-2: Analysis of peduncle length in Sosl;tdl double mutants ................125

Figure A-3: Analysis of branch number in Sos 1;fea 2 double mutants ...............126 
Figure A-4: Analysis of peduncle length in Sos 1 ;fea2 double mutants .............127

Figure A-5: Analysis of branch number in Sos $1 ; c t 2$ double mutants ...............128

Figure A-6: $\quad$ Analysis of peduncle length in Sos $1 ; c t 2$ double mutants ...............129 


\section{LIST OF TABLES}

Table 2-1: Quantification of spikelet numbers in plants segregating for the Sos1;td1 double mutant ..........................................................69

Table 2-2: $\quad$ Two-tail t-test values calculated for the number of paired spikelets, single spikelets, and meristem initiations in Sos $1 ; t d 1$ double mutants ................70

Table 2-3: Two-tail t-test values calculated for the differences in main spike length in Sos $1 ; t d 1$ double mutants .............................................71

Table 2-4: Quantification of spikelet numbers in plants segregating for the Sos 1 ;ct2

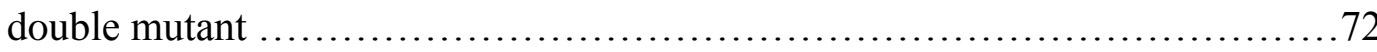

Table 2-5: Two-tail t-test values calculated for the number of paired spikelets, single spikelets, and meristem initiations in Sos 1;ct2 double mutants ................73

Table 2-6: Two-tail t-test values calculated for the differences in main spike length in Sos $1 ; c t 2$ double mutants ................................................. 74

Table 2-7: Quantification of spikelet numbers in plants segregating for the Sos 1;fea2

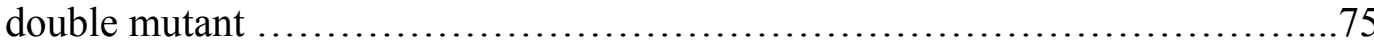

Table 2-8: $\quad$ Two-tail t-test values calculated for the number of paired spikelets, single spikelets, and meristem initiations in Sos 1;fea2 double mutants ...............76

Table 2-9: Two-tail t-test values calculated for the differences in main spike length in Sos1;fea2 double mutants .77 


\begin{abstract}
Meristems are composed of groups of tightly-regulated cells that coordinate the number of stem cells in the central zone of the meristem with the number of cells migrating to organ primordia in the peripheral zones of the meristem. Mutations disturbing this balance can cause significant changes to the resulting plant structure. In order to buffer the meristem against drastic changes, it is necessary to have overlapping pathways regulating meristem maintenance and meristem determinacy. Furthermore, components and functions of these pathways are often conserved between plant lineages. While flowering in Arabidopsis occurs from the direct transition of the shoot apical meristem to a floral meristem, the grasses develop numerous axillary meristems that specify several different structures (i.e. inflorescences, branches, and grass spikelets), making the maintenance and identity of these meristems interesting areas of research. Thus, my first chapter reviews the mechanisms by which meristems are initiated and maintained through the complex organization of meristem size and determinacy pathways in plants.
\end{abstract}

Members of the grass family develop inflorescences composed of spikelets, which house the inconspicuous grass flowers. One compelling difference between grass species is that, while the majority of the approximately 12,000 taxa develop single spikelets, there are also a significant number of species that produce paired spikelets. It is widely acknowledged that the subfamily Panicoideae contains many paired spikelet species, namely within three tribes that include significant crop species (i.e., maize, sorghum, setaria, and switchgrass). However, there are many cereal crops (i.e., wheat and rice) 
which develop single spikelets, indicating that the paired spikelet trait may be important to study as a way to increase yield in single spikelet species.

My research into the semi-dominant maize mutant Suppressor of sessile spikelet 1 (Sosl) investigated the developmental basis behind the paired spikelet trait. While maize plants normally bear paired spikelets, Sos 1 mutants develop single spikelets in the tassel inflorescence and alternating rows of single kernels in the ear. A previous study examined this mutant early in development and revealed that the mutant inflorescence meristems were smaller than normal, which suggested a potential role for the sos 1 gene in meristem maintenance. The objective of my second chapter was to summarize what is known about the Sos 1 mutant, and uncover the role of the sos 1 gene in meristem maintenance. Double mutants were generated between Sos 1 and members of the CLAVATA signaling pathway, which is a well-known pathway shown to be critical for maintaining meristem size in maize, Arabidopsis, and other plant systems. Analysis of these double mutants indicated that sos 1 functions in this important meristem maintenance pathway.

Research into the Sos1 maize mutant also prompted a more in-depth investigation into the evolution of the paired spikelet trait in the grasses, which was previously only assumed to occur in three tribes of the Panicoideae subfamily. The objective of my third chapter was to determine if the paired spikelet trait evolved multiple times in the grasses. My analysis highlighted the fact that the paired spikelet trait originated before the Panicoideae subfamily. This study uncovered that species developing paired spikelets are prevalent in more grass lineages than previously shown, and highlights a pattern of repeated losses and origins of the paired spikelet trait throughout the family. 


\section{CHAPTER ONE}

The roles of maintenance and determinacy pathways in meristem initiation and development

Eden A. Johnson 


\subsection{INTRODUCTION}

\subsubsection{Grass morphology and spikelet traits}

The grass family (Poaceae) is the fifth-largest plant family containing approximately 780 genera with 12,000 species, including staple crops such as wheat, rice, corn, and sorghum (Stevens 2012; Kellogg 2000). Due to the large number of species, the family is divided into twelve subfamilies. Subfamilies with large numbers of species are often further subdivided into tribes. Poaceae is estimated to be approximately 83 million years old (Janssen and Bremer 2004), and is distinguished by long, sheathed leaves with ligules that delineate the junction between the sheath and the blade, round and hollow stems (culms), and inflorescences or "flowering branches" that bear spikelets (Stevens 2012).

With very few exceptions, grasses produce conventional spikelets that consist of one or more florets subtended by additional bracteolate organs called glumes (Kellogg 2000). Grass florets consist of a lemma and palea surrounding the reproductive organs, producing typically bisexual florets, depending on the species. The earliest-diverging grass subfamily, Anomochlooideae, is sister to the rest of Poaceae (Figure 1-1). Anomochlooideae is made up of a few species divided into two genera that develop structures called "pseudospikelets" which lack tissues homologous to the lemma, palea, or leaf-like glumes typical of the rest of the family (Sajo et al. 2008). Excluding Anomochlooideae, the Pharoideae subfamily is sister to the remaining Poaceae lineages 
and contains only one genus, Pharus (Figure 1-1). Species within Pharus represent the earliest-diverging grasses that develop true spikelets (Sajo et al. 2007).

Research by the Grass Phylogeny Working Group (2000) shows that conventional spikelet morphology originated in several steps, indicating that typical grass spikelets are a characteristic feature of most but not all species in the Poaceae family. For example, many typical monocots develop ovaries comprised of three fused carpels, each with a single locule, as well as six stamens (Kellogg and Linder, 1995). Most modern grasses develop only one carpel, one locule, and three stamens, suggesting there was a reduction in the number of carpels and stamens at some point during evolution. The earliest grass species (Anomochlooideae subfamily) developed three stigmas, which is consistent with the three fused carpels and six stamens they would have inherited from their ancestor (Kellogg 2000). Another early-diverging grass genus, Pharus, was the product of a speciation event that resulted in the loss of a single stigma, perhaps the first step in the evolution of conventional spikelets (Grass Phylogeny Working 2012). The next step in the development of the conventional grass spikelet was a transition from six to three stamens. The precise timing of the transition to three stamens, and thus the origin of the spikelet anatomy of most grasses, is uncertain. This anatomy may have occurred in or before the common ancestor of maize and rice (Figure 1-1, black arrow). Another anomaly in the early-diverging grasses is seen in the Anomochloa and Streptochaeta genera, which develop neither petals nor the homologous lodicules seen in conventional grass anatomy. This represents an evolutionary question in the stepwise development of grass spikelets: Either lodicules originated in the most ancestral grasses 
and were lost in Anomochloa and Streptochaeta, or this defining character evolved after the origin of the Poaceae family (Grass Phylogeny Working 2012; Kellogg 2001).

Spikelets vary widely in number, position, ontogeny (developmental origin of a structure/organ), and mature morphology between species (Figure 1-2). Thus, the grasses are an excellent model system for studies in the interdisciplinary field of evolutionary developmental biology (Evo-Devo) because there is a well-resolved phylogeny, several species are amenable to genetic modification and have sequenced genomes (i.e., rice, brachypodium, setaria, maize, etc.), and there is a huge amount of morphological diversity between lineages (Kellogg et al. 2013). Furthermore, differences in inflorescence architecture have been identified as targets of selection during crop domestication and improvement (Kellogg 2007; Doebley 2004), making these traits an important and fundable area of plant research.

One significant difference in inflorescence architecture between grass species is that, while the majority of grasses develop single spikelets along their inflorescences (Figure 1-1), one grass subfamily (Panicoideae) is known to contain economically important species that develop spikelets in pairs. Specifically, Panicoideae is the secondmost specious subfamily in the grass family including maize, sorghum, setaria, and switchgrass, and is further subdivided into 12 grass tribes. Thus, studies of the Panicoideae subfamily may provide insight into the origin of the paired spikelet trait either paired spikelets originated in the Panicoideae and were subsequently lost in single spikelet species, or there were multiple origins of paired spikelets. 


\subsubsection{Meristem types}

All plant organs, including grass spikelets, arise from pools of undifferentiated stem cells known as meristems. Throughout early development, the above-ground vegetative plant tissues (i.e., stem, leaves) are derived from the shoot apical meristem (SAM). The organizing center (OC) is centrally located in the shoot apical meristem and is composed of a small number of pluripotent stem cells, which can give rise to all mature tissues. The stem cells utilize signals that act in a non-cell autonomous fashion to promote stem cell identity in the surrounding cells (Daum et al. 2014; Gaillochet et al. 2015). The stem cell niche is regulated by several signaling modules, which coordinate the balance between the number of undifferentiated stem cells located directly above the OC in the central zone (CZ) with the number of cells undergoing differentiation in the peripheral zone (PZ) alongside the $\mathrm{CZ}$ (Figure 1-3). As cells in the $\mathrm{PZ}$ undergo differentiation they become incorporated into organ primordia, the youngest of which is designated as $\mathrm{P}_{0}$, and is not visible without the aid of molecular markers (Brooks et al. 2009; Barton 2010). As each new primordia is initiated, the previous $\mathrm{P}_{0}$ will become $\mathrm{P}_{1}$, $\mathrm{P}_{1}$ will become $\mathrm{P}_{2}$ and so on (Figure 1-3). Underlying the $\mathrm{CZ}$ and $\mathrm{OC}$ is a rib zone (RZ) that functions in the production of stem tissue (Steeves and Sussex 1989). The balance between stem cell maintenance in the $\mathrm{CZ}$ and differentiation in the $\mathrm{PZ}$ enables the plant to produce organs indefinitely.

During the plant's transition from vegetative to reproductive development, the SAM is converted into an inflorescence meristem (IM), which will produce the floral structures. In maize, two inflorescences are produced: the male tassel at the top of the 
plant, and female ears that grow in the axils of leaves. In branched inflorescences, such as the maize tassel, the first axillary meristems that are produced in the IM are branch meristems (BM). Next, spikelet pair meristems (SPM) arise along the length of the branches and the main spike (Figure 1-4). The SPM then produce two spikelet meristems (SM), which subsequently develop into the floral meristems that will give rise to the grass florets (Figure 1-4). Unbranched inflorescences like the maize ear do not initiate BMs. Instead, the IM gives rise to SPM directly. Interestingly, it is predicted that SPM are only found in grasses that bear paired spikelets (i.e., maize), and may not be produced in grass species that bear single spikelets (i.e., rice, wheat) where the IMs will produce SMs directly (Figure 1-4).

While all species in Andropogoneae are thought to produce paired spikelets, a maize mutant called Suppressor of sessile spikelet1 (Sos1) that produces primarily single spikelets has been described (Wu et al. 2009; Doebley et al. 1995). Thus, this mutant could be of critical importance in understanding the evolution and development of the paired spikelet trait in maize, as well as the variation in spikelet characteristics within other grass lineages. The striking single spikelet phenotype of Sos 1 may result from a combination of developmental defects in the pathways of meristem maintenance and meristem identity. Proper maintenance enables the meristem to regulate its population of self-renewing stem cells with the number of differentiating cells leaving the meristem. Accurate identity is the meristem's ability to regulate the predetermined types of axillary meristems (and the resulting organs) that will develop from primordia. 


\subsection{MERISTEM MAINTENANCE PATHWAYS}

The ability of the SAM and IM to maintain their stem cell populations is critical for normal plant development. The capacity to perform these critical functions is maintained by highly conserved regulatory networks that are reiterated in all shoot meristems. These regulatory networks coordinate the balance between the number of undifferentiated stem cells in the central zone with cells undergoing differentiation in the peripheral zone. Many important signaling modules converge on WUSCHEL (WUS), a homeodomain transcription factor that functions to initiate and maintain the stem cell niche (Durbak and Tax 2011; Schoof et al. 2000). Thus, normal meristem structure and function relies on a delicate balance between activation and repression of stem cell maintenance factors.

\subsubsection{Receptor-kinase signaling pathways regulate meristem maintenance}

Regulation of WUS must be tightly controlled in order to maintain proper meristem patterning and function. Based on work from the model system Arabidopsis thaliana, the CLAVATA (CLV) signaling pathway is essential for restricting stem cell populations in shoot meristems through regulation of WUS (Schoof et al. 2000). Components of the CLV signaling pathway include the CLV3 secreted peptide ligand, membrane-bound leucine rich-repeat receptor-like kinase (LRR-RLK) CLV1, the LRRreceptor-like protein CLV2, and the membrane-localized CORYNE (Figure 1-5) (Kayes 
and Clark 1998; Müller et al. 2008; Clark et al. 1993; Deyoung and Clark 2008). Within the meristem, the transcription factor WUS functions in a negative feedback loop by promoting expression of $C L V 3$, a secreted ligand expressed in the cell layers above $W U S$, and CLV3 then binds the CLV1 and CLV2 extracellular receptors and activates downstream signaling events that ultimately repress WUS (Figure 1-6) (Brand et al. 2000). Mutations in the CLV pathway ligand or receptor(s) result in expansion of WUSexpressing cells and increased numbers of stem cells, which give rise to enlarged and fasciated inflorescences. On the other hand, wus mutants are unable to maintain stem cell populations, resulting in premature arrest of growth and thus smaller inflorescences (Mayer and Jurgens 1998).

Studies in monocot systems such as maize and rice show that the WUS-CLV feedback loop is conserved in most plant species (reviewed in (Pautler et al. 2013)), and have revealed further insight into the nature of this pathway. thick tassel dwarfl (tdl) was identified in Zea mays, and FLORAL ORGAN NUMBERI (OSFON1) in rice, as the functional orthologues of AtCLVI (Bommert et al. 2005; Suzaki et al. 2004). Additionally, the fasciated ear2 (fea2) gene encodes the maize orthologue of AtCLV2 (Figure 1-5) (Bommert et al. 2013). Similar to the $C L V$ pathway mutants in Arabidopsis, maize $t d l$ and fea 2 mutants display large increases in IM size and the number of developing organs, which is correlated with decreased inhibition of the stem cell promoting factors in the IM (Bommert et al. 2005; Bommert et al. 2013). Recent work in maize also identified the compact plant2 (ct2) gene encoding a G-protein $\alpha$-subunit as acting in the same pathway as $f e a 2$, but in a separate pathway from $t d l$ (Figure 1-5) (Bommert et al. 2013; Bommert et al. 2013). While ct2;tdl double mutants exhibit 
additive defects in meristem overproliferation, $c t 2$;fea 2 double mutants have a phenotype similar to the fea 2 single mutant, indicating that CT2 and FEA2 function in the same genetic pathway (Bommert et al. 2013). Further biochemical studies showed that the CT2 and FEA2 proteins physically bind (Bommert et al. 2013). Similar to the genetic results shown in maize, there is evidence from work in Arabidopsis that the CLV1 and CLV2 receptors work in parallel pathways (Durbak and Tax 2011).

Another transmembrane LRR receptor-like protein found to function in the CLV pathway in maize is FASCIATED EAR3 (FEA3), which is expressed in the developing shoot apical meristem (SAM) and causes fasciation in mutant tassel and ear inflorescences (Je et al. 2016). FEA3 functions at the plasma membrane to inhibit WUS expression from expanding the stem cell niche to cell layers outside of the meristem's organizing center. However, unlike $t d l$ which acts in the cell layers above the organizing center to inhibit ZmWUS expression from expanding upwards, FEA3 was found to function in the region below the OC (Je et al. 2016). In fact, ZmWUS expression in fea3 mutants extended downward into the regions of normal FEA3 expression instead of spreading to the upper layers of the SAM as seen in other $C L V$ receptor mutants. This finding suggests that FEA3 functions below the OC to repress the lower boundaries of ZmWUS expression, thereby keeping the integrity of the stem cell niche intact (Je et al. 2016). Additionally, Je and colleagues (2016) found that FEA3 does not interact with the maize ortholog of the known CLV pathway ligand, CLV3, but instead recognizes another peptide in maize, FON2-LIKE CLE PROTEIN 1 (ZmFCP1). Double mutant and overexpression studies showed that FEA2 and FEA3 are in separate pathways, and that 
overexpression and/or application of exogenous $Z m F C P 1$ peptide was sufficient to repress ZmWUS expression and limit the stem cell niche in the SAM (Je et al. 2016).

An interesting finding showed that regulation of meristem size does not only occur within the cell layers above and below the meristem's central zone and organizing center, but can also be derived from the peripheral meristematic zones. Another fasciated mutant, fasciated ear4 (fea4), was discovered to be a bZIP transcription factor functioning in the peripheral zone of the SAM, where cells leave the stem cell niche in order to further differentiate (Pautler et al. 2015). Genetic interaction screens indicated that FEA4 acts to regulate meristem size in a separate but parallel pathway than the CLAVATA pathway (Pautler et al. 2015). In another study, transposition of MALE STERILE CONVERTED ANTHERI (MSCA1), a glutaredoxin gene in maize, caused a novel phenotype in Aberrant phyllotaxy2 (Abph2) dominant mutants (Yang et al. 2015). Research into the function of both genes found that FEA4 is a direct target of MSCA1. Additionally, MSCA1 functions in the same pathway as FEA4 by negatively regulating its expression (Yang et al. 2015). The fact that there are several signaling pathways implicated in maintaining meristem size that converge on $Z m W U S$ further supports the idea that $Z m W U S$ is the master regulator of stem cell identity.

\subsubsection{Transcription factors and plant hormones contribute to meristem homeostasis}

Similar to the CLV pathway, several other pathways have been implicated in finetuning WUS expression, including the interactions between transcription factors (TFs) 
and plant hormones to mediate stem cell numbers and meristem outgrowth. One such pathway in Arabidopsis centers around SHOOTMERISTEMLESS (STM), a homeodomain transcription factor that is broadly expressed in the SAM (Figure 1-6). The STM protein can act as a mobile signal that promotes stem cell identity and inhibits expression of differentiation factors in the $\mathrm{CZ}$, and is turned off in the $\mathrm{P}_{0}$ as primordia differentiate (Hay et al. 2003) (reviewed in (Heidstra and Sabatini 2014). stm loss-of-function mutants display under-developed or completely absent meristems, similar to wus mutants (Scofield et al. 2014; Barton 2010), highlighting the critical role of STM and WUS in maintaining stem cell populations.

The founding member of a family of homeobox genes in maize, KNOTTED1 $(Z m K N 1)$ is a homolog of STM in Arabidopsis. These genes also share a similar expression pattern and function in the SAM (Kerstetter et al. 1997). KN1 expression is not restricted to the SAM, and is used as an identity marker for inflorescence, axillary, and floral meristems (Kerstetter et al. 1997). Interestingly, null knl-E1 alleles were epistatic to null $t d l$ - $g$ lf alleles (maize ortholog of $A t C L V 1$ ), indicating that KN1 interacts with the CLV pathway in maize inflorescences to maintain a pool of meristematic cells in the central zone (Lunde and Hake 2009; Vollbrecht et al. 2000). KN1 is involved in maintaining meristem multipotency; sites of decreased KN1 expression indicates regions of developing organ primordia. In developing inflorescences, transporters funnel the plant hormone auxin towards developing organ primordia. Because KN1 expression is a marker of meristematic cells, $\mathrm{KN} 1$ expression decreases and disappears when auxin is transported to mark organ primordia (Jackson et al. 1994). 
Two of the main hormones involved in maintaining the balance between the different regions of the SAM are cytokinin (CK), which functions to maintain stem cell fate, and auxin (Indole 3 Acetic Acid), which is important for establishing the outgrowth of organ primordia. High $\mathrm{CK}$ levels are required in the $\mathrm{OC}$ to maintain the stem cell population, while high auxin levels are found in the $\mathrm{PZ}$ where incipient primordia are formed (Figure 1-6). Auxin transport mediates organogenesis in Arabidopsis through the action of auxin efflux carriers. In particular, PIN-FORMED1 (PIN1) is responsible for directing the flow of auxin transport (Petrasek et al., 2006; Wisniewska et al., 2006), and PIN1 localization is regulated in part by the serine/threonine kinase PINOID (PID) (Friml et al., 2004). The maize barren inflorescence2 (bif2) gene is orthologous to PID in Arabidopsis, and similarly plays a critical role in axillary meristem initiation in maize inflorescences (Skirpan et al. 2009). Research into the functions of BIF2 identified another important regulator in axillary meristem initiation, barren stalkl (bal), as a downstream target of BIF2 (Skirpan et al. 2008). BAl is a bHLH transcription factor that acts in all axillary meristems of maize inflorescences (Gallavotti et al. 2004).

Maize plants treated with the auxin transport inhibitor $N$-1-naphthylphthalamic acid (NPA) at different points in development showed a variety of meristematic defects. When treated with NPA early in development, maize plants failed to produce axillary meristems, including branch meristems, SPM, and SMs (Wu and McSteen 2007). However, if the plants had already initiated axillary meristems, treatment with NPA did not stop the meristems themselves from growing, but did inhibit lateral primordia from forming (Wu and McSteen 2007). This effected the maize inflorescences by suppressing the SPM from branching into two SM. Instead, the SPM itself converted into a single SM 
and the resulting maize inflorescence developed single spikelets (Wu and McSteen 2007). The phenotype of a maize plant treated with an auxin transport inhibitor was similar to the maize mutant barren inflorescence2 (bif2) (McSteen and Hake 2001). The researchers also discovered that the bif2 gene was expressed in plants treated with NPA, indicating that bif2 functions upstream of polar auxin transport (Wu and McSteen 2007). Clearly auxin, as well as genes that function in its perception and transport, plays a pivotal role in inflorescence development in the grasses.

Both stem-cell promoting genes, AtSTM (ZmSTM) and WUS, have been shown to affect CK homeostasis in the SAM (Figure 1-6). STM was shown to directly regulate the expression of ISOPENTENYLTRANSFERASE7 (IPT7), a CK biosynthesis gene in Arabidopsis (Gaillochet et al. 2015; Scofield et al. 2014), which results in high CK levels in the SAM and promotes stem cell fate (Figure 1-6). While STM is primarily involved in maintaining high levels of $\mathrm{CK}$ broadly across the meristem through regulation of $\mathrm{CK}$ synthesis, the WUS-CLV pathway plays an important role in fine-tuning CK signaling and perception in order to maintain the domains of the SAM, namely the OC. In the OC, WUS expression overlaps with expression of a known CK receptor, ARABIDOPSIS HISTIDINE KINASE 4 (AHK4), which binds CK and promotes WUS expression (Figure 1-6) (Yamada et al. 2001). WUS also acts to regulate CK signaling by repressing members of the type A ARABIDOPSIS RESPONSE REGULATOR (ARR) family, which function to negatively regulate $\mathrm{CK}$ signaling components, including the $A H K 4 \mathrm{CK}$ receptor (Figure 1-6) (Gordon et al. 2009). Repression of $A H K 4$ in the CZ by CLV3 helps to restrict CK signaling to the more internal cells, aiding in restricting WUS expression to the OC (Chickarmane et al. 2012). These interactions establish a feedback 
loop whereby the interactions between WUS, ARRs, and AHK4 produce sensitized cells in the OC that readily perceive $\mathrm{CK}$, which is critical to control meristem size and shape (Chickarmane et al. 2012; Gordon et al. 2009).

Cytokinin also functions in grasses to maintain meristem activity. For instance, a study in maize showed that KN1 targets thousands of loci in the maize genome, including many hormone pathway regulators (Bolduc et al. 2012). One gene targeted by KN1 was found to be a maize ortholog of the Arabidopsis AHK4 cytokinin receptor (Bolduc et al. 2012). Another gene orthologous to the LONELY GUY CK synthesis gene in rice was found to be a target of KN1 (Bolduc et al. 2012). In addition, the same study found that genes involved in auxin synthesis, transport, and signaling were particularly enriched among the direct targets of KN1 (Bolduc et al. 2012). These results indicate that KN1 may interact with components of auxin and CK synthesis, transport, signaling, and perception in order to maintain meristematic regions within maize meristems.

\subsubsection{Integration of signaling pathways occurs at many levels for normal meristem patterning}

Because plant cells are immobile, cell-cell signaling and non-cell autonomous transmission of signals between cells are vital for communication and coordination between meristem domains. For instance, WUS mRNA is initially expressed in the OC (Gaillochet and Lohmann 2015). Following translation, WUS protein moves into the CZ through plant cells via cytoplasmic connections between neighboring plant cells called 
plasmodesmata to maintain stem cell identity in the CZ cells (Daum et al. 2014).

Importantly, WUS restricts its own expression in the meristem to prevent stem cell overproliferation (Daum et al. 2014). While mobility is promoted by the protein's homeodomain, a separate protein domain prevents WUS from moving beyond the bounds of the CZ (Daum et al. 2014). STM also moves between cells to coordinate stem cell identity and repression of differentiation factors throughout the CZ (Scofield et al. 2014). Transcription factors are not the only mobile signals that are known to facilitate communication between the different domains of the meristem. Intercellular communication also occurs through the synthesis and transport of other proteins, such as peptide ligands like CLV3, in addition to other molecules such as microRNAs, mobile hormone signals such as auxin and $\mathrm{CK}$, and enzymes affecting cell wall integrity, which are critical for actively dividing cells (i.e., cell wall loosening proteins, receptors) (reviewed in (Tameshige et al. 2015).

While research into WUS-CLV signaling has yielded substantial insights into the mechanisms of meristem homeostasis, there are still many holes in the understanding of the functional mechanisms regulating these pathways. For instance, although it is widely accepted that CLV1 and the CLV2/CORYNE complex are CLV3 peptide receptors in Arabidopsis, it was unknown until recently whether CLV3 directly or indirectly binds these receptors. Studies of the ligand-receptor interactions using photoaffinity labeling indicate that CLV3 directly binds to CLV1 and its most closely related family member BARELY ANY MERISTEM1 (BAM1), but binds indirectly to CLV2 and RPK2 receptor kinases (Shinohara and Matsubayashi 2015). This research suggests that CLV2 and 
RPK2 may be co-receptors for the CLV3 ligand acting through a still-undetermined mediator (Shinohara and Matsubayashi 2015).

Research to determine the localization patterns of the CLV1 and CLV2 receptors in Arabidopsis showed that there are three signaling modules of CLV1/2 receptor complexes, instead of two as originally thought (Bleckmann et al. 2010). First, CLV1 forms homodimers and is able to function alone to perceive and transmit signals once it is bound. Next, and also previously shown, CLV2 forms a tetrameric complex with CRN that signals independently of CLV1. The third receptor complex identified determined that CLV1 forms homodimers that are able to bind the CLV2/CRN complex (Bleckmann et al. 2010). Additionally, the kinase domain of CRN has been shown to be nonfunctional, and it has been proposed that CRN functions as more of a scaffold protein than functioning directly in signal transduction (Nimchuk et al. 2011). The relationships among the many CLV3 receptors remains unclear, and may be much more dynamic than originally thought.

Furthermore, alterations in expression of $C R N$ may be mediated in part by chromatin modifications, such as histone methylation (Yue et al. 2013), suggesting that factors other than physical interactions between genes may be acting to regulate these complex signaling pathways. Alternative levels of molecular regulation of the WUSCLV feedback loop were discovered from studies outside of Arabidopsis. It was found first in tomato and confirmed in Arabidopsis that arabinosyltransferase genes are required for the arabinosylation of the CLV3 peptide (Shinohara and Matsubayashi 2013). These post-translational modifications were found to be critical for CLV3 function, and thus maintenance of meristem homeostasis, as un-arabinosylated CLV3 decreases CLV3 
expression and results in an increase in meristem size due to increased WUS expression (Xu et al. 2015). Multiple levels of regulation enable the CLV-WUS pathway to operate in a tightly-regulated system that resists fluctuations in gene expression and physical development that would otherwise result in larger meristems.

\subsection{MERISTEM IDENTITY AND DETERMINACY}

Models of meristem identity and determinacy have been well studied in grass model species. This is because the grasses have numerous types of axillary meristems that specify many different structures (i.e., IM, BM, SPM, SM, FM), while Arabidopsis transitions directly from SAM to producing floral meristems.

The change from single to paired spikelets in the grasses is correlated with a decrease in meristem determinacy, which is regulated in part by genes of the RAMOSA pathway (Bortiri et al. 2006; Vollbrecht et al. 2005; Satoh-Nagasawa et al. 2006). When the genes in this pathway are mutated, outgrowth of branches occurs. RA1 encodes a zinc finger transcription factor, while RA2 encodes a LOB domain-containing transcription factor, and RA3 encodes a trehalose-6-phosphate phosphatase. The ra mutants produce branches with additional spikelets, instead of the normal paired spikelets. Two lines of evidence from maize ral mutants suggest that paired spikelets may result from suppressed branching events. First, ral expression correlates with branch identity, and second, ral orthologues are not present in grass relatives that bear single spikelets, such as rice (Vollbrecht et al. 2005). Furthermore, these genes may be 
used as markers of meristem identity because $R A I$ and $R A 3$ are expressed in at the base of developing SPMs and SMs, and RA2 is generally expressed in developing BM, SPM, SM, and FM (reviewed in (McSteen 2006)). Several studies have indicated that RA3 functions upstream of RA1, and that both function in a separate pathway than RA2 (Satoh-Nagasawa et al. 2006). Unsurprisingly, this finding indicates that there are multiple pathways affecting meristem identity, much like the process of meristem maintenance. Another important marker of meristem identity is branched silklessl (bdl), a putative ERF transcription factor (Chuck et al. 2002). BDl was shown to be expressed in specific domains of SMs, and is conserved between grass lineages (Chuck et al. 2002). Variation in the numbers of floral organs between grass species may be the result of altered regulation or activity of the indeterminate spikelet1 (ids 1 ) gene identified in maize. The IDS protein has $86 \%$ amino acid identity to the APETALA2 (AP2) domain found in the Arabidopsis AP2 gene involved in determining floral organ identity (Chuck et al. 1998). In loss-of-function ids 1 mutants, the spikelet meristem produces many more florets than the usual two per spikelet, indicating a shift toward indeterminacy of the SM. Thus, the $i d s 1$ gene is involved in regulating spikelet determinacy, which lends itself to the normal 2 florets per spikelet (Chuck et al. 1998). Research into the physical basis behind the additional florets seen in ids 1 mutants revealed that around the stage of development when the SM branches to form the upper floret, the SM appeared to elongate; SEM and RNA in situ hybridization experiments showed that SPM and SM of ids1 mutants are enlarged compared to normal plants (Chuck et al. 1998). Meristem size is a necessary trigger in order to begin the process of branching (Sundberg and Orr, 
1996). Thus, a larger spikelet meristem may facilitate additional branching events, leading to additional floral organs.

However, the ability of the SM to confer increased determinacy based on size is not necessarily the case for all meristems. For example, the first upper floral meristem is larger in size than the lower floral meristem, but both will produce equal numbers of florets (Chuck et al., 1998). Other maize mutants have defects in meristem size, such as Suppressor of sessile spikelet1 (Sos1), which develops a smaller inflorescence meristem than in normal plants and develops single instead of paired spikelets at maturity (Wu et al., 2009). Based on the findings in the ids 1 mutant, it may be interesting to determine if, like in SMs, size is a trigger for further development and initiating new meristems.

\subsection{CONCLUSIONS}

Meristems in plants are composed of groups of cells that exist in a highly regulated balance in order to coordinate the number of stem cells within the meristem with the number of cells migrating to organ primordia in the peripheral zones of the meristem. Considering the effects that mutations disturbing this balance cause, it is necessary to have numerous pathways regulating meristem maintenance and meristem determinacy in order to buffer the meristems against drastic changes. Furthermore, components and functions of these pathways are often conserved between plant lineages.

Despite decades of research into the mechanisms driving meristem maintenance and determinacy, there are still many holes in our understanding. For instance, while 
many maize mutants develop single spikelets instead of the normal spikelet pair typical of grasses in the Andropogoneae lineage, the genetic basis for the paired and single spikelet traits remain unknown. Instead, there are many pieces of evidence that correlate smaller meristem sizes, inhibition of auxin transport, or decreased meristem determinacy with single spikelets, but the literature lacks a synthesized and tested model that incorporates these data. Extensive high-throughput sequencing of Poaceae species within the past decade has resulted in a robust phylogeny of the family and the public availability of valuable cereal genomes. Combining both the molecular data with observed spikelet attributes will undoubtedly contribute to advances in our knowledge of agronomically important grass traits. 


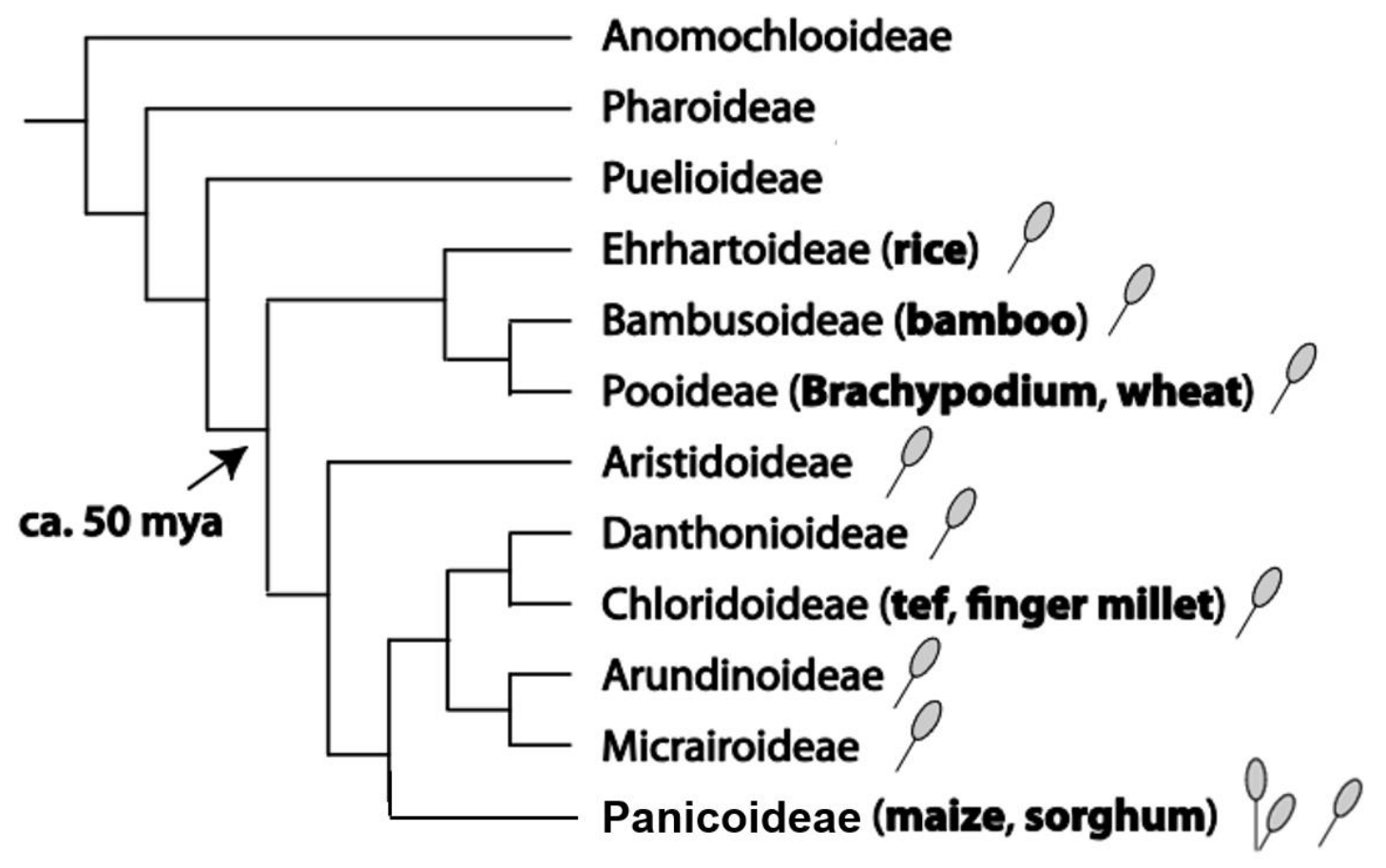

Figure 1-1. Phylogeny of the grasses showing the occurrence of single versus paired spikelets. This depiction suggests that paired spikelets only occur within a single subfamily, Panicoideae. Additionally, it indicates that the majority of grass species bear single spikelets, indicating that single spikelets may be the ancestral trait in the "Core Poaceae" lineages (marked with spikelets). Adapted from Grass Phylogeny Working Group, 2012. 


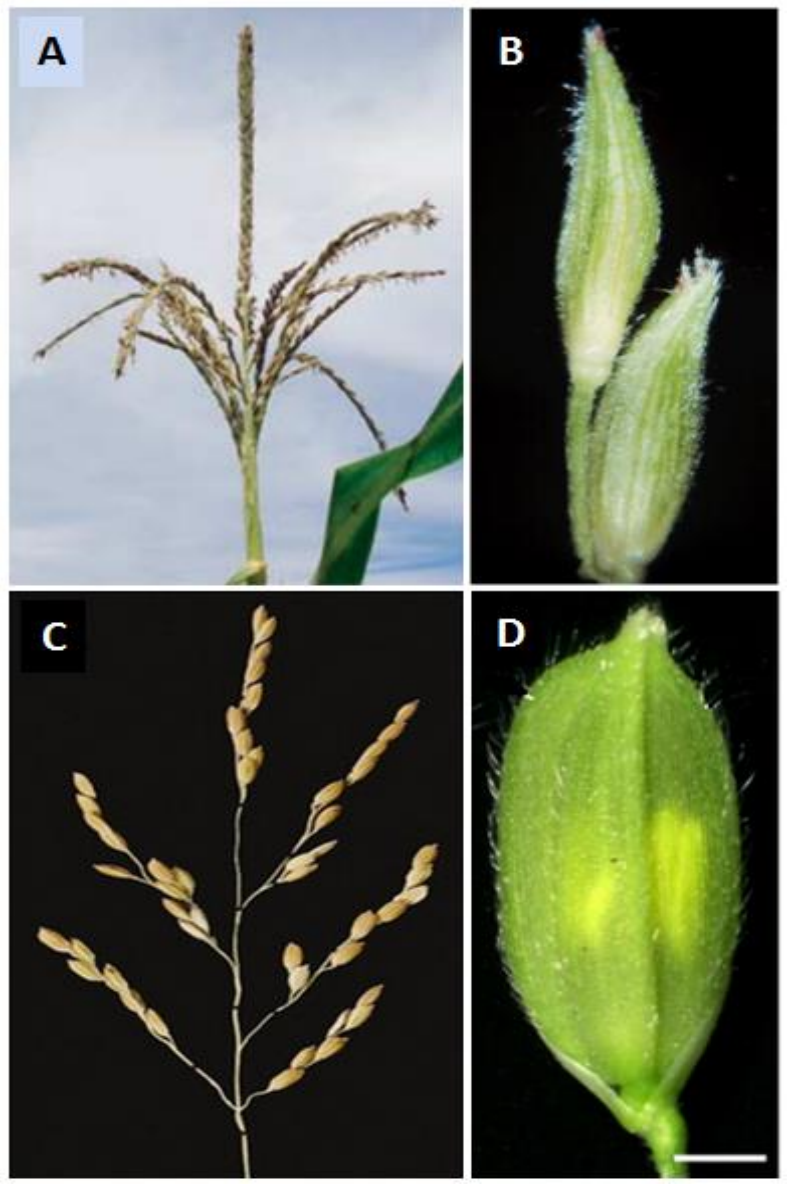

Figure 1-2. Differences in inflorescence morphology between grass species. A) Mature maize inflorescence (tassel) with (B) paired spikelets. C) Mature rice panicle with (D) single spikelets. Inflorescence images from Vollbrecht et al. 2005 (maize) and Miura et al. 2010 (rice). 


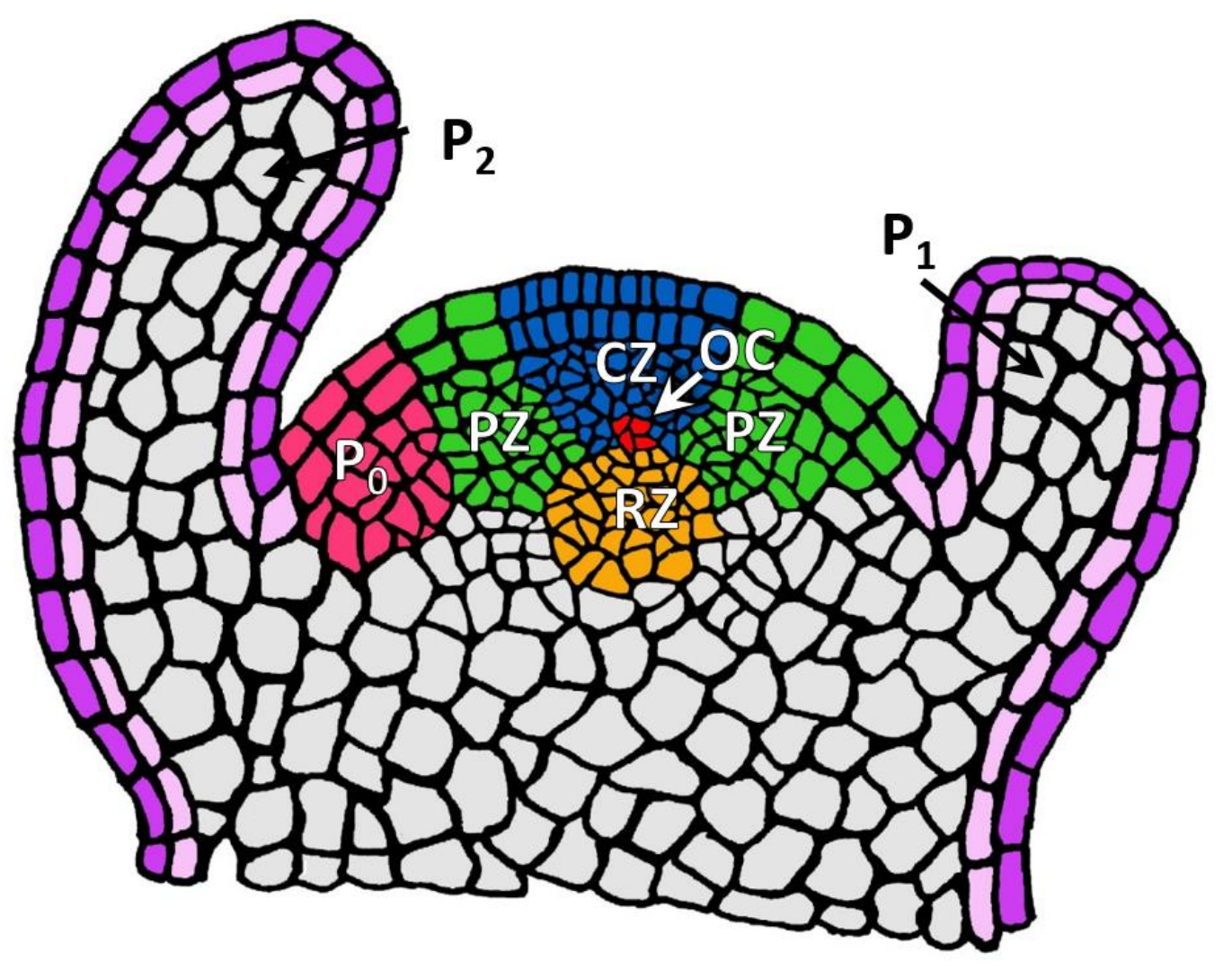

Figure 1-3. Meristematic zones within an Arabidopsis shoot apical meristem.

The shoot apical meristem is composed of several distinct domains. The central zone (CZ; blue) resides at the top of the meristem dome directly above the organizing center (OC; red), which specifies the stem cell niche. Adjacent to the $\mathrm{CZ} / \mathrm{OC}$ are rapidly dividing cells in the peripheral zone (PZ; green) that will differentiate to form organ primordia $\left(\mathrm{P}_{0}\right.$; pink). Mature organs are labeled youngest $\left(\mathrm{P}_{1}\right)$ to oldest $\left(\mathrm{P}_{2}\right)$. The rib zone (RZ; orange) contains cells fated to become stem tissue. The epidermal tissue surrounds the meristem and is subdivided into two layers, L1 (dark purple) and L2 (light pink). Figure created in conjunction with Katy L. Guthrie for a review article. 


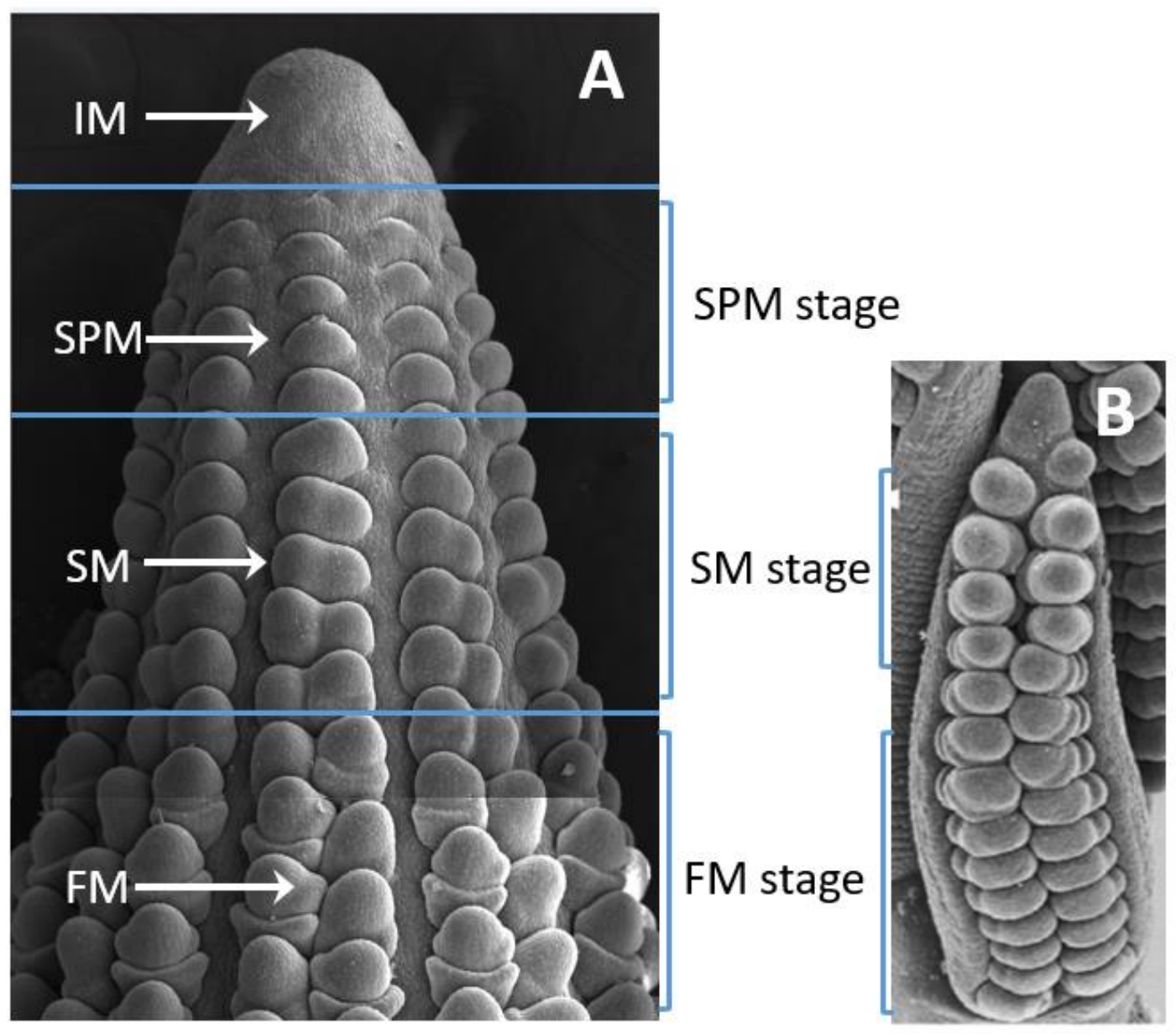

Figure 1-4. Meristem development occurs in a gradient along the inflorescence. SEM images depicting the stages of inflorescence development in Zea mays (A), a paired spikelet species, and Urochloa ruziziensis (B), a single spikelet species. In grasses that develop paired spikelets, inflorescence meristems (IM) will give rise to spikelet pair meristems (SPM), which then produce two spikelet meristems (SM). Alternatively, the IM in single spikelet species will give rise to SMs directly instead of producing the SPM intermediate. Finally, SMs produce floral meristems (FM) that initiate the floral organ primordia (i.e., juvenile stamens, etc.). SEM of single spikelet species (B) was adapted from Zanotti et al. 2010. 

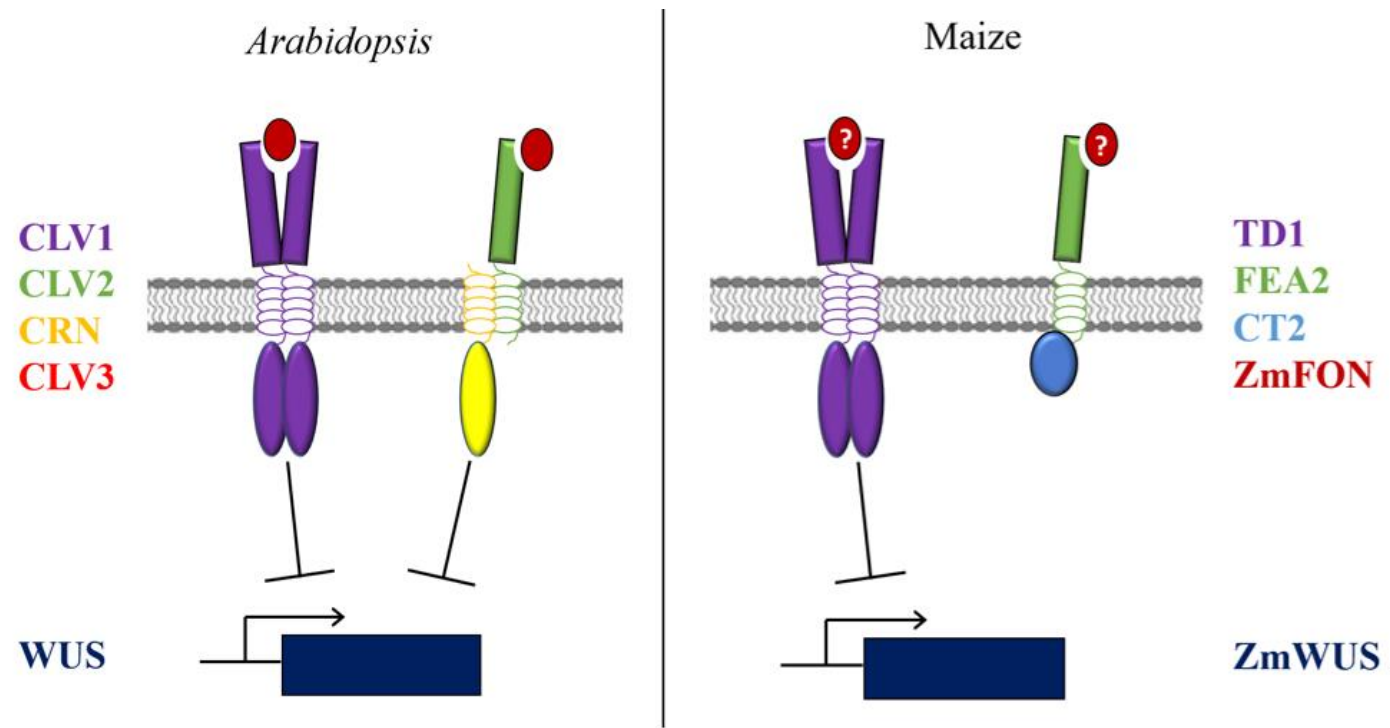

Figure 1-5. CLAVATA signaling components in Arabidopsis and maize. The canonical CLAVATA (CLV) signaling pathway tightly regulates WUS expression through a negative feedback loop. The CLV3 ligand (red), which is positively regulated by WUS (navy) expression, binds to the CLV1 (purple) and CLV2 (green) extracellular receptors in order to stimulate a signaling cascade that represses WUS expression. The orthologs found in maize are also depicted. The major difference between these pathways in Arabidopsis and maize is the intracellular signaling component that CLV2/FEA2 binds to, as well as the fact that the ligand for the maize CLV signaling pathway has not yet been identified. 


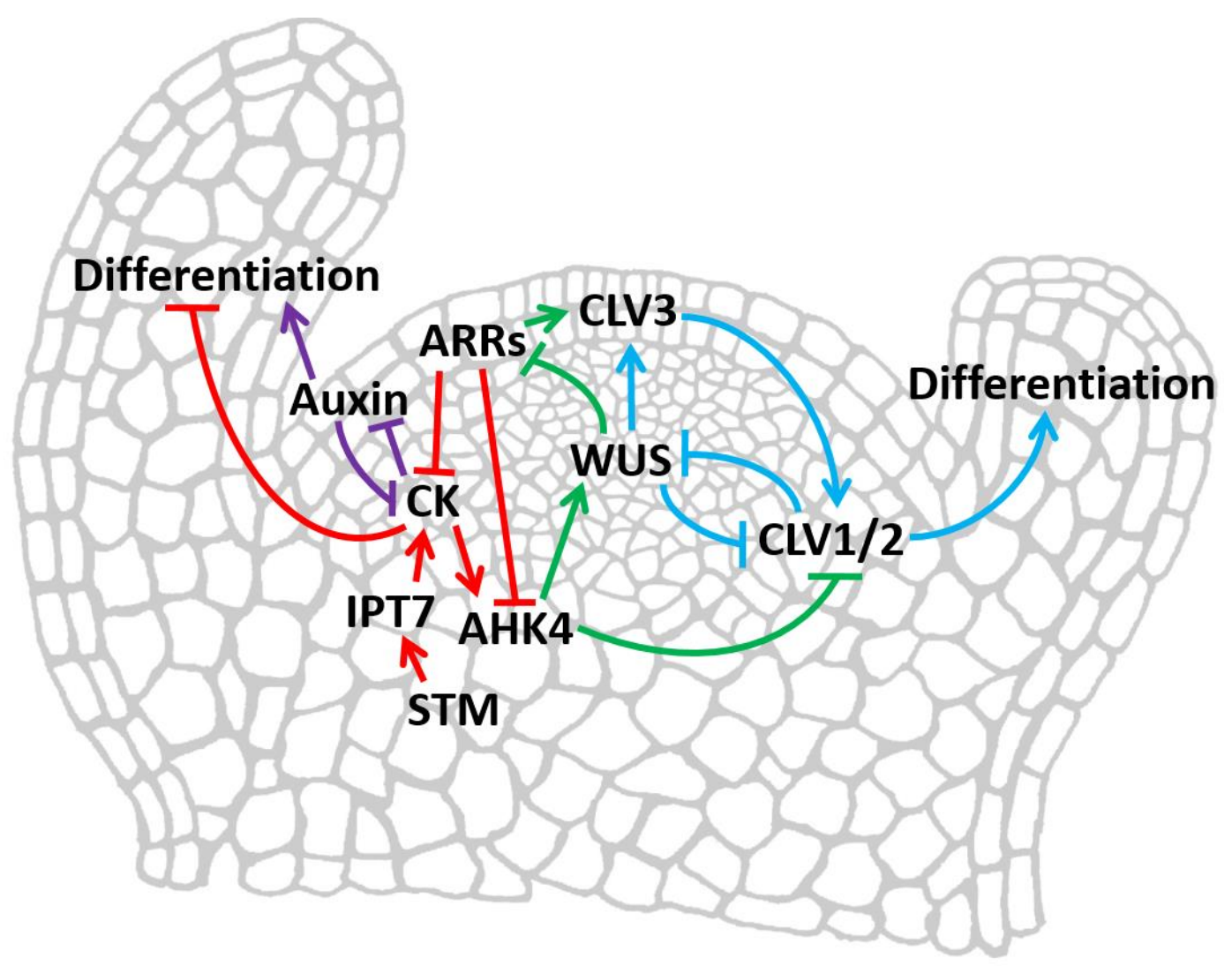

Figure 1-6. Gene regulatory network integrating hormone regulation and signaling pathways. Regulatory network of genes involved in mediating the balance between SAM stem cell maintenance and cellular differentiation in the model dicot species Arabidopsis. The CLAVATA ( $C L V$; blue), auxin (purple), and cytokinin (CK; red) pathways, and crosstalk between pathways (green) are represented. 


\subsection{LITERATURE CITED}

Barton, M. 2010. Twenty years on: the inner workings of the shoot apical meristem, a developmental dynamo. Developmental Biology 341: 95-113.

Bleckmann, A., S. Weidtkamp-Peters, C. A. M. Seidel, AND R. Simon. 2010. Stem cell signaling in Arabidopsis requires CRN to localize CLV2 to the plasma membrane. Plant Physiology 152: 166-76.

Bolduc, N., A. Yilmaz, M. K. Mejia-Guerra, K. Morohashi, D. O'Connor, E. Grotewold, AND Sarah Hake. 2012. Unraveling the KNOTTED1 regulatory network in maize meristems. Genes \& Development 26: 1685-90.

Bommert, P., B. I. Je, A. Goldshmidt, AND D. Jackson. 2013. The maize G $\alpha$ gene COMPACT PLANT2 functions in CLAVATA signalling to control shoot meristem size. Nature 502: 555-58.

Bommert, P., C. Lunde, J. Nardmann, E. Vollbrecht, M. Running, D. Jackson, S. Hake, AND W. Werr. 2005. thick tassel dwarf1 encodes a putative maize ortholog of the Arabidopsis CLAVATA1 leucine-rich repeat receptor-like kinase. Development 132: $1235-45$.

Bommert, P., N. S. Nagasawa, AND D. Jackson. 2013. Quantitative variation in maize kernel row number is controlled by the FASCIATED EAR2 locus. Nature Genetics 45: 334-37.

Bortiri, E., G. Chuck, E. Vollbrecht, T. Rocheford, R. Martienssen, AND S. Hake. 2006. ramosa2 encodes a LATERAL ORGAN BOUNDARY domain protein that 
determines the fate of stem cells in branch meristems of maize. Plant Cell 18: 574-85.

Brand, U., J. C. Fletcher, M. Hobe, E. M. Meyerowitz, AND R. Simon. 2000. Dependence of stem cell fate in Arabidopsis on a feedback loop regulated by CLV3 activity. Science 289: 617-19.

Brooks, L., J. Strable, X. L. Zhang, K. Ohtsu, R. L. Zhou, A. Sarkar, S. Hargreaves, R. J. Elshire, D. Eudy, T. Pawlowska, D. Ware, D. Janick-Buckner, B. Buckner, M. C. P. Timmermans, P. S. Schnable, D. Nettleton, AND M. J. Scanlon. 2009. Microdissection of shoot meristem functional domains. PLOS Genetics 5.

Chickarmane, V. S., S. P. Gordon, P. T. Tarr, M. G. Heisler, AND E. M. Meyerowitz. 2012. Cytokinin signaling as a positional cue for patterning the apical-basal axis of the growing Arabidopsis shoot meristem. Proceedings of the National Academy of Sciences of the United States of America 109: 4002-07.

Chuck, G., R. B. Meeley, AND S. Hake. 1998. The control of maize spikelet meristem fate by the APETALA2-like gene indeterminate spikelet1. Genes \& Development 12: $1145-54$.

Chuck, G., M. Muszynski, E. Kellogg, S. Hake, AND R. J. Schmidt. 2002. The Control of Spikelet Meristem Identity by the branched silkless1 Gene in Maize. Science 298: $1238-41$.

Clark, S.E., M.P. Running, AND E.M. Meyerowitz. 1993. CLAVATA1, a regulator of meristem and flower development in Arabidopsis. Development 119: 397-418. 
Daum, G., A. Medzihradszky, T. Suzaki, AND J. U. Lohmann. 2014. A mechanistic framework for noncell autonomous stem cell induction in Arabidopsis. Proceedings of the National Academy of Sciences 111: 14619-24.

Deyoung, B. J., AND S. E. Clark. 2008. BAM receptors regulate stem cell specification and organ development through complex interactions with CLAVATA signaling. Genetics 180: 895-904.

Doebley, J. 2004. The genetics of maize evolution. Annual Review of Genetics 38: 37-59.

Doebley, J., A. Stec, AND B. Kent. 1995. Suppressor of Sessile spikelets 1 (Sos1): A dominant mutant affecting inflorescence development in maize. American Journal of Botany 82: 571-77.

Durbak, A. R., AND F. E. Tax. 2011. CLAVATA signaling pathway receptors of arabidopsis regulate cell proliferation in fruit organ formation as well as in meristems. Genetics 189: 177-94.

Gaillochet, C., G. Daum, AND J. U. Lohmann. 2015. O cell, where art thou? The mechanisms of shoot meristem patterning. Current Opinion in Plant Biology 23: 91-97.

Gaillochet, C., AND J. U. Lohmann. 2015. The never-ending story: From pluripotency to plant developmental plasticity. Development (Cambridge) 142: 2237-49.

Gallavotti, A., Q. Zhao, J. Kyozuka, R. B. Meeley, M. Ritter, J. F. Doebley, M. E. Pe, AND R. J. Schmidt. 2004. The role of barren stalk1 in the architecture of maize. Nature 432: 630-35.

Gordon, S. P., V. S. Chickarmane, C. Ohno, AND E. M. Meyerowitz. 2009. Multiple feedback loops through cytokinin signaling control stem cell number within the 
Arabidopsis shoot meristem. Proceedings of the National Academy of Sciences 106: 16529-34.

Grass Phylogeny Working Group, II. 2012. New grass phylogeny resolves deep evolutionary relationships and discovers C4 origins. New Phytologist 193: 30412.

Hay, A., D. Jackson, N. Ori, AND S. Hake. 2003. Analysis of the competence to respond to KNOTTED1 activity in Arabidopsis leaves using a steroid induction system. Plant Physiology 131: 1671-80.

Heidstra, R., AND S. Sabatini. 2014. Plant and animal stem cells: Similar yet different. Nature Reviews Molecular Cell Biology. 15: 301-12.

Jackson, D., B. Veit, AND S. Hake. 1994. Expression of maize KNOTTED1 related homeobox genes in the shoot apical meristem predicts patterns of morphogenesis in the vegetative shoot. Development 120: 405-13.

Janssen, T., AND K. Bremer. 2004. The age of major monocot groups inferred from 800+ rbcL sequences. Botanical Journal of the Linnean Society 146: 385-98.

Je, B. I., J. Gruel, Y. K. Lee, P. Bommert, E. D. Arevalo, A. L. Eveland, Q. Wu, A. Goldshmidt, R. Meeley, M. Bartlett, M. Komatsu, H. Sakai, H. Jonsson, AND D. Jackson. 2016. Signaling from maize organ primordia via FASCIATED EAR3 regulates stem cell proliferation and yield traits. Nature Genetics 48: 785-91.

Kayes, J.M., AND S.E. Clark. 1998. CLAVATA2, a regulator of meristem and organ development in Arabidopsis. Development 125: 3843-51.

Kellogg, E. A. 2007. Floral displays: genetic control of grass inflorescences. Current Opinion in Plant Biology 10: 26-31. 
Kellogg, E. A., P. E. A. S. Camara, P. J. Rudall, P. Ladd, S. T. Malcomber, C. J.

Whipple, AND A. N. Doust. 2013. Early inflorescence development in the grasses (Poaceae). Frontiers in Plant Science 4.

Kellogg, E. A. 2001. Evolutionary history of the grasses. Plant Physiology. 125: 1198205.

Kellogg, E. A. 2000. The grasses: A case study in macroevolution. Annual Review of Ecology and Systematics 31: 217-38.

Kerstetter, R. A., D. Laudencia-Chingcuanco, L. G. Smith, AND S. Hake. 1997. Loss-offunction mutations in the maize homeobox gene, knotted1, are defective in shoot meristem maintenance. Development. 124: 3045-54.

Lunde, C., AND S. Hake. 2009. The interaction of knotted1 and thick tassel dwarfl in vegetative and reproductive meristems of maize. Genetics 181: 1693-97.

McSteen, P. 2006. Branching Out: The ramosa pathway and the evolution of grass inflorescence morphology. The Plant Cell 18: 518-22.

McSteen, P., AND S. Hake. 2001. barren inflorescence2 regulates axillary meristem development in the maize inflorescence. Development 128: 2881-91.

Müller, R., A. Bleckmann, AND R. Simon. 2008. The receptor kinase CORYNE of Arabidopsis transmits the stem cell-limiting signal CLAVATA3 independently of CLAVATA1. The Plant Cell 20: 934-46.

Nimchuk, Z. L., P. T. Tarr, AND E. M. Meyerowitz. 2011. An evolutionarily conserved pseudokinase mediates stem cell production in plants. The Plant Cell 23: 851-54. 
Pautler, M., W. Tanaka, H. Y. Hirano, AND D. Jackson. 2013. Grass meristems I: Shoot apical meristem maintenance, axillary meristem determinacy and the floral transition. Plant and Cell Physiology 54: 302-12.

Pautler, M., A. L. Eveland, T. LaRue, F. Yang, R. Weeks, C. Lunde, B. I. Je, R. Meeley, M. Komatsu, E. Vollbrecht, H. Sakai, AND D. Jackson. 2015. FASCIATED EAR4 encodes a bZIP transcription factor that regulates shoot meristem size in maize. The Plant Cell 27: 104-20.

Sajo, M., H. Longhi-Wagner, AND P. Rudall. 2008. Reproductive morphology of the early-divergent grass Streptochaeta and its bearing on the homologies of the grass spikelet. Plant Systematics \& Evolution 275.

Sajo, M. G., H. Longhi-Wagner, AND P. J. Rudall. 2007. Floral development and embryology in the early-divergent grass Pharus. International Journal of Plant Sciences 168: 181-91.

Satoh-Nagasawa, N., N. Nagasawa, S. Malcomber, H. Sakai, AND D. Jackson. 2006. A trehalose metabolic enzyme controls inflorescence architecture in maize. Nature 441: 227-30.

Schoof, H., M. Lenhard, A. Haecker, K. F. X. Mayer, G. Jürgens, AND T. Laux. 2000. The stem cell population of Arabidopsis shoot meristems is maintained by a regulatory loop between the CLAVATA and WUSCHEL genes. Cell 100: 63544.

Scofield, S., W. Dewitte, AND J. A. H. Murray. 2014. STM sustains stem cell function in the Arabidopsis shoot apical meristem and controls KNOX gene expression 
independently of the transcriptional repressor AS1 Plant Signaling and Behavior 9.

Shinohara, H., AND Y. Matsubayashi. 2013. Chemical synthesis of arabidopsis CLV3 glycopeptide reveals the impact of hydroxyproline arabinosylation on peptide conformation and activity. Plant and Cell Physiology 54: 369-74.

Shinohara, H., AND Y. Matsubayashi. 2015. Reevaluation of the CLV3-receptor interaction in the shoot apical meristem: Dissection of the CLV3 signaling pathway from a direct ligand-binding point of view. Plant Journal 82: 328-36.

Skirpan, A., A. H. Culler, A. Gallavotti, D. Jackson, J. D. Cohen, AND P. McSteen. 2009. BARREN INFLORESCENCE2 interaction with ZmPIN1a suggests a role in auxin transport during maize inflorescence development. Plant and Cell Physiology 50: 652-57.

Skirpan, A., X. Wu, AND P. McSteen. 2008. Genetic and physical interaction suggest that BARREN STALK1 is a target of BARREN INFLORESCENCE2 in maize inflorescence development. The Plant Journal 55: 787-97.

Steeves, A., AND I. M. Sussex. 1989. Patterns in Plant Development (Cambridge University Press).

Stevens, P. F. 2012. Angiosperm Phylogeny Website. http://www.mobot.org/MOBOT/research/APweb/.

Suzaki, T., M. Sato, M. Ashikari, M. Miyoshi, Y. Nagato, AND H. Y. Hirano. 2004. The gene FLORAL ORGAN NUMBER1 regulates floral meristem size in rice and encodes a leucine-rich repeat receptor kinase orthologous to Arabidopsis CLAVATA1. Development 131: 5649-57. 
Tameshige, T., Y. Hirakawa, K. U. Torii, AND N. Uchida. 2015. Cell walls as a stage for intercellular communication regulating shoot meristem development. Frontiers in Plant Science 6: 1-10.

Vollbrecht, E., L. Reiser, AND S. Hake. 2000. Shoot meristem size is dependent on inbred background and presence of the maize homeobox gene, knotted1.

Development 127: 3161-72.

Vollbrecht, E., P. S. Springer, L. Goh, E. S. Buckler, AND R. Martienssen. 2005. Architecture of floral branch systems in maize and related grasses. Nature 436: 1119-26.

Wu, X., AND P. McSteen. 2007. The role of auxin transport during inflorescence development in maize (Zea mays, Poaceae). American Journal of Botany 94: 1745-55.

Wu, X., A. Skirpan, AND P. McSteen. 2009. Suppressor of sessile spikelets1 functions in the ramosa pathway controlling meristem determinacy in maize. Plant Physiology 149: 205-19.

Xu, C., K. L. Liberatore, C. A. Macalister, Z. Huang, Y. H. Chu, K. Jiang, C. Brooks, M. Ogawa-Ohnishi, G. Xiong, M. Pauly, J. Van Eck, Y. Matsubayashi, E. Van Der Knaap, and Z. B. Lippman. 2015. A cascade of arabinosyltransferases controls shoot meristem size in tomato. Nature Genetics 47: 784-92.

Yamada, H., T. Suzuki, K. Terada, K. Takei, K. Ishikawa, K. Miwa, T. Yamashino, AND T. Mizuno. 2001. The Arabidopsis AHK4 histidine kinase is a cytokinin-binding receptor that transduces cytokinin signals across the membrane. Plant and Cell Physiology 42: 1017-23. 
Yang, F., H. T. Bui, M. Pautler, V. Llaca, R. Johnston, B. Lee, A. Kolbe, H. Sakai, AND D. Jackson. 2015. A maize glutaredoxin gene, Abphyl2, regulates shoot meristem size and phyllotaxy. The Plant Cell 27: 121-31.

Yue, M., Q. Li, Y. Zhang, Y. Zhao, Z. Zhang, AND S. Bao. 2013. Histone H4R3 methylation catalyzed by SKB1/PRMT5 is required for maintaining shoot apical meristem. PLOS ONE 8. 


\section{CHAPTER TWO}

Genetic interaction of Suppressor of sessile spikelet1 (Sos1) with meristem mutants in the CLAVATA signaling pathway

Eden A. Johnson 


\subsection{INTRODUCTION}

In contrast to animals, which generate their body plan during embryogenesis, plants continue to grow and produce new organs (i.e., leaves and flowers) after embryogenesis. One mechanism by which plants maintain their developmental plasticity is through the maintenance of pools of stem cells within structures called meristems. The shoot apical meristem (SAM) gives rise to all of the aboveground plant organs through the initiation of additional meristem types. For instance, during the transition from vegetative to reproductive development, the SAM elongates to form an inflorescence meristem (IM), which will give rise to an inflorescence, or clusters of flowers along a main branch. Highly conserved signaling pathways are reiterated in these meristems, which creates an intricate system that balances the number of undifferentiated stem cells with the number of cells undergoing differentiation.

\subsubsection{The role of the CLAVATA signaling pathway in meristem maintenance}

Signaling modules in the meristem converge on the master regulatory transcription factor WUSCHEL (WUS) and related gene family members, which specify stem cell niches and are thus critical in maintaining growth and organogenesis in plants (Durbak and Tax 2011; Schoof et al. 2000). Without proper negative regulators surrounding the organizing center, WUS is able to confer stem cell identity on cell layers that are normally situated outside of the stem cell niche, thereby increasing the overall 
size of the meristem. Research in the past decade has unveiled many genes and other factors known to interact with WUS to maintain the balance between stem cell maintenance and differentiation. Extensive research in Arabidopsis has identified components of the CLAVATA (CLV) signaling pathway which interact in a negative feedback loop with WUS to restrict the stem cell populations in meristems (Schoof et al. 2000).

The main components of the CLV pathway in Arabidopsis include a peptide ligand (CLV3) that binds to two receptors (CLV1 and CLV2) to transmit repressive signals to WUS (Kayes and Clark 1998; Müller et al. 2008; Clark et al. 1993; Deyoung and Clark 2008). CLV1 is a receptor-kinase that is able to function independently to transduce signals to WUS (Clark et al. 1993); however, CLV2 does not have an intracellular kinase domain (Kayes and Clark 1998). Instead, CLV2 forms a complex with a membrane-localized protein, CRN, which is necessary to transmit repressive signals from CLV2 (Müller et al. 2008). WUS expression in turn promotes the expression of the CLV3 ligand, thereby restricting its own expression levels in the meristem (Brand et al. 2000).

Mutating components of the CLV pathway - namely the peptide ligand and receptors - eliminates WUS repression in the meristem center. If WUS expression is not restricted, it expands to other cell layers and greatly increases the stem cell niche. Thus, clv3, $c l v 1$, and $\operatorname{clv} 2$ mutants display greatly increased meristem sizes (Brand et al. 2000; Clark et al. 1993; Kayes and Clark 1998; Schoof et al. 2000). On the other hand, mutating the stem cell promoting factor WUS results in meristems that are unable to maintain pools of cells with stem cell identity. Due to the reduction of stem cells, wus 
mutants often display smaller inflorescences, or plant growth may arrest altogether once the remaining stem cells differentiate (Mayer and Jurgens 1998).

Expressing $C L V 3$ under a constitutive promoter results in decreased organ initiation in the shoot meristem after the first leaf emerged (Brand et al. 2000). However, a small proportion of the studied plants continued growing and initiated inflorescence meristems, which developed flowers without a female gynoecium (Brand et al. 2000). The $C L V 3$ overexpression phenotypes are similar to wus loss-of-function phenotypes, indicating that levels of CLV3 influence the expression of WUS. Follow-up experiments tested whether the CLV1 and CLV2 receptors were required for CLV3 signaling, or if CLV3 was able to transmit a restrictive signal to WUS via alternative pathways. By overexpressing $C L V 3$ under a constitutive promoter in either clv 1 or $c l v 2$ mutant plants, Brand and colleagues (2000) showed that instead of meristems terminating, the plants showed typical fasciated $c l v 1$ and $c l v 2$ mutant phenotypes. This result indicated that functional CLV1 and CLV2 receptors are required for CLV3 signaling.

Localization studies identified that CLV1 is predominantly expressed at the plasma membrane, as well as lowly expressed in the transport vesicles of the endoplasmic reticulum (ER) (Bleckmann et al. 2010). Contrary to the expectation that the CLV3 peptide is perceived and transmitted at the plasma membrane, CLV2 and CRN were each found to co-localize in the ER with no expression observed in transport vesicles of the ER (Bleckmann et al. 2010). However, when CLV2 and CRN formed a functional complex in the ER, transport vesicles were initiated and the complex was found to function at the plasma membrane as expected (Bleckmann et al. 2010). The interaction between CLV2 and CRN is not sufficient for localization to the plasma membrane. 
Instead, a functional extracellular domain in the $\mathrm{CRN}$ protein is required to initiate transport from the ER to the plasma membrane (Bleckmann et al. 2010).

The canonical CLV pathway in Arabidopsis has orthologs in other, distantly related plant lineages such as the grasses, indicating that the CLV pathway exists in both monocot and dicot systems (reviewed in Pautler et al. 2013). In maize, thick tassel dwarfl (tdl) and fasciated ear2 (fea2) were identified as functional orthologs of AtCLV1 and AtCLV2, respectively (Figure 2-1) (Bommert et al. 2005; Bommert et al. 2013). Much like AtCLV2, fea2 does not have a kinase domain, and thus cannot independently transmit repressive signals to $\mathrm{ZmWUS}$. Instead, fea2 interacts with compact plant2 (ct2) in a functional complex to repress $\mathrm{ZmWUS}$ (Bommert et al. 2013). Consistent with effects in Arabidopsis, mutating components of the CLV pathway in maize results in large increases in meristem sizes due to expanded expression of ZmWUS (Bommert et al. 2005; Bommert et al. 2013).

\subsubsection{Sos 1 may function in the CLAVATA signaling pathway}

Grasses are an intriguing model to study inflorescence development because the inflorescence is composed of spikelets, a characteristic unique to species within the Poaceae family. Spikelets are structures surrounded by leaf-like glumes that enclose the inconspicuous grass flowers. Following the reproductive transition, pools of stem cells located in the inflorescence meristem (IM) serve to maintain the tissue's multipotency. Cells from the IM will differentiate and form axillary meristems as the organ grows. The 
first axillary meristem to arise from the IM is the spikelet pair meristem (SPM), which will further differentiate into two spikelet meristems (SM) as the inflorescence develops. Ultimately, each spikelet meristem will develop into a mature spikelet with functional florets.

Maize typically produces spikelets in pairs, with one sessile spikelet and one spikelet on a pedicel (pedicellate). A notable exception is Suppressor of sessile spikelet 1 (Sos1-ref), a semi-dominant maize mutant characterized by a change from paired to single spikelet development (Figure 2-2). Sos1 arose spontaneously in a farmer's maize field, and a mutant ear was catalogued in the University of Wisconsin Herbarium (Doebley et al. 1995). A second, weaker Sos1 allele called Sos1-unpaired (Sos1-up) was identified through an allelism test, after it was acquired from the Maize Genetics Cooperation Stock Center.

Defects characteristic of the Sos1-ref mutant include fewer branches and single spikelets in the tassel (Figure 2-2) (Wu et al. 2009). Sos1-ref ears have similar spikelet defects, including alternating rows of single kernels (Figure 2-2). Interestingly, Sos 1 produces less than half the number of kernel rows typical of a normal maize ear. This finding indicates that the mutation likely causes other defects in addition to the development of single instead of paired spikelets. Subsequent SEM analyses of Sos1-ref ears identified two defects. First, while normal SPM develop two SMs, Sos1 mutant SPMs give rise to a single SM, causing the single spikelet phenotype. Second, the IM of homozygous mutants were significantly shorter (and borderline statistical significance for width) than normal ears, causing fewer overall SPM to be produced (Wu et al. 2009). The molecular basis for the IM and SPM defects in Sosl have yet to be determined. A 
testable hypothesis is that the smaller IM size results from an overall defect in meristem maintenance pathways in the mutant. Additionally, Sos1 SPM initiating one instead of two SMs may result from defects in either meristem identity or meristem maintenance. For example, maintaining fewer cells in the Sos1 IM suggests that there are fewer cells available to establish subsequent axillary meristems. Thus, the IM in Sos 1 mutants may initiate smaller SPM, which then develop into a single SM due to reduced cell availability or the inability to divide into two SM. Alternatively, Sos 1 mutants may develop SM directly from the IM due to altered expression of SPM genes, occurring separately from the reduced IM size defect.

Dr. Andrea Skirpan, a former postdoc in the McSteen lab, fine mapped the Sos 1 mutation by genotyping plants from Sos 1-ref mapping population (B73/Mo17) that were segregating $1 / 2$ normal and $1 / 2$ Sos 1 plants (1:1 line). She was able to narrow down the region by testing for recombinants until she exhausted all of the publicly available markers and seven SNP markers, which she designed from genes in the region. The results of fine mapping indicated that the Sos 1 mutation is located on chromosome 4, bin 2, BAC number c0026I20, containing three genes for which no recombinant plants were found. The lack of recombinant plants in this region suggests that these are candidate genes causing the Sos 1 mutation.

The first candidate gene identified in this region without recombinants was ZmFON, an orthologue of FLORAL ORGAN NUMBER4 (OsFON4) in rice. OsFON4 is a secreted peptide ligand and the putative orthologue of the Arabidopsis CLV3 gene (Chu et al. 2006), which has an established role in meristem maintenance by negatively regulating the stem cell promoter WUS (Schoof et al. 2000). The increased number of 
floral organs in loss-of-function fon 4 mutants were attributed to larger floral meristems (Chu et al. 2006).

The second candidate gene identified by Dr. Skirpan is ZmTPR, a protein-coding gene with a tetratricopeptide repeat (protein interaction) domain and zinc finger (DNA binding domain). Tetratricopeptide repeats are structural motifs with 3-16 tandem repeats of 34 amino acids (D'Andrea and Regan 2003). Proteins with TPRs are found in a wide range of organisms, including humans, plants, and bacteria, and function in wide ranges of biological functions (Goebl and Yanagida 1991). ZmTPR has orthologues in Sorghum, Setaria, and rice, and GO annotation suggests it functions in protein binding as well as metabolic, catabolic, and cellular processes (http://www.gramene.com).

The final candidate gene in the region of the $\operatorname{Sos} 1$ mutation is a hypothetical protein $(\mathrm{ZmHYP})$ that is a predicted transposable element. BLAST searches indicated that $H Y P$ is annotated as a NAM-like protein in rice, but has no homology to the Petunia NO APICAL MERISTEM (NAM) gene required for shoot development (Souer et al. 1996). Additionally, HYP does not contain the conserved NAC domain shared by proteins (such as NAM) in the NAC gene family in rice (Kikuchi et al. 1999).

In order to deduce which of the three candidate genes were affected in Sos1, Dr. Skirpan performed preliminary semi-quantitative RT-PCR analyses and found that ZmFON and ZmHYP were over-expressed, and ZmTPR was ectopically expressed in mutant compared to normal tassels. Subsequent semi-quantitative RT-PCR performed by Dr. Hong Yao, a former McSteen Lab research scientist, indicated that similar patterns of ZmFON and ZmTPR over-expression occurred in Sos1-up ear samples. Unlike Sos1-ref, ZmHYP shows no altered expression in Sos1-up (Yao and McSteen, unpublished). Dr. 
Yao furthermore developed qRT-PCR assays for ZmTPR and ZmHYP, but was unable to develop a ZmFON assay. Results of the qRT-PCR experiment indicated that Sos1-ref homozygote and heterozygote tassels have similar ectopic expression of ZmTPR, and homozygous mutants showed significantly greater levels of ZmHYP expression than heterozygote or normal tassels.

While it is unknown which candidate gene is responsible for the Sosl phenotype, the double mutant experiments conducted in Chapter 2 allowed us to further elucidate the role of Sosl in an important meristem maintenance pathway in maize. Because ZmFON is a putative orthologue of the CLAVATA pathway and thus may play a role in meristem maintenance, we predict that $Z m F O N$ is the most promising candidate gene. The observed defect in meristem maintenance implies that the sos 1 gene is important in controlling the balance between stem cell proliferation and cellular differentiation. While $t d 1$, fea2, and $c t 2$ are known to function in CLV signaling, evidence has shown that $t d l$ functions in a different pathway than fea2 and ct2 (Taguchi-Shiobara et al. 2001) (Bommert et al. 2013). The interactions of Sos 1 with each of these meristem mutants were tested to determine if and/or which pathway Sos 1 functions. If $\operatorname{sos} 1$ is not involved in the CLV signaling pathway, I would expect the phenotype of the double mutants to be additive (i.e., exhibit a phenotype that has characteristics of both mutants). However, if the gene overexpressed in the Sos 1 mutants does function in the CLV signaling pathway, I would expect an epistatic interaction, whereby the ligand-receptor double mutant (i.e., Sos $1 ; t d 1)$ would exhibit the receptor mutant phenotype. 


\subsection{MATERIALS \& METHODS}

\subsubsection{Generating double mutants}

Maize (Zea mays) plants homozygous for the meristem mutants of interest, namely thick tassel dwarf1 (td1), fasciated ear2 (fea2), compact plant2 (ct2), and Suppressor of sessile spikelet1 (Sos1), were introgressed more than three times into the B73 inbred background to minimize background effects on the observed phenotypes. Double mutant F1 were generated in the summer of 2015 in Columbia, MO by crossing the homozygous parents together. The F1 generation was planted and selfed (pollen from a tassel was applied to an ear of the same plant) during the 2016 field season in Molokai, HI by Hawaiian Research. The F2 double mutant seed segregating for both Sos 1 and a meristem mutant was then planted in the 2016 field season in Missouri. Before maturity, plants were genotyped for the single mutants. $t d l$ genotyping required three primers: $t d l$ glf F1 GTGACGTCGCTCAAGATCC, $t d l$ - $g l f$ R1 GATGATGTTGTCCTCCTTGAGA, and $M u$ tdl GCCTCCATTTCGTCGAATC (Bommert et al. 2005). fea2 genotyping also required three primers: fea2-F2 CTCCGTTGCCGAACTCTC, fea2-R2

CTATCCCCGGAGGAATGTC, and $M u 9242$

AGAGAAGCCAACGCCAWCGCCTCYA (Taguchi-Shiobara et al. 2001). ct2

genotyping requires only one primer pair: $c t 2-r e f$ Fo

TGAGGAGCTCTACTTCCAAAGC, and $c t 2-r e f$ Re TGGCTTATAACACCACATCCTC (Bommert et al. 2013). Sos 1 was genotyped with a linked, polymorphic short single repeat (SSR) DNA marker, umc 1294: umc1294-A 
GCCGTCAACGGGCTTAAACT and umc1294-B GCCTCCAGCTCTCTCGTCTCTT

(Wu et al. 2009). The F2 plants were used to quantify the genetic interactions between Sos1 and meristem mutants in the CLAVATA signaling pathway. Phenotypes were scored in two independent seasons to confirm phenotypes of the double mutants.

\subsubsection{Tassel quantification}

Tassels and ears (pollinated and unpollinated) were harvested from F2 plants following anthesis. Tassels were measured for tassel height, main spike height, peduncle length, number of branches, first branch length, main spike diameter, and number of paired and single spikelets along the main spike. The tassel heights were determined by measuring the length from the ligule of the flag leaf to the tip of the main spike. Main spike lengths were obtained by measuring the distance from the last-emerging branch to the tip of the tassel. Two measurements were obtained for peduncle length, first by measuring the distance from the ligule of the flag leaf to the first branch, and second by measuring from the ligule of the flag leaf to the beginning of the main spike. Irregular spikelet growth generally occurs at the base and tips of maize tassels, so $3-5 \mathrm{~cm}$ of spikelets at the tip and base of tassels were not counted for single or paired spikelets. Because the number of spikelets is limited by the length of the main spike, and the main spike length varies based on the genotype of the plant, the number of paired and single spikelets were normalized as a proportion to the number of spikelets along $10 \mathrm{~cm}$ of main spike. In addition, the fasciated inflorescences observed in the meristem mutants are 
correlated with spikelet density. As a proxy for spikelet density, the number of paired spikelets and number of single spikelets were added together to determine the number of meristem initiations for each tassel that was studied. The number of meristem initiations is equivalent to the number of SPM that develop along the immature tassel inflorescences.

Data were compiled and graphs were generated in Microsoft Excel. Custom standard error bars were calculated by dividing the standard deviation by the square root of the number of data points (n), and the custom error bars were then applied to graphs. Two-tailed t-tests assuming unequal variances were performed in Excel to determine statistical differences between measurements, and are included in six tables at the end of this Chapter.

\subsection{RESULTS}

\subsubsection{Sos1 mutants develop additional single spikelets}

Sos1 is a semi-dominant maize mutant, so the heterozygous plants have an intermediate phenotype. Consistent with this characteristic, quantitative measurements show that Sos 1 homozygous mutant tassels have significantly fewer single spikelets $(\mathrm{p}<$ $0.009)$ and meristem initiations $(\mathrm{p}<7.7 \mathrm{E}-05)$ than heterozygous tassels, but display no differences in the number of paired spikelets that develop $(\mathrm{p}=0.91)$ (Figure 2-3). Sos 1 homozygous mutant tassels have significantly more single spikelets $(\mathrm{p}<5.17 \mathrm{E}-06)$ and 
significantly fewer paired spikelets $(\mathrm{p}<0.01)$ compared to normal siblings, which is consistent with a previous finding (Wu et al. 2009). The Sosl mutants do not differ from normal siblings in either plant height or tassel main spike height, indicating that the sos 1 gene specifically affects the reproductive organs. Previous research by $\mathrm{Wu}$ and colleagues (2009) showed that Sos I IMs are smaller than normal, which suggests there is a possible defect in meristem maintenance in Sos 1 plants. Sos 1 double mutants were generated with known mutants affecting meristem maintenance in order to test whether Sosl functions in the CLAVATA meristem maintenance pathway.

\subsubsection{Double mutant analyses indicate that td1 is epistatic to Sos 1}

Maize TD1 has been identified as the ortholog of AtCLV1, a receptor-kinase that functions at the plasma membrane to transmit regulatory signals to ZmWUS (Bommert et al. 2005; Bleckmann et al. 2010). TD1 functions in a parallel, but separate, pathway than FEA2. Thus, double mutants between Sos 1 and these receptor mutants will allow the dissection of which branch of the pathway (if any) Sos 1 functions. $t d l$ receptor mutants develop enlarged inflorescences as a result of eliminating the repressive signaling from $t d l$ that normally regulates $Z m W U S$ expression. If $Z m F O N$ is the ligand for the $t d l$ branch of the maize CLV pathway, double mutants between Sosl and $t d l$ would be expected to show a $t d l$ mutant phenotype, indicating that Sos 1 functions upstream of $t d l$.

Interestingly, Sos $1 ; t d 1$ double mutant tassels have no significant differences in the number of paired or single spikelets, or the total number of meristem initiations compared 
to $t d 1$ mutants (Table 2-1). Consistent with this finding, Sos 1 ; $t$ d l double mutants also have no differences in the main spike length $(\mathrm{p}=0.39)$ or plant height $(\mathrm{p}=0.24)$ compared to $t d l$ (Figure 2-3). However, comparing Sos 1 ; $t d 1$ double mutants to Sos 1 tassels uncovers differences in the number of single spikelets $(\mathrm{p}>0.003)$ and paired spikelets ( $\mathrm{p}>0.003)$, as well as longer main spikes in Sos1 mutants ( $\mathrm{p}>0.004)$ (Tables 2-2 \& 2-3). The fact that the double mutants are significantly different from Sos 1 , but do not differ from $t d l$ in tassel composition, indicates that $t d l$ is epistatic to Sosl. Thus, Sos 1 functions in the same pathway, upstream of $t d l$ in maize tassel development.

tdl mutants, which develop enlarged, fasciated inflorescence meristems, have the opposite defect as Sos1. Two mutants with opposite defects in IM size would predictably have differences in the spikelet composition of their tassels as well. For example, if Sos 1 is predicted to have an increase in the number of single spikelets due to the smaller IM, then we may expect that the larger IM in $t d l$ mutants would result in a larger number of paired spikelets than in normal tassels. Thus, the finding that $t d l$ homozygous mutants (td1-glass finger allele) develop significantly more single spikelets $(\mathrm{p}>0.001)$, but the same number of paired spikelets $(\mathrm{p}=0.89)$, was unexpected (Figure 2-3). Furthermore, this result highlights the fact that inflorescence meristem size alone is not correlated with the development of single spikelets, since single spikelets arise in mutants with smaller or larger IMs. 


\subsubsection{Sos 1 and ct2 interact additively}

Much like the phenotypes seen in $t d 1$ mutants, ct2 mutants develop enlarged, fasciated ears as a result of the lack of inhibition of $Z m W U S$ in the inflorescence meristem, which expands the stem cell niche. Thus, as with the Sos 1;tdl double mutants, if ZmFON functions through $c t 2$, the Sos $1 ; c t 2$ double mutants would be expected to develop a $c t 2$ mutant phenotype. Consistent with these expectations, in the field environment the double mutant plants (and tassels) are virtually indistinguishable from ct2 plants at first sight (Figure 2-4). However, the differences between the Sos 1 and ct2 mutants are not as straightforward as was seen with Sosl;tdl double mutant interactions. Sos 1;ct2 double mutants develop significantly fewer paired spikelets ( $\mathrm{p}>0.0008)$ and more single spikelets ( $\mathrm{p}>0.0004)$ than $\mathrm{c} t 2$ tassels, but there was no notable difference in the number of meristem initiations $(\mathrm{p}=0.38)$ (Figure 2-4). The deviation from the expected double mutant phenotype indicates that $c t 2$ is not epistatic to Sos 1 . To further investigate the interaction between Sos 1 and $c t 2$, double mutants were compared to Sos 1 .

Comparing the Sos1;ct2 double mutants to Sos1 tassels indicated that there were no statistically significant differences in the number of paired or single spikelets, but the double mutant tassels do produce significantly more meristem initiations $(p>0.01)$

(Tables 2-4 \& 2-5). Furthermore, although there were no differences in spikelet composition on the tassel other than the number of initiations, the main spikes of Sos1;ct2 double mutants were significantly shorter than Sos 1 tassels $(\mathrm{p}>0.005)$ (Figure 2-4; Table 2-6). Significantly greater numbers of meristem initiations and main spike length between the double mutant plants and Sos1 indicated that Sos 1 is not epistatic to 
$c t 2$ either. Instead, the data reveal that $c t 2$ and Sos 1 interact additively. This finding suggests that $Z m F O N$ does not function in the same pathway as $c t 2$ in inflorescence development.

Another clear phenotype observed in $c t 2$ mutants is a very short tassel, consistent with the "compact plant" namesake. ct2 mutants develop significantly more paired spikelets than normal plants $(\mathrm{p}>0.003)$, which may be due to the increased number of meristem initiations also seen in the mutant $(\mathrm{p}>0.003)$. Interestingly, the additional meristem initiations observed in $c t 2$ tassels occur along a main spike that is significantly smaller than in normal tassels ( $\mathrm{p}>0.002)$. This finding is noteworthy because it indicates that the number of meristem initiations is not dictated by the size of the mutant tassel.

\subsubsection{Compensation from other CLV receptors may cause the Sos1;fea2 double mutant} phenotype

A previous study showed that TD1 functions independently from the FEA2/CT2 complex (Bommert et al. 2005). Genetic evidence from Sos 1;ct2 double mutants indicates that $\mathrm{ZmFON}$ does not function through $\mathrm{CT} 2$. In order to confirm that the putative ZmFON ligand does not function through the FEA2/CT2 branch of the CLV pathway in maize, double mutants between Sos 1 and fea 2 were analyzed. Previous research into the maize CLV pathway has only shown that FEA2 functions through CT2 
to transmit repressive signals to ZmWUS. Thus, the Sos 1;fea2 double mutants are expected to develop an additive phenotype similar to the Sos $1 ;$ ct 2 double mutants.

While fea 2 homozygous ears develop large, fasciated ear inflorescences, there are no obvious phenotypes in the tassel inflorescence. Specifically, comparing fea 2 tassels to normal tassels shows no significant differences between the number of paired $(p=0.46)$ or single spikelets $(p=0.19)$, the number of axillary meristem initiations $(p=0.14)$, or the length of the main spikes $(\mathrm{p}=0.44)$ (Figure 2-6). Consistent with these findings, fea2 homozygotes have no significant differences from fea2 heterozygotes, which should be phenotypically normal due to the recessive mutation (Table 2-7).

In the field, tassels of Sos 1;fea2 double mutants had a similar phenotype to fea2 mutant tassels (Figure 2-6). However, statistical analyses uncovered significant differences in spikelet composition between both $\operatorname{Sos} 1$ and fea 2 single mutants (Figure 26). Specifically, double mutants are taller $(\mathrm{p}>0.02)$, and have significantly fewer paired spikelets $(\mathrm{p}>0.002)$ and more single spikelets $(\mathrm{p}>0.005)$ than fea2 homozygous tassels. Similarly, Sos1;fea2 double mutants have significantly fewer paired spikelets ( $\mathrm{p}>4.51 \mathrm{E}-$ 07) and more single spikelets $(\mathrm{p}>0.0009)$ than Sos 1 tassels. There are no differences in the number of meristem initiations or main spike length between Sos 1;fea2 double mutants and either single mutant (Tables $2-8$ \& 2-9). These data indicate that, unlike the interaction between $\operatorname{Sos} 1$ and $t d 1, f e a 2$ is not completely epistatic to Sos 1 . Additionally, Sos1;fea2 double mutants do not show an additive phenotype observed in Sos 1;ct2 double mutants. Instead, the phenotype is intermediate between both Sos 1 and fea 2 single mutants. 
Interestingly, the spikelet composition of Sos l,fea 2 tassels is strikingly similar to that of Sos $1 ; t d 1$ tassels. In fact, Sos 1;fea 2 tassels have the same number of paired $(\mathrm{p}=$ $0.44)$ and single spikelets $(\mathrm{p}=0.62)$, and no differences in the number of meristem initiations $(\mathrm{p}=0.69)$ compared to Sos 1; td1 tassels. If Sos 1 did not interact with fea2, we would have expected to observe a Sos 1 mutant phenotype in the tassel inflorescence, since the fea 2 phenotype is very weak in the tassel. We propose in this study that eliminating the function of fea 2 does not result in an epistatic phenotype in the double mutant because TD1 is still able to transmit regulatory signals to ZmWUS. Thus, we cannot conclude that Sos 1 and fea 2 interact additively or epistatically, but propose an alternative mechanism of receptor action in the Discussion.

\subsection{DISCUSSION}

\subsubsection{Sos1 interacts with known orthologs of the CLAVATA signaling pathway}

The present study provides genetic evidence that TD1, the maize orthologue of AtCLVI and transmembrane receptor kinase in the CLAVATA pathway, is epistatic to Sos1. Regardless of how much ligand is present (due to the overexpression seen in Sos1 mutants), the signal to repress the stem cell marker ZmWUS cannot be transmitted if the receptor is absent. Thus, Sos 1 may be the ligand for the TD1 branch of the CLV pathway. Supporting this finding, one of the three genes in the region that the sos 1 gene maps to is ZmFON, named because it is the putative maize ortholog of FON4 in rice and AtCLV3 
peptide ligand. The gene model for ZmFON (GRMZM2G372364) is associated with the cle7 locus in maize (clavata3/esr-related7), and the locus is a candidate for a CLV3 ortholog, noting that peptides encoded by this gene have negative effects on SAM size when the peptide is applied to meristems exogenously (Je et al. 2016). However, because ZmTPR is also overexpressed in Sos 1 mutants, further research is needed to determine the effects, if any, of ZmTPR in maize inflorescences.

The data presented in this study clearly show that Sos 1 interacts additively with ct2. Double mutants develop alternating rows of single kernels in the ears (Figure 2-5) as seen in the Sos 1 phenotype, while the mature vegetative and tassel phenotypes are strikingly similar to $c t 2$. This suggests that $\operatorname{Sos} 1$ does not act in the same pathway as $c t 2$, which has a significant impact on our interpretation of the Sos1;fea2 double mutants.

If Sos 1 does not function through fea2, we would have expected the double mutants to exhibit a clear additive phenotype similar to the Sos1;ct2 double mutant phenotype. Instead, the Sos I;fea2 double mutant phenotype is strikingly similar to the Sos $1 ; t d 1$ double mutant plants. In fact, the Sosl;fea 2 and Sos $1 ; t d 1$ double mutants have no significant differences in the number of paired or single spikelets, or the number of meristem initiations. Curiously, the Sosl;fea2 double mutants display an intermediate phenotype between Sos 1 and fea2. Sos 1 ; fea 2 plants produce more single spikelets than fea2, but more paired spikelets than Sos1. To accurately interpret the Sosl;fea2 double mutant results, I propose that FEA2 forms two functional complexes in maize: First, FEA2 forms a known complex with CT2, and second, FEA2 interacts with TD1 to transmit the Sos1 (or cle7) signal to ZmWUS. 


\subsubsection{Model for CLAVATA signaling complexes in maize}

Based on the double mutant analyses completed in this study, I propose a model in which the CLAVATA pathway receptors in maize form at least three functional complexes (Figure 2-7). First, TD1 homodimerizes and is able to transmit the signal from sos 1 independently. Second, TD1 and FEA2 form a complex which is also capable of transmitting the sos 1 signal to regulate WUS. Finally, FEA2 forms a heterodimer with CT2, which does not respond to sos1, but rather recognizes a different, unknown, signaling peptide from the other complexes.

This model asserts that a typical Sos 1 mutant overexpresses the putative $C L V 3$ ortholog in maize, which then binds to the TD1 homodimer and TD1-FEA2 heterodimer to transmit a signal that in turn represses ZmWUS (Figure 2-7). Overexpression of the ligand leads to the stem cell niche being severely restricted in size, resulting in a smaller inflorescence meristem seen in Sos 1 mutants. In this model, the FEA2-CT2 complex has no effect on signaling because $\operatorname{Sos} 1$ is not functioning through the CT2-containing complex (Figure 2-7).

Based on the proposed model, the epistatic phenotype seen in Sos 1;tdl double mutants can be explained by the fact that mutating $t d l$ would eliminate $s o s l$ signaling through both the TD1-TD1 homodimer and the TD1-FEA2 heterodimer (Figure 2-7). This also suggests that, while sos 1 may signal through FEA2 when it forms a functional complex with TD1, CT2 is resistant to the putative sos 1 ligand. Thus, even though sos 1 
is still overexpressed in Sos $1 ; t d 1$ double mutants, the double mutants display the phenotype characteristic of a receptor mutant because no signal is able to be transmitted.

Furthermore, this model can also explain the intermediate phenotype seen in Sos 1;fea 2 double mutants. When fea 2 is mutated, signal cannot be transmitted through either complex that $f e a 2$ functions in, namely the TD1-FEA2 heterodimer or the FEA2CT2 heterodimer (Figure 2-7). Because the FEA2-CT2 complex does not recognize sos 1, the only signal that is lost is from the TD1-FEA2 heterodimer; however, the TD1TD1 homodimer complex is still functional and able to recognize and transmit the signal from sos1. Thus, the TD1-TD1 complex is partially compensating for the loss of the TD1-FEA2 complex, which explains why the Sosl;fea2 double mutant phenotype is intermediate between each of the single mutants. If the TD1-TD1 homodimer was solely responsible for transmitting the sos 1 signal (i.e., if there was not a TD1-FEA2 heterodimer contributing to signal transmission), then we would have expected the Sosl;fea2 double mutants to exhibit an Sos 1 phenotype. These results indicate that the TD1-FEA2 complex proposed in this model represents an additional layer of receptor coordination that is necessary to observe the typical Sos 1 phenotype.

Consistent with this model, evidence from Sos $1 ; \operatorname{ct} 2$ double mutants supports the assertion that a functional TD1-FEA2 complex is necessary for the Sos 1 phenotype. In Sos 1; $c$ 2 double mutants, the function of a protein shown to not be involved in Sos 1 signaling is mutated (ct2), which results in tassels bearing the same number of single and paired spikelets as Sos 1 single mutants. The Sos 1 spikelet composition observed in Sos 1;ct2 double mutants is therefore due to the ability of the TD1-TD1 and TD1-FEA2 complexes to function, regardless of the FEA2-CT2 complex formation (Figure 2-7). 
Finally, the mature plant phenotypes of Sos $1 ; c t 2$ double mutants are nearly identical to $c t 2$ homozygous plants, which further supports the idea that $c t 2$ acts independently of Sosl to affect both vegetative and reproductive phenotypes.

Research in maize and Arabidopsis further supports the model proposed in the current study. Previous studies showed that TD1 and FEA2 act independently, but with parallel functions (Bommert et al. 2013). Furthermore, studies in maize have shown that FEA2 interacts with CT2 in a protein complex, which transmits the repressive signal to WUS (Bommert et al. 2013). This interaction is necessary for FEA2 to signal because FEA2 does not contain an intracellular kinase domain required for signal transduction (Taguchi-Shiobara et al. 2001). In Arabidopsis, a plasma membrane-localized protein called CORYNE (CRN) forms a dimer with CLV2 in order to transmit the CLV3 signal to WUS (Durbak and Tax 2011). Studies which aimed to determine the localization patterns of the two CLV receptors in Arabidopsis showed that there are indeed three models of CLV receptor complexes: 1) CLV1 forms a homodimer and is able to function alone to perceive and transmit signals once it is bound by the CLV3 ligand; 2) CLV2 forms a tetrameric complex with CRN, signaling independently of CLV1; and 3) CLV1 forms a homodimer that can in turn interact with the CLV2/CRN complex (Figure 2-1) (Bleckmann et al. 2010). Thus, results from this study are consistent with other models, and suggest that components of the CLAVATA signaling pathway and their functions appear to be highly conserved between Arabidopsis and maize.

In order to definitively conclude that $\mathrm{ZmFON}$ is also the ligand for the FEA2 branch of the CLV pathway, the next logical step is to generate triple mutants between Sos $1, t d 1$, and fea 2 . Triple mutants between the putative ligand and the receptors of the 
$C L V$ signaling pathway could elucidate the effect of Sos 1 overexpression with a nonfunctional FEA2 receptor when $T D 1$ is unable to compensate. If FEA2 forms additional complexes that recognize Sos 1 independently of TD1 and CT2, we would expect a fasciated phenotype in triple mutants that is more severe than Sos 1;tdl double mutants. A more fasciated phenotype is expected due to the inability of the TD1-TD1 complex to compensate for the loss of the TD1-FEA2 complex, which is predicted to occur in Sosl;fea2 double mutants.

Additionally, it would need to be demonstrated biochemically that $\mathrm{ZmFON}$ is a ligand in the $C L V$ pathway in maize. Future studies should test the physical interactions between the putative ZmFON ligand and the TD1 and FEA2 receptor proteins using coimmunoprecipitation techniques. Interactions can then be observed in vivo by utilizing fluorescence resonance energy transfer (FRET) or fluorescent protein fusion. Subsequent experiments will also determine the interaction between Sos 1 , double mutants, and ZmWUS by performing confocal microscopy analyses. Analyzing mutants with the ZmWUS-RFP transgene will allow a more detailed understanding of the mechanism by which these mutants are able to alter meristem size through the fine regulation of ZmWUS.

\subsubsection{Reasoning for single spikelets}

The present study found that the $t d 1$-glf allele developed significantly more single spikelets in the homozygotes than the heterozygotes, which is consistent with what was 
found in tassels of the $t d 1$-reference allele (Bommert et al. 2005). In a species that normally develops paired spikelets, one would reasonably expect a bigger IM would develop more SPM, which in turn would produce more SMs, ultimately leading to greater numbers of paired spikelets. Thus, a testable hypothesis is that $t d l$-glf mutants produce significantly more single spikelets due to the initiation of more than two spikelet meristems from the enlarged SPM, instead of the normal two. This would indicate that single spikelets arise when there are not enough cells in the progenitor meristem (SPM) to initiate a branching event that would form the second SM. In contrast, a mutant that develops significantly smaller IMs, such as in Sos 1, may produce fewer or smaller SPM and ultimately lead to growth of abnormal single spikelets.

The original research on the $t d l$-ref allele showed a greatly enlarged inflorescence meristem in the ear inflorescence, which corresponded to increased SPM and SM sizes (Bommert et al. 2005). Increased sizes of SPM then correlated with an increase in the number of spikelets that were produced in the ear. Specifically, a single SPM divided to produce three SMs instead of the normal two, a result that was common in developing tdl-ref ear inflorescences (Bommert et al. 2005). The larger SMs also produced extranumerary glumes, which are derived from the SMs (McSteen and Hake 2001), as well as additional stamens compared to normal (Bommert et al. 2005). Thus, it appears that larger SPMs may be a developmental trigger for the $t d 1$-glf mutants in this study to grow significantly more single spikelets than observed on normal tassels.

However, the single spikelets observed in Sos 1 are clearly not caused by larger SPM producing extranumerary spikelets. Instead, it is more likely that there are multiple size thresholds that SPM meet. For example, the first size threshold (smaller than 
normal) may result in single spikelets due to an inadequate number of cells required to initiate a branching event that would result in paired spikelets. Next, when the appropriate meristem size is achieved, paired spikelets are produced by the SPM.

Finally, mutants which produce larger meristems may surpass yet another size threshold, which results in a larger SPM that develops more than two spikelets. This threshold hypothesis may explain why single spikelets can develop through either larger (tdl, fea2, $c t 2$ ) or smaller (Sos1) inflorescence meristems. Future research should aim to test this hypothesis by utilizing developmental techniques, such as scanning electron microscopy, to measure the SPM sizes in inflorescences of different mutants.

\subsubsection{Possible function of Sos1 in meristem determinacy}

In the present study, we aimed to characterize the role of Sos 1 in meristem maintenance based on the smaller inflorescence meristems observed in the mutant. However, the change from paired spikelets in normal plants to single spikelets in the Sos 1 semi-dominant mutant could also represent a change in determinacy of the SPM. McSteen (2006) proposed that an SPM that gives rise to one instead of two SMs is due to increased determinacy (McSteen 2006). SPM determinacy in maize is regulated in part by the RAMOSA ( $r a l, r a 2$, and $r a 3$ ) pathway (Vollbrecht et al. 2005; Bortiri et al. 2006; Satoh-Nagasawa et al. 2006).

Because the single spikelets of Sos 1 may be caused by a change in determinacy, a previous study of Sos 1 generated double mutants between Sos 1 and the three genes of the 
RAMOSA pathway (Wu et al. 2009). Results from Sos 1;ral double mutants indicate that Sos1 suppresses the ral phenotype; in addition, Sos 1;ra2 double mutants have a synergistic phenotype, while Sos 1 and $r a 3$ were found to interact additively (Wu et al. 2009). Notably, the mRNA levels of ral were increased in Sos1 mutants, while ra2 and ra3 levels remained unchanged ( $\mathrm{Wu}$ et al. 2009). Wu and colleagues proposed that the sos 1 gene negatively regulated determinacy while positively regulating ral expression, which in turn promotes SPM determinacy. In the sense that negative regulators (sos1) also promote the function of positive regulators ( $\mathrm{ral}$ ), their model of determinacy appears to be parallel to the model of CLAVATA signaling, and suggests that the sos 1 gene is working through multiple pathways.

Clearly both meristem maintenance and determinacy contribute to the overall structure of the growing inflorescence. In order to test the interaction between meristem maintenance and meristem determinacy pathways, double mutants between members of the CLAVATA and RAMOSA pathways need to be evaluated. Double mutants with Sos1 and the CLAVATA and RAMOSA pathways have already been analyzed, but have failed to clearly elucidate this complex interaction. Double mutants between CLV and RA components will further unravel the complexity of interactions between these important and intricate pathways. It would also be interesting to determine whether the other genes overexpressed in Sos 1 mutant tassels, ZmTPR and ZmHYP, are also implicated with these important meristem maintenance or determinacy pathways. 

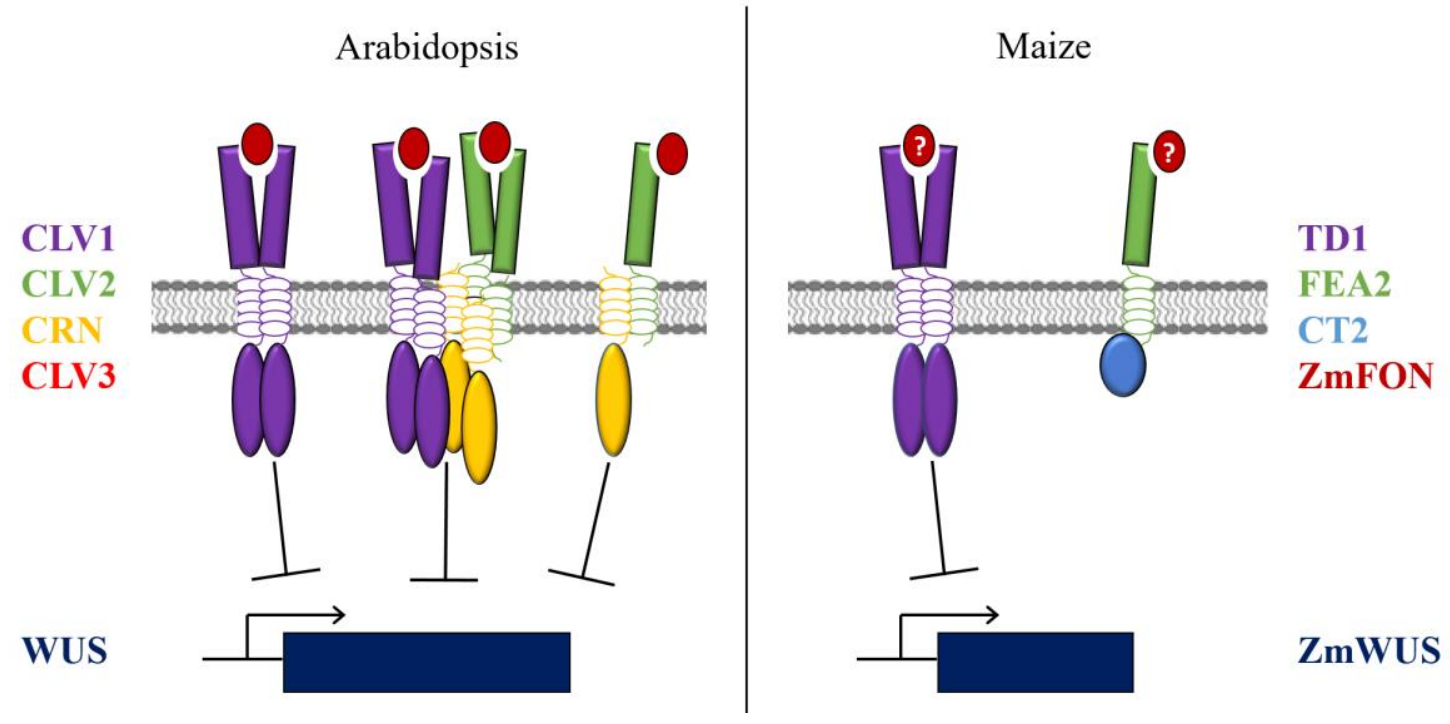

Figure 2-1. CLAVATA signaling components in Arabidopsis and maize. The canonical CLAVATA (CLV) signaling pathways in both Arabidopsis and maize tightly regulate WUS expression through a negative feedback loop. The major difference between these pathways in Arabidopsis and maize is the intracellular signaling component that CLV2/FEA2 binds to, as well as the fact that the ligand of the CLV pathway in maize has not yet been identified. Furthermore, CLV1, CLV2, and CRN in Arabidopsis have been shown to form tetramers at the plasma membrane, adding another complex regulating WUS expression. 

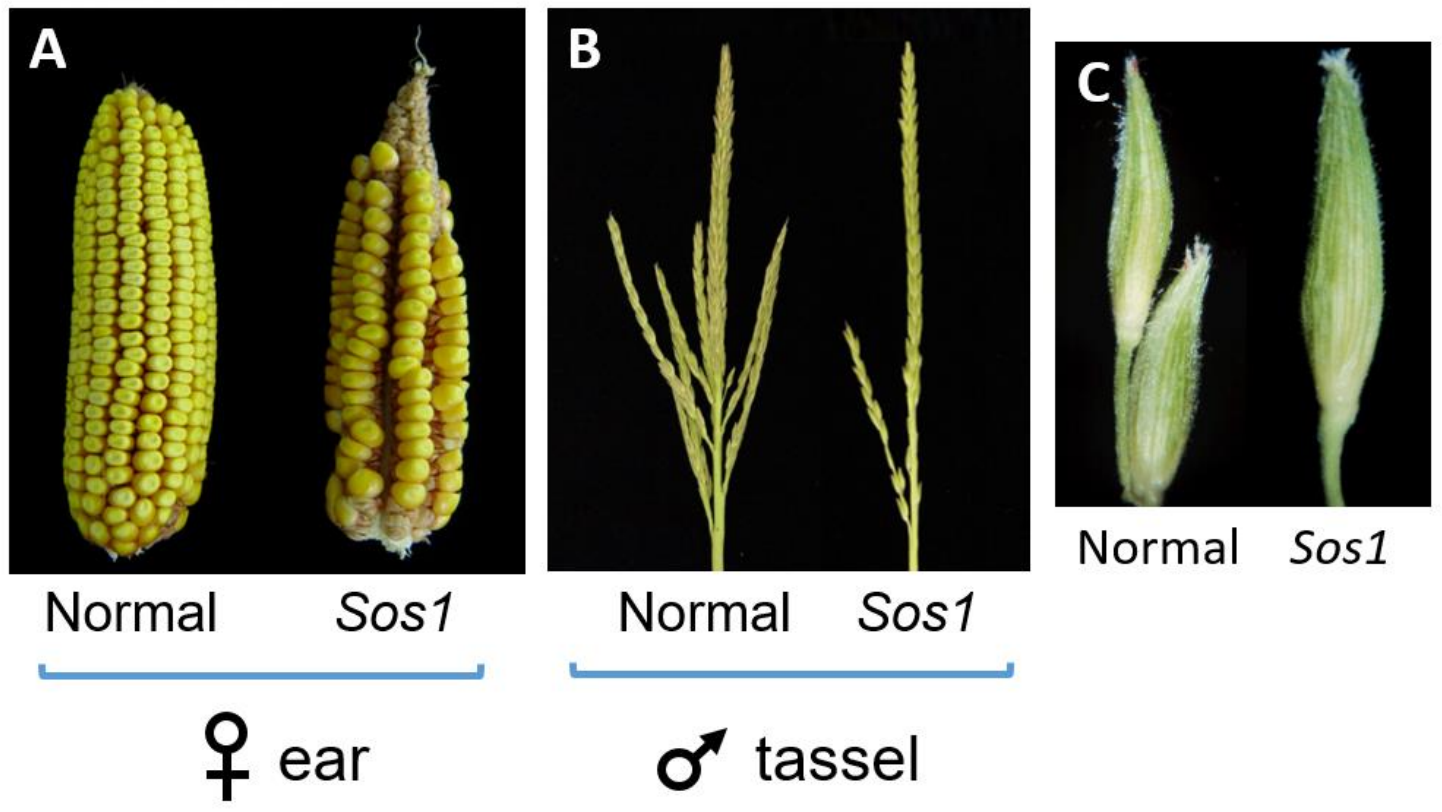

Figure 2-2. Suppressor of sessile spikelet1 (Sos1) phenotype. Sos 1 ears (A) produce alternating rows of single instead of paired kernels, as well as less than half the number of kernel rows, indicating additional meristem defects. The Sos 1 tassel (B) develops single instead of paired spikelets as well as fewer branches alone the main spike. Maize normally produces spikelets in pairs, but the Sos 1 mutant develops only the pedicellate spikelet (C). Adapted from Wu et al. 2009. 

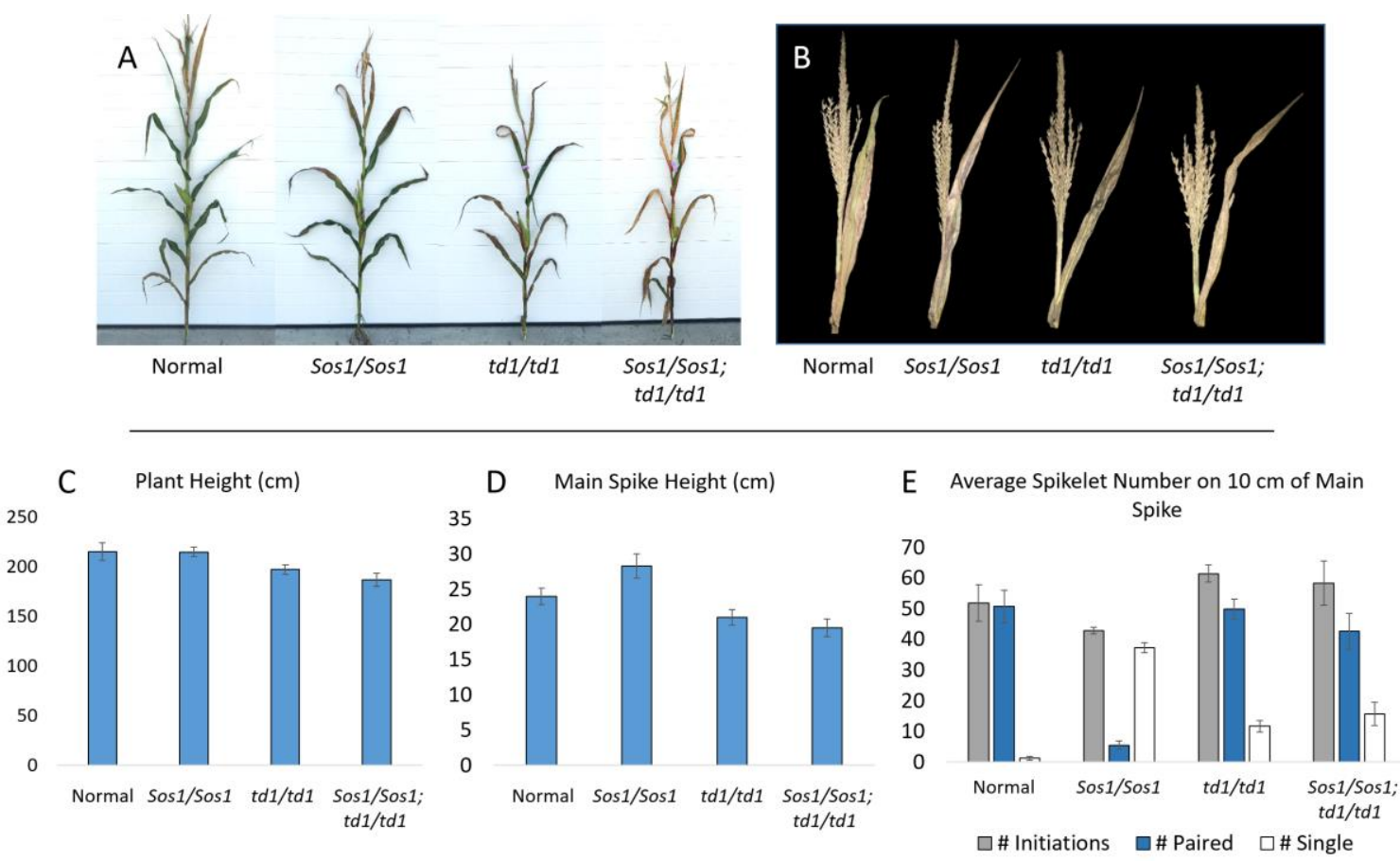

Figure 2-3. Analysis of Sos1;td1 double mutant phenotypes. Mature plant (A) and tassel (B) phenotypes of $S o s 1$ and $t d l$ double and single mutants. Quantitative analyses indicate that Sos $1 ; t d 1$ double mutants resemble $t d 1$ in plant height $(\mathrm{C})$ and height of the main spike on the tassel inflorescence (D). Analysis of spikelet composition in single and double mutant tassels (E) reveals that Sos 1;td 1 mutants have no significant differences from $t d l$, suggesting an epistatic relationship between $S o s 1$ and $t d l$. Error bars represent custom standard error values. N =3, 5, 6, 5 for Normal, Sos 1/Sos 1, $t d 1 / t d 1$, and $\operatorname{Sos} 1 ; t d 1$ double mutants, respectively. 


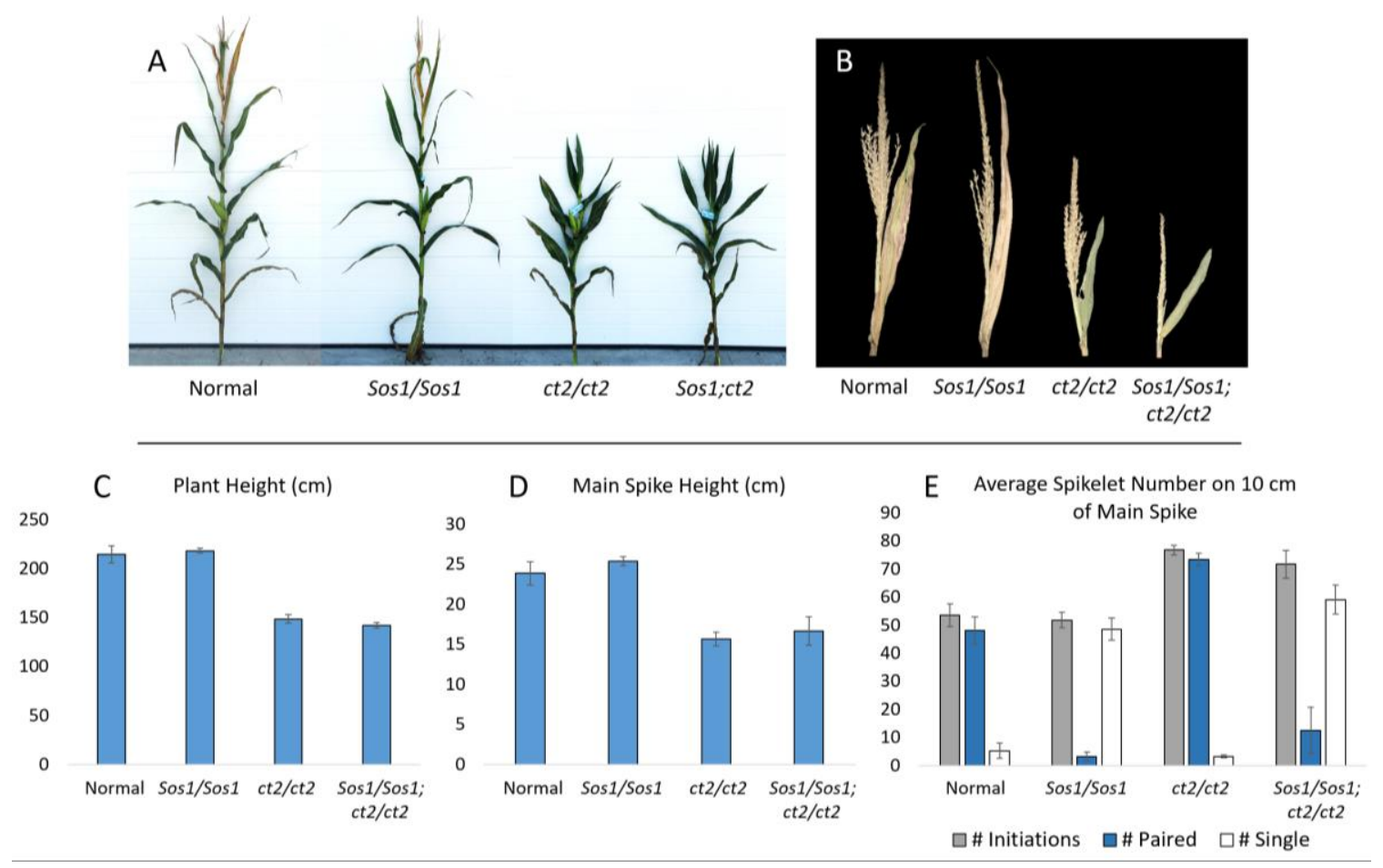

Figure 2-4. Analysis of Sos 1;ct2 double mutant phenotypes. Mature plant (A) and tassel (B) phenotypes of Sos 1 and ct 2 double and single mutants.

Quantitative analyses indicate that Sos 1;ct2 double mutants resemble ct2 in plant height (C) and height of the main spike on the tassel inflorescence (D). However, analysis of spikelet composition in single and double mutant tassels (E) reveals that $\operatorname{Sos} 1$; ct 2 mutants resemble an $\operatorname{Sos} 1$ phenotype, suggesting that $\operatorname{Sos} 1$ and ct 2 interact additively. Error bars represent custom standard error values. $\mathrm{N}=5,6$, 5, 5 for Normal, $\operatorname{Sos} 1 / \operatorname{Sos} 1$, ct 2/ct2, and $\operatorname{Sos} 1$; ct 2 double mutants, respectively. 


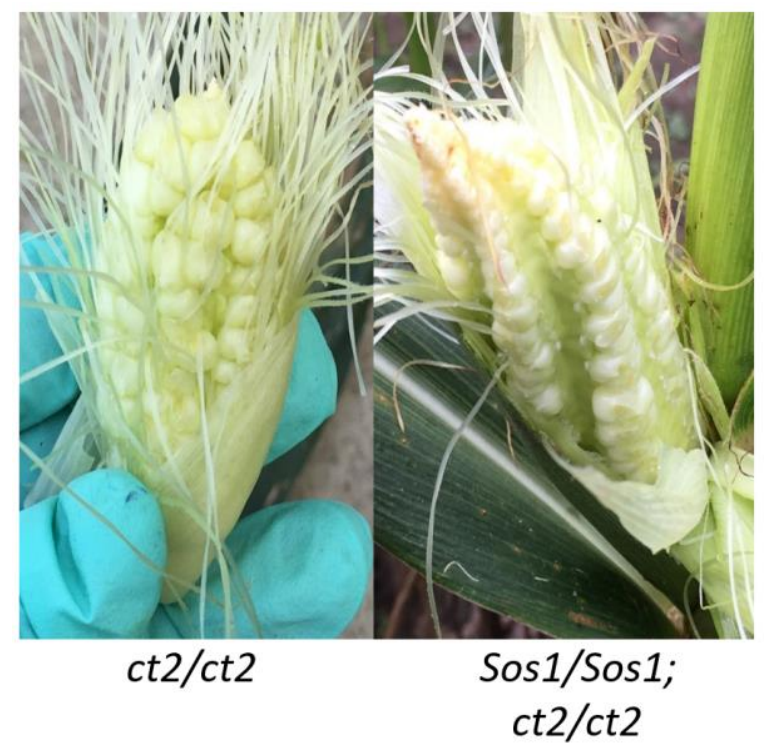

Figure 2-5. Ear phenotype in Sos1; ct2 double mutant. ct 2 mutants develop a short but fasciated ear with disorganized kernels. Sos 1;ct2 double mutants resemble ct 2 ears in size and thickness, but develop a clear Sos 1 phenotype in the kernels. 

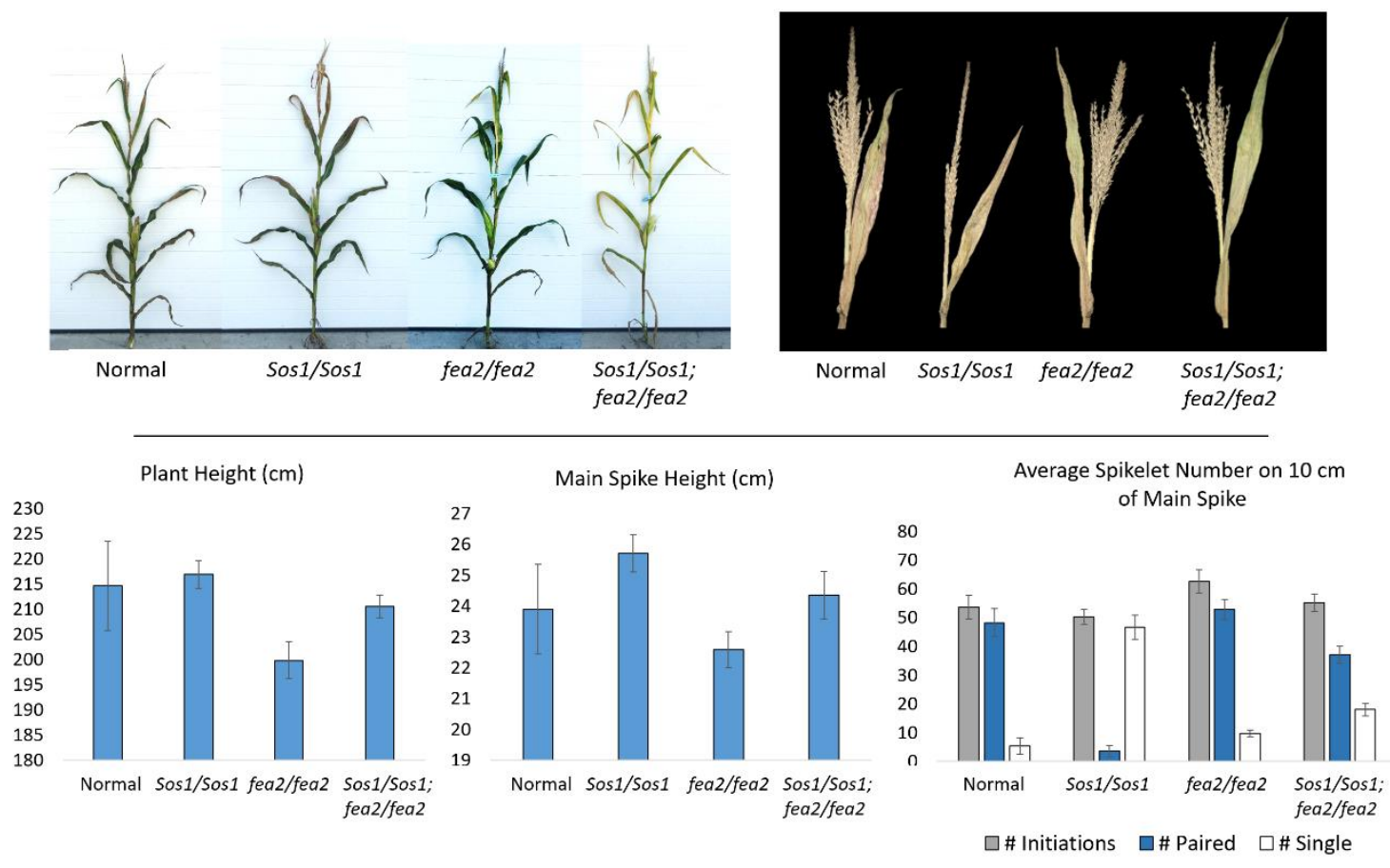

Figure 2-6. Analysis of Sos1;fea2 double mutant phenotypes. Mature plant (A) and tassel (B) phenotypes of Sos 1 and fea 2 double and single mutants. Quantitative analyses indicate that Sos 1;fea2 double mutants have an intermediate phenotype (i.e., between Sos 1 and fea2 single mutant plants) in plant height (C) and height of the main spike on the tassel inflorescence (D). Analysis of spikelet composition in single and double mutant tassels (E) reveals that Sos 1;fea2 mutants again have an intermediate phenotype, suggesting that receptor compensation may be occurring, perhaps from TD1 receptor complexes. Error bars represent custom standard error values. $\mathrm{N}=5,5,18,10$ for Normal, Sos 1/Sos1, fea2/fea2, and Sos1;fea2 double mutants, respectively. 


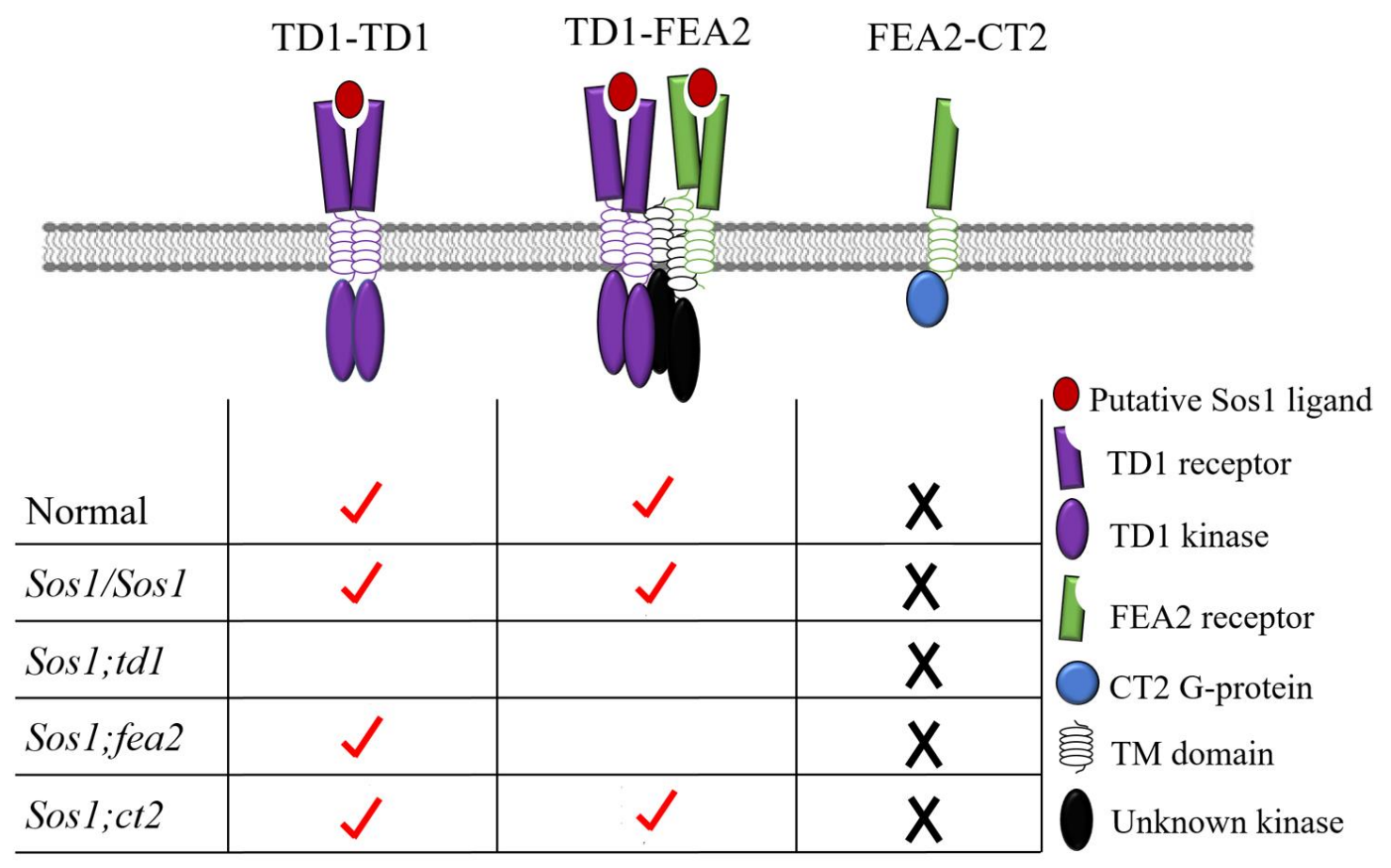

Figure 2-7. Model of proposed receptor complexes. In normal plants, signaling through the putative Sos1 ligand only occurs through the TD1-TD1 and TD1-FEA2 receptor complexes, because CT2 is resistant to Sos1. In Sos 1;td1 double mutants, both complexes that are proposed to transmit signal from Sos1 are knocked out, resulting in a receptor mutant phenotype in the double mutant plants. Compensation from the TD1-TD1 complex occurs in Sos 1;fea2 double mutants, resulting in an intermediate phenotype. 


\begin{tabular}{|c|c|c|c|c|}
\hline & \# Paired & \# Single & \# Initiations & $\mathrm{N}$ \\
\hline Normal & $50.67 \pm 9.24$ & $1.2 \pm 1.09$ & $51.87 \pm 10.28$ & 3 \\
\hline Sos 1/+ & $14.65 \pm 6.66$ & $37.63 \pm 7.17$ & $52.29 \pm 3.53$ & 10 \\
\hline Sos 1/Sos 1 & $5.5 \pm 3.08$ & $37.29 \pm 3.68$ & $42.8 \pm 2.41$ & 5 \\
\hline$t d 1 /+$ & $51.83 \pm 9.46$ & $1.97 \pm 0.79$ & $53.80 \pm 9.72$ & 9 \\
\hline$t d 1 / t d 1$ & $49.78 \pm 8.31$ & $11.63 \pm 4.64$ & $61.42 \pm 6.93$ & 6 \\
\hline $\operatorname{Sos} 1 /+; t d 1 /+$ & $15.68 \pm 7.95$ & $36.04 \pm 10.67$ & $51.72 \pm 7.03$ & 18 \\
\hline $\operatorname{Sos} 1 / \operatorname{Sos} 1 ; t d 1 /+$ & $4.88 \pm 3.56$ & $43.36 \pm 9.19$ & $48.24 \pm 5.86$ & 7 \\
\hline $\operatorname{Sos} 1 /+; \operatorname{td} 1 / t d 1$ & $39.87 \pm 9.24$ & $17.68 \pm 10.47$ & $57.56 \pm 3.97$ & 8 \\
\hline $\operatorname{Sos} 1 / \operatorname{Sos} 1 ; t d 1 / t d 1$ & $42.58 \pm 13.22$ & $15.71 \pm 8.42$ & $58.29 \pm 15.90$ & 5 \\
\hline
\end{tabular}

Table 2-1. Quantification of spikelet numbers in plants segregating for the Sos 1;td1 double mutant. The number of paired and single spikelets, and the number of spikelet meristem initiations are listed $+/$ - the standard deviation calculated for each genotype. Red numbers indicate genotypes for which few plants were available for collection. 


\begin{tabular}{|c|c|c|c|c|c|c|}
\hline & Normal & Sos1/+ & Sos1/Sos 1 & $t d 1 / t d 1$ & $\begin{array}{c}\text { Sos1/Sos1; } \\
t d 1 /+\end{array}$ & $\begin{array}{l}\text { Sos1/+; } \\
\text { td1/td1 }\end{array}$ \\
\hline Sos1/Sos1 & $\begin{array}{rl}* & 0.01 \\
* & 5.17 \mathrm{E}-06 \\
& 0.27\end{array}$ & 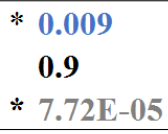 & & & & \\
\hline$t d 1 /+$ & $\begin{array}{l}0.86 \\
0.4 \\
0.79 \\
\end{array}$ & & $* 0.009$ & $\begin{array}{rl} & 0.66 \\
* & 0.003 \\
& 0.1 \\
\end{array}$ & & \\
\hline$t d 1 / t d 1$ & $\begin{array}{c}0.89 \\
* 0.001 \\
0.24 \\
\end{array}$ & & $\begin{array}{l}* 6.07 \mathrm{E}-06 \\
* 2.98 \mathrm{E}-06 \\
* 0.0008\end{array}$ & & & \\
\hline $\begin{array}{c}\text { Sos1/+; } \\
\text { td1/+ }\end{array}$ & & & $\begin{array}{rl}* & 0.0003 \\
& 0.68 \\
* & 0.0002\end{array}$ & & & \\
\hline $\begin{array}{l}\operatorname{Sos} 1 /+ \\
t d 1 / t d 1\end{array}$ & & $\begin{array}{l}* 0.0003 \\
* 0.0006 \\
* 0.01\end{array}$ & & $\begin{array}{r}\sim 0.05 \\
0.17 \\
0.26 \\
\end{array}$ & $\begin{array}{l}* 3.87 \mathrm{E}-06 \\
* 0.0002 \\
* 0.005\end{array}$ & \\
\hline $\begin{array}{c}\operatorname{Sos} 1 / \operatorname{Sos} 1 \\
t d 1 / t d 1\end{array}$ & & & $\begin{array}{rl}* & 0.003 \\
* & 0.003 \\
& 0.09\end{array}$ & $\begin{array}{l}0.32 \\
0.37 \\
0.7\end{array}$ & & $\begin{array}{l}0.7 \\
0.71 \\
0.92\end{array}$ \\
\hline
\end{tabular}

PAIRED

SINGLE

INITIATIONS

Table 2-2. Two-tail t-test values calculated for the number of paired spikelets, single spikelets, and meristem initiations in Sos 1;td1 double mutants. The two-tailed t-test values assuming unequal variances are listed for paired and single spikelets, and the number of spikelet meristem initiations calculated for each genotype. Blue $=$ Paired spikelets; Black $=$ Single spikelets; Grey $=$ Number of meristem initiations. Significant values $(\mathrm{p}<0.05)$ are marked with $\mathrm{a} *$. Values bordering significance $(\mathrm{p}=$ $\sim 0.05$ ) are marked with $\mathrm{a} \sim$. 


\begin{tabular}{|c|c|c|c|}
\hline & Normal & Sos1/Sos1 & td1/td1 \\
\hline Sos1/Sos1 & $* 0.08$ & & \\
\hline td1/td1 & 0.11 & $* 0.009$ & \\
\hline $\begin{array}{c}\text { Sos1/Sos1; } \\
\text { td1/td1 }\end{array}$ & $* 0.03$ & $* 0.004$ & 0.39 \\
\hline
\end{tabular}

Table 2-3. Two-tail t-test values calculated for the differences in main spike length in Sos1;td1 double mutants. The two-tailed ttest values assuming unequal variances are listed for main spike length, which was calculated for each genotype. Significant values $(\mathrm{p}<0.05)$ are marked with a $*$. 


\begin{tabular}{|r|c|c|c|c|}
\cline { 2 - 5 } \multicolumn{1}{c|}{} & \# Paired & \# Single & \# Initiations & N \\
\hline Normal & $48.20 \pm 10.87$ & $5.35 \pm 6.24$ & $53.55 \pm 9.06$ & 5 \\
\hline Sos1/+ & $14.46 \pm 7.42$ & $37.98 \pm 7.93$ & $52.44 \pm 3.71$ & 9 \\
Sos1/Sos1 & $3.24 \pm 4.04$ & $48.58 \pm 9.66$ & $51.83 \pm 6.70$ & 6 \\
ct2/+ & $55.75 \pm 9.90$ & $1.62 \pm 0.35$ & $57.38 \pm 9.55$ & 2 \\
ct2/ct2 & $73.44 \pm 4.96$ & $3.33 \pm 1.16$ & $76.78 \pm 3.85$ & 5 \\
\hline Sos1/+; ct2/+ & $22.43 \pm 6.15$ & $39.22 \pm 9.15$ & $61.65 \pm 5.42$ & 6 \\
Sos1/Sos1; ct2/+ & $17.92 \pm 15.73$ & $37.56 \pm 9.86$ & $55.49 \pm 7.19$ & 3 \\
Sos1/+; ct2/ct2 & $2.98 \pm 3.39$ & $74.18 \pm 3.74$ & $77.17 \pm 2.64$ & 6 \\
Sos1/Sos1; ct2/ct2 & $12.62 \pm 18.21$ & $59.09 \pm 11.45$ & $71.72 \pm 11.18$ & 5 \\
\hline
\end{tabular}

Table 2-4. Quantification of spikelet numbers in plants segregating for the Sos1;ct2 double mutant. The number of paired and single spikelets, and the number of spikelet meristem initiations are listed $+/-$ the standard deviation calculated for each genotype. Red numbers indicate genotypes for which few plants were available for collection. 


\begin{tabular}{|c|c|c|c|c|c|c|}
\hline & Normal & $\operatorname{Sos} 1 /+$ & $\operatorname{Sos} 1 / \operatorname{Sos} 1$ & $c t 2 / c t 2$ & $\begin{array}{c}\operatorname{Sos} 1 / \operatorname{Sos} 1 ; \\
\text { ct } 2 /+\end{array}$ & $\begin{array}{l}\text { Sos } 1 /+; \\
\text { ct } 2 / \text { ct } 2\end{array}$ \\
\hline $\operatorname{Sos} 1 / \operatorname{Sos} 1$ & $\begin{array}{rl}* & 0.0003 \\
* & 8.97 \mathrm{E}-06 \\
& 0.73\end{array}$ & $\begin{array}{rl}* & 0.002 \\
\sim & 0.05 \\
& 0.84\end{array}$ & & & & \\
\hline ct $2 /+$ & $\begin{array}{l}0.46 \\
0.25 \\
0.67\end{array}$ & & & $\begin{array}{r}0.25 \\
* \quad 0.03 \\
0.21 \\
\end{array}$ & & \\
\hline$c t 2 / c t 2$ & $\begin{array}{rl}* & 0.003 \\
& 0.51 \\
* & 0.003\end{array}$ & & $\begin{array}{l}* 6.25 \mathrm{E}-09 \\
* 9.20 \mathrm{E}-05 \\
* 4.79 \mathrm{E}-05\end{array}$ & & & \\
\hline $\begin{array}{c}\operatorname{Sos} 1 /+; \\
\operatorname{ct} 2 /+\end{array}$ & & $\begin{array}{rl}* & 0.04 \\
& 0.79 \\
* & 0.003\end{array}$ & $\begin{array}{rl}* & 0.0001 \\
& 0.11 \\
* & 0.01\end{array}$ & $\begin{array}{l}* 1.00 \mathrm{E}-07 \\
* \mathbf{0 . 0 0 0 2} \\
* 0.0001\end{array}$ & & \\
\hline $\begin{array}{l}\operatorname{Sos} 1 /+; \\
\operatorname{ct} 2 / \operatorname{ct} 2\end{array}$ & & $\begin{array}{l}* 0.001 \\
* \mathbf{5 . 5 6 E - 0 8} \\
* 1.32 \mathrm{E}-09\end{array}$ & $\begin{array}{rl} & 0.9 \\
* & 0.0009 \\
* & 5.68 \mathrm{E}-05\end{array}$ & $\begin{array}{rl}* & 2.50 \mathrm{E}-08 \\
* & 9.41 \mathrm{E}-09 \\
& 0.84\end{array}$ & $\begin{array}{r} \\
0.24 \\
* 0.02 \\
* \quad 0.03\end{array}$ & \\
\hline $\begin{array}{c}\operatorname{Sos} 1 / \operatorname{Sos} 1 \\
\operatorname{ct} 2 / \operatorname{ct} 2\end{array}$ & & & $\begin{array}{r}0.32 \\
0.14 \\
* 0.01\end{array}$ & $\begin{array}{rl}* & 0.0008 \\
* & 0.0004 \\
& 0.37\end{array}$ & & $\begin{array}{rl} & 0.3 \\
* & 0.03 \\
0.34\end{array}$ \\
\hline
\end{tabular}

PAIRED

SINGLE

INITIATIONS

Table 2-5. Two-tail t-test values calculated for the number of paired spikelets, single spikelets, and meristem initiations in Sos 1;ct 2 double mutants. The two-tailed t-test values assuming unequal variances are listed for paired and single spikelets, and the number of spikelet meristem initiations calculated for each genotype. Blue $=$ Paired spikelets; Black $=$ Single spikelets; Grey $=$ Number of meristem initiations. Significant values $(\mathrm{p}<0.05)$ are marked with $\mathrm{a} *$. Values bordering significance $(\mathrm{p}=$ $\sim 0.05$ ) are marked with $\mathrm{a} \sim$. 


\begin{tabular}{|c|c|c|c|}
\hline & Normal & Sos1/Sos1 & ct2/ct2 \\
\hline Sos1/Sos1 & 0.37 & & \\
\hline ct2/ct2 & $* 0.002$ & $* 3.16 \mathrm{E}-05$ & \\
\hline $\begin{array}{c}\text { Sos1/Sos1; } \\
\text { ct2/ct2 }\end{array}$ & $* 0.01$ & $* 0.005$ & 0.62 \\
\hline
\end{tabular}

Table 2-6. Two-tail t-test values calculated for the differences in main spike length in Sos 1 ;ct 2 double mutants. The two-tailed ttest values assuming unequal variances are listed for main spike length, which was calculated for each genotype. Significant values $(\mathrm{p}<0.05)$ are marked with $\mathrm{a} *$. 


\begin{tabular}{|c|c|c|c|c|}
\hline & \# Paired & \# Single & \# Initiations & $\mathrm{N}$ \\
\hline Normal & $48.20 \pm 10.87$ & $5.35 \pm 6.24$ & $53.55 \pm 9.06$ & 5 \\
\hline Sos 1/+ & $17.75 \pm 12.25$ & $34.21 \pm 13.42$ & $51.97 \pm 3.51$ & 11 \\
\hline Sos 1/Sos 1 & $3.61 \pm 4.41$ & $46.58 \pm 9.31$ & $50.19 \pm 6.01$ & 5 \\
\hline $\mathrm{fea} 2 /+$ & $50.63 \pm 11.15$ & $8.19 \pm 7.55$ & $58.83 \pm 4.83$ & 4 \\
\hline fea2/fea2 & $52.82 \pm 15.12$ & $9.72 \pm 5.03$ & $62.54 \pm 17.52$ & 18 \\
\hline Sos $1 /+$; fea $2 / f e a 2$ & $47.89 \pm 10.80$ & $16.94 \pm 6.33$ & $64.84 \pm 8.48$ & 11 \\
\hline Sos1/Sos 1; fea2/fea 2 & $37.09 \pm 9.62$ & $17.98 \pm 7.02$ & $55.08 \pm 9.23$ & 10 \\
\hline
\end{tabular}

Table 2-7. Quantification of spikelet numbers in plants segregating for the Sos 1;fea 2 double mutant. The number of paired and single spikelets, and the number of spikelet meristem initiations are listed $+/-$ the standard deviation calculated for each genotype. Red numbers indicate genotypes for which few plants were available for collection. 


\begin{tabular}{|c|c|c|l|l|c|}
\hline & Normal & Sos1/+ & Sos1/Sos1 & fea2/fea2 & $\begin{array}{c}\text { Sos1/+; } \\
\text { fea2/fea2 }\end{array}$ \\
\hline Sos1/Sos1 & $\begin{array}{c}* 0.0003 \\
* 7.65 \mathrm{E}-05 \\
0.51\end{array}$ & $\begin{array}{c}* 0.004 \\
\text { 0.056 } \\
0.56\end{array}$ & & & \\
\hline & & & & & \\
fea2/+ & & & & 0.75 & \\
& 0.3 & & $* 0.004$ & 0.44 & \\
\hline & 0.46 & & $* 6.50 \mathrm{E}-11$ & & 0.31 \\
fea2/fea2 & 0.19 & & $* 0.0003$ & & $* 0.004$ \\
& 0.14 & & $* 0.02$ & & 0.63 \\
\hline Sos1/Sos1; & & & $* 4.51 \mathrm{E}-07$ & $* 0.002$ & $* 0.02$ \\
fea2/fea2 & 0.77 & 0.36 & 0.255 & 0.15 & $* 0.02$ \\
\hline
\end{tabular}

PAIRED SINGLE INITIATIONS

Table 2-8. Two-tail t-test values calculated for the number of paired spikelets, single spikelets, and meristem initiations in Sos1;fea2 double mutants. The two-tailed t-test values assuming unequal variances are listed for paired and single spikelets, and the number of spikelet meristem initiations calculated for each genotype. Blue $=$ Paired spikelets; Black $=$ Single spikelets; Grey $=$ Number of meristem initiations. Significant values $(\mathrm{p}<0.05)$ are marked with $\mathrm{a} *$. Values bordering significance $(\mathrm{p}=$ $\sim 0.05)$ are marked with $\mathrm{a} \sim$. 


\begin{tabular}{|l|c|c|c|}
\hline & Normal & Sos1/Sos1 & fea2/fea2 \\
\hline Sos1/Sos1 & 0.3 & & \\
\hline fea2/fea2 & 0.43 & $* 0.002$ & \\
\hline $\begin{array}{l}\text { Sos1/Sos1; } \\
\text { fea2/fea2 }\end{array}$ & 0.79 & 0.19 & 0.08 \\
\hline
\end{tabular}

Table 2-9. Two-tail t-test values calculated for the differences in main spike length in Sos1;fea 2 double mutants. The two-tailed $\mathrm{t}$-test values assuming unequal variances are listed for main spike length, which was calculated for each genotype. Significant values $(\mathrm{p}<0.05)$ are marked with a * 


\subsection{LITERATURE CITED}

Bleckmann, A., S. Weidtkamp-Peters, C. A. M. Seidel, AND R. Simon. 2010. Stem cell signaling in Arabidopsis requires CRN to localize CLV2 to the plasma membrane. Plant Physiology 152: 166-76.

Bommert, P., B. I. Je, A. Goldshmidt, AND D. Jackson. 2013. The maize G $\alpha$ gene COMPACT PLANT2 functions in CLAVATA signalling to control shoot meristem size. Nature 502: 555-58.

Bommert, P., C. Lunde, J. Nardmann, E. Vollbrecht, M. Running, D. Jackson, S. Hake, AND W. Werr. 2005. thick tassel dwarf1 encodes a putative maize ortholog of the Arabidopsis CLAVATA1 leucine-rich repeat receptor-like kinase. Development 132: $1235-45$.

Bommert, P., N. S. Nagasawa, AND D. Jackson. 2013. Quantitative variation in maize kernel row number is controlled by the FASCIATED EAR2 locus. Nature Genetics 45: 334-37.

Bortiri, E., G. Chuck, E. Vollbrecht, T. Rocheford, R. Martienssen, AND S. Hake. 2006. ramosa 2 encodes a LATERAL ORGAN BOUNDARY domain protein that determines the fate of stem cells in branch meristems of maize. Plant Cell 18: $574-85$.

Brand, U., J. C. Fletcher, M. Hobe, E. M. Meyerowitz, AND R. Simon. 2000. Dependence of stem cell fate in Arabidopsis on a feedback loop regulated by CLV3 activity. Science 289: 617-19. 
Chu, H., Q. Qian, W. Liang, C. Yin, H. Tan, X. Yao, Z. Yuan, J. Yang, H. Huang, D. Luo, H. Ma, AND D. Zhang. 2006. The FLORAL ORGAN NUMBER4 gene encoding a putative ortholog of Arabidopsis CLAVATA3 regulates apical meristem size in rice. Plant Physiology 142: 1039-52.

Clark, S.E., M.P. Running, AND E.M. Meyerowitz. 1993. CLAVATA1, a regulator of meristem and flower development in Arabidopsis. Development 119: 397-418.

D'Andrea, L. D., AND L. Regan. 2003. TPR proteins: the versatile helix. Trends in Biochemical Sciences 28: 655-62.

Deyoung, B. J., AND S. E. Clark. 2008. BAM receptors regulate stem cell specification and organ development through complex interactions with CLAVATA signaling. Genetics 180: 895-904.

Doebley, J., A. Stec, AND B. Kent. 1995. Suppressor of Sessile spikelets 1 (Sos1): A dominant mutant affecting inflorescence development in maize. American Journal of Botany 82: 571-77.

Durbak, A. R., AND F. E. Tax. 2011. CLAVATA signaling pathway receptors of arabidopsis regulate cell proliferation in fruit organ formation as well as in meristems. Genetics 189: 177-94.

Goebl, M., AND M. Yanagida. 1991. The TPR snap helix: a novel protein repeat motif from mitosis to transcription. Trends in Biochemical Sciences 16: 173-77.

Je, B. I., J. Gruel, Y. K. Lee, P. Bommert, E. D. Arevalo, A. L. Eveland, Q. Wu, A. Goldshmidt, R. Meeley, M. Bartlett, M. Komatsu, H. Sakai, H. Jonsson, AND D. Jackson. 2016. Signaling from maize organ primordia via FASCIATED EAR3 regulates stem cell proliferation and yield traits. Nature Genetics 48: 785-91. 
Kayes, J.M., AND S.E. Clark. 1998. CLAVATA2, a regulator of meristem and organ development in Arabidopsis. Development 125: 3843-51.

Kikuchi, K., M. Ueguchi-Tanaka, T. K. Yoshida, Y. Nagato, M. Matsusoka, AND Y. H. Hirano. 1999. Molecular analysis of the NAC gene family in rice. Molecular and General Genetics 262: 1047-51.

McSteen, P. 2006. Branching Out: The ramosa pathway and the evolution of grass inflorescence morphology. The Plant Cell 18: 518-22.

McSteen, P., AND S. Hake. 2001. barren inflorescence2 regulates axillary meristem development in the maize inflorescence. Development 128: 2881-91.

Müller, R., A. Bleckmann, AND R. Simon. 2008. The receptor kinase CORYNE of Arabidopsis transmits the stem cell-limiting signal CLAVATA3 independently of CLAVATA1. The Plant Cell 20: 934-46.

Pautler, M., W. Tanaka, H. Y. Hirano, AND D. Jackson. 2013. Grass meristems I: Shoot apical meristem maintenance, axillary meristem determinacy and the floral transition. Plant and Cell Physiology 54: 302-12.

Satoh-Nagasawa, N., N. Nagasawa, S. Malcomber, H. Sakai, AND D. Jackson. 2006. A trehalose metabolic enzyme controls inflorescence architecture in maize. Nature 441: 227-30.

Schoof, H., M. Lenhard, A. Haecker, K. F. X. Mayer, G. Jürgens, AND T. Laux. 2000. The stem cell population of Arabidopsis shoot meristems is maintained by a regulatory loop between the CLAVATA and WUSCHEL genes. Cell 100: 63544. 
Souer, E., A. van Houwelingen, D. Kloos, J. Mol, AND R. Koes. 1996. The no apical meristem gene of Petunia is required for pattern formation in embryos and flowers and is expressed at meristem and primordia boundaries. Cell 85: 159-70.

Suzaki, T., M. Sato, M. Ashikari, M. Miyoshi, Y. Nagato, AND H. Y. Hirano. 2004. The gene FLORAL ORGAN NUMBER1 regulates floral meristem size in rice and encodes a leucine-rich repeat receptor kinase orthologous to Arabidopsis CLAVATA1. Development 131: 5649-57.

Taguchi-Shiobara, F., Z. Yuan, S. Hake, AND D. Jackson. 2001. The fasciated ear2 gene encodes a leucine-rich repeat receptor-like protein that regulates shoot meristem proliferation in maize. Genes and Development 15: 2755-66.

Vollbrecht, E., P. S. Springer, L. Goh, E. S. Buckler, AND R. Martienssen. 2005. Architecture of floral branch systems in maize and related grasses. Nature 436: 1119-26.

Wu, X., A. Skirpan, AND P. McSteen. 2009. Suppressor of sessile spikelets1 functions in the ramosa pathway controlling meristem determinacy in maize. Plant Physiology 149: 205-19. 


\title{
CHAPTER THREE
}

Elucidating the origin of the paired spikelet trait in the grasses (Poaceae)

\author{
Eden A. Johnson
}




\subsection{INTRODUCTION}

The Poaceae family of grasses, the fifth most specious angiosperm family, is perhaps most well-known for the agricultural and economic significance of the cereal crops, including maize, wheat, rice, and barley. In the United States alone, 168.4 bushels per acre of corn were harvested - the second highest yield on record - and 2 billion bushels of wheat were harvested in 2015 (USDA 2016). Not only do grasses represent several of the most widely grown and consumed crops, but the Poaceae family also includes many species commonly classified as "weeds," which contribute to yield losses

in the crop species. Approximately 350 species of weeds have been identified that cause serious disturbances to rice production (as high as 15\% loss in the U.S.) (Smith et al. 1977). Weed impacts on farming include increased expenses for farmers due to the costs of herbicide application and hand-weeding practices (Smith 1983). The study of prominent grass species as model organisms has shed light on the selective pressures driving some of their adaptations (Washburn et al. 2015; Vollbrecht et al. 2005; Doebley 2004). Thus, basic research into grasses, even the less desirable grass traits (i.e., invasiveness), may be harnessed for beneficial purposes, such as wetlands restoration or landfill revegetation initiatives.

A recent study hypothesized that the specious Poaceae family may have undergone adaptive radiations - initiated by monsoonal climates during the Eocene Optimum ( 55 mya) - that facilitated the evolution of the grass spikelets in open, dry savannah habitats (Bouchenak-Khelladi et al. 2015). The ability of the grasses to inhabit a wide variety of environments - approximately $20 \%$ of land on Earth - has contributed to their classification as "ecological dominants" today (Shantz 1954). Extensive research 
has also shown more recent grass adaptations, including a shift from shaded forest dwellings to open habitats and the repeated evolution of novel forms of photosynthesis, which facilitated grass expansion into arid climates (Washburn et al. 2015; Shantz 1954). It is clear that multiple trait gains and losses have occurred not only at the origin of Poaceae, but also as the family continues to diversify (Washburn et al. 2015). Thus, it is not only informative to use major cereal crops to study grass complexity, but we can also exploit earlier-diverging species to understand the physiological evolutionary changes that contributed to the cereals' agronomic importance.

An agronomically significant difference in grass inflorescence architecture is the growth of solitary versus paired spikelets. Combining a recent Poaceae phylogeny based on genetic information (Grass Phylogeny Working 2012) with spikelet phenotype suggests that the majority of grass species develop spikelets singly. The grass subfamily Panicoideae (which includes the Paniceae, Paspaleae, and Andropogoneae tribes) is notable because it includes the only grass tribe (Andropogoneae) composed of approximately 1,100 species that exclusively bear paired spikelets. Furthermore, although the Paniceae and Paspaleae tribes include mainly solitary spikelet species, they also include species with paired spikelets. Based on this phylogenetic overview, the paired spikelet trait could have arisen independently several times, or as a single event in the common ancestor of the three tribes, which was subsequently lost in single spikelet species (Figure 3-1). Thus, three Poaceae tribes (subfamily: Panicoideae) in particularAndropogoneae, Paspaleae, and Paniceae-provide a unique opportunity to study the genetic and developmental pathways that enabled the evolution of paired spikelets in the grasses (Figure 3-1). Insight into the developmental and genetic mechanisms underlying 
paired and single spikelet evolution can be gained by applying what has been learned in model systems, such as Arabidopsis and maize, to additional phylogenetically important species, an overarching concept in Evo-Devo.

\subsubsection{Overview of spikelet development}

Following the transition to reproductive development in maize and other grasses, the inflorescence meristem (IM) gives rise to several different types of axillary meristems that dictate the overall pattern of inflorescence architecture, and contribute to the complexity of different inflorescence types. The IM in paired spikelet species give rise to spikelet pair meristems (SPM), which will subsequently produce two spikelet meristems (SM). The SMs continue to develop and will ultimately transition into the floral meristems, which give rise to the grass reproductive organs. Interestingly, it is predicted that the SPM is a meristem specific to paired spikelet species, while single spikelet species (i.e., wheat, rice) will proceed directly to producing SMs from the IM.

There are two hypotheses for how paired spikelets develop. First, two SMs arise via the conversion model; this hypothesis assumes that once the SPM is formed, expression of SM-specific genes will increase and cause the cells of the SPM to further differentiate and form two distinct meristems (Irish 1998). Furthermore, the conversion model assumes that all cells convert from SPM to SM identity (Irish 1998). In contrast, the lateral branching model assumes that cells of the SPM initiate a branching event to form two new SM, leaving a small pool of cells with SPM identity at the center of these 
newly-formed SMs (Irish 1998). Three Poaceae tribes (subfamily: Panicoideae) in particular-Andropogoneae, Paspaleae, and Paniceae - provide a unique opportunity to study the genetic and developmental pathways that enabled the evolution of paired spikelets, as well as a new meristem type (the SPM), in the grasses.

My long-term goal is to understand the development and genetic regulation of paired spikelet trait evolution. This is important not only from the basic research perspective, but also because this research could potentially be used to engineer paired spikelets in economically important single spikelet species such as rice and wheat, effectively doubling grain yield. The current study aims to determine the prevalence of paired spikelets in mature grass inflorescences in order to further inform a future developmental study on immature spikelet ontogeny. Mapping spikelet characterizations onto an existing species phylogeny of the grasses will determine how many times this derived paired spikelet trait has evolved.

\subsection{METHODS AND RESULTS}

Using herbarium specimens, live plant tissue, SEM images from the literature, and the Kew Royal Botanical Garden GrassBase (Vorontsova et al. 2015), I characterized the inflorescences of forty grass species in the Paniceae, Paspaleae, and Andropogoneae tribes (subfamily: Panicoideae) to determine whether they produced spikelets singly or in pairs. Two characters (solitary spikelets vs. paired spikelets) were scored on a presence/absence character matrix for each of the 40 study species. If spikelet number is 
unknown or could not be determined, a '?' was left in the character matrix for that species, which Mesquite analyzes as 'unknown'. The spikelet characterizations obtained were mapped onto a recent chloroplast phylogeny of these species, developed by Jacob Washburn in the Pires lab (Washburn et al. 2015), using Mesquite ancestral character state reconstruction software (Figure 3-2) (Maddison and Maddison, 2008). The ancestral spikelet traits were inferred by the 'Trace Character History' analysis with parsimony-based reconstruction. The maximum-likelihood character history was consistent with the results of the parsimony-based reconstruction (data not shown).

Out of the 40 species included in the Mesquite phylogeny, 18 have paired spikelets, 18 have solitary spikelets, and 4 species were scored as unknown in the character matrix. The resulting Mesquite character mapping suggests that the paired spikelet trait was both gained and lost multiple times in the evolution of the grasses (Figure 3-2). Specifically, within the Paniceae tribe (blue), there is one paired spikelet species (Urochloa fusca) within a clade that is otherwise composed of single spikelet species, indicating one potential origin of paired spikelets. There appear to be as many as seven independent origins of the paired spikelet trait in this depiction. In fact, the phylogeny shows one instance where there are both single and paired spikelet species within a single genus (e.g., Urochloa, tribe Paniceae); this also occurs in the genus Paspalum (not depicted; (Zanotti et al. 2010)). These results are consistent with the fact that the majority of paired spikelet species are members of the Paniceae, Paspaleae, and Andropogoneae (PPA) tribes, within the subfamily Panicoideae. Unexpectedly, the outgroup taxa in this phylogeny, Danthoniopsis dinteri (subfamily Panicoideae: Tristachyideae), was characterized as having paired spikelets, which suggests that species 
outside of the PPA tribes do not exclusively bear single spikelets. In order to further investigate the evolution of the paired spikelet trait, a more thorough investigation of species both within and outside of the Panicoideae subfamily was required.

To address this, I expanded the analysis beyond the initial 40 grass species. Further literature, database, and herbarium searches for additional paired spikelet species within the Panicoideae subfamily were performed. A well-sampled phylogeny from the literature was chosen for character mapping in this study due to the large number of species represented from all tribes of Panicoideae. In addition, the study originally sought to combine morphological characteristics of the taxa with plastid DNA sequences (Morrone et al. 2012). A database was made to document the spikelet characterization, inflorescence type (i.e., panicle, raceme), number of lodicules, and number of anthers for each of the 250 grass species in the Morrone et al. (2012) phylogeny.

The Morrone (2012) phylogeny expanded the number of Panicoideae species to 230 - increased significantly from 36 species within this subfamily in the Mesquite study (Figure 3-3). Furthermore, it represents eight additional tribes from this subfamily, which are necessary in order to understand the evolution of the paired spikelet trait. As expected, the Paniceae and Paspaleae tribes contain species with single spikelets in addition to species bearing paired spikelets. It is typically accepted that Andropogoneae is the only grass tribe that includes species that bear only paired spikelets. However, upon further inspection of the expanded Panicoideae phylogeny we found that at least three genera within the Andropogoneae tribe have species that develop either single or triple spikelets (Figure 3-3). First, and most unexpectedly, Cleistachne sorghoides is classified as a species that bears single spikelets. The Cleistachne genus includes only 
one species, which is native to eastern and southeastern Africa and parts of Asia (Vorontsova et al. 2015). Next, both Chrysopogon fulvus and Apluda mutica develop triple spikelets. Further investigation into these genera uncovered that Chrysopogon includes both paired and triple spikelet species, but Apluda species exclusively grow triple spikelets. Results from Cleistachne, Chrysopogon, and Apluda indicate that, while most species within the Andropogoneae tribe develop paired spikelets as previously thought, not all species within this tribe develop spikelets in pairs as expected.

Furthermore, expanding the character mapping in this study to include all twelve tribes within the Panicoideae subfamily identified five tribes with paired or triple spikelet species: Paniceae, Paspaleae, Andropogoneae, Arundinelleae, and Tristachyideae (Figure 3-3). However, the phylogeny includes significantly fewer species from the seven remaining tribes. To address this I searched for paired or triple spikelet species in the genera sampled in the phylogeny. No additional paired or single spikelet species were found in the genera representing the Gynerieae, Steyermarkochloeae, Chasmanthieae, Zeugiteae, Centotheceae, or Cyperochloeae tribes. However, one genus from the Thysanolaeneae tribe, Thysanolaena, was found to contain both single and paired spikelet species, which represents at least one additional paired spikelet origin (Figure 3-3, marked '*'). It is particularly interesting that Thysanolaena has species bearing paired spikelets, considering the last common ancestor shared by this genus and the five tribes with numerous paired spikelet species was at the origin of the Panicoideae subfamily. This is a significant finding. It suggests that paired spikelets were either present in the common ancestor of all Panicoideae tribes (and subsequently lost numerous times), or 
that paired spikelets evolved independently several times after the origin of the Panicoideae subfamily.

To further investigate whether paired spikelets arose before or after the origin of the Panicoideae subfamily, I searched the Kew Grassbase online database for paired spikelet species within the Chloridoideae, Danthonioideae, Micrairoideae, Ehrhartoideae, and Bambusoideae subfamilies. Sister to the Panicoideae subfamily (PaniceaePaspaleae-Andropogoneae clade) is another monophyletic clade that includes the Danthonioideae, Chloridoideae, Arundinoideae, and Micrairoideae subfamilies (Figure 3-4). Searching first through these subfamilies, which are all equally related to Panicoideae, I discovered several genera with paired spikelet species. Three genera within Danthonioideae were identified that each included one species with paired spikelets (Rytidosperma, Chionochloa, and Pentameris). Four species with paired spikelets were identified in three genera from the Chloridoideae subfamily (Triraphis, Tetrachaete, and Uniola). Uniola is a genus with both single and paired spikelet species that is represented in the outgroup taxa of the expanded Panicoideae phylogeny (Figure 3-4; marked '**’). In addition, one species (Limnopoa meeboldii) from the Micrairoideae subfamily was also found to bear paired spikelets (Figure 3-4). These results definitively indicated that the paired spikelet trait arose before the origin of the Panicoideae subfamily.

Interestingly, both the Bambusoideae and Ehrhartoideae subfamilies also contain species with paired or triple spikelets (Figure 3-4). Ehrhartoideae includes only one species with triple spikelets, Phyllorachis sagittata. Finally, I identified 11 species from six genera within the Bambusoideae subfamily that develop paired spikelets 
(Diandrolyra, Maclurolyra, Piresia, Rehia, Reitzia, and Sucrea), as well as two species from one genus (Cryptochloa) that develop triple spikelets. These results indicate that the paired spikelet trait clearly did not evolve for the first time within the Panicoideae, and instead suggests that this trait is present within many grass subfamilies. Evidence from both character mapping analyses (i.e., paired and single spikelet species within one genus) suggests that this trait was lost and gained multiple times independently.

\subsection{DISCUSSION}

Extensive high-throughput sequencing of Poaceae species within the past decade has resulted in publicly available cereal genomes and a robust phylogeny of the family. By combining the molecular data with observed spikelet attributes, a recent Poaceae phylogeny (Grass Phylogeny Working 2012) suggests that single spikelets are the ancestral trait, and paired spikelets arose later in the evolution of the grasses (i.e., derived trait). In fact, it was previously assumed that the paired spikelet trait found in some species of the Paniceae, Paspaleae, and Andropogoneae tribes could have arisen independently several times, or arisen in the common ancestor of the three tribes but was subsequently lost (i.e., reversion to single spikelets; Figure 3-1). Additionally, the Andropogoneae tribe was classified as the only grass tribe composed exclusively of paired spikelet species (Tanaka et al. 2013; Reinheimer et al. 2013).

The Mesquite character state reconstruction indicated that paired spikelets do occur outside of the Paniceae, Paspaleae, and Andropogoneae tribes, despite previous 
assumptions (Figure 3-2). Furthermore, the results of the expanded Panicoideae phylogeny uncovered evidence that species within the Andropogoneae tribe do not exclusively bear paired spikelets (Figure 3-3). Rather, this tribe contains at least one species with single spikelets and two genera with triple spikelet species. These results imply that the paired spikelet is not a fixed trait within Andropogoneae.

Further investigation revealed that the paired spikelet trait evolved before the origin of the Paniceae, Paspaleae, and Andropogoneae tribes (Figure 3-3). Specifically, there is at least one genus within the earlier-diverging Thysanolaeneae tribe that contains both single and paired spikelet species. This indicates that the paired spikelet trait either arose in the common ancestor of the Panicoideae subfamily, or paired spikelets first evolved before the origin of this subfamily. Thus, further research was needed to determine if paired spikelet species existed outside of the Panicoideae subfamily.

A search for additional paired spikelet species resulted in data suggesting that, indeed, this trait is not unique to the Panicoideae subfamily. While single spikelets are much more prevalent in other grass subfamilies, several genera that included paired spikelet species were identified in four subfamilies outside of the Panicoideae (Figure 34). Unexpectedly, there are also a single species in the Ehrhartoideae subfamily and two species in the Bambusoideae subfamily that develop triple spikelets. These findings suggest that the common ancestor of the Panicoideae, Ehrhartoideae, and Bambusoideae subfamilies (Figure 3-4, black arrow) could have had single, paired, or triple spikelets. In any case, it is clear from this study that if the common ancestor did bear paired or triple spikelets, this trait was subsequently lost and regained multiple times throughout 
the evolution of the grasses. Furthermore, the present study also concluded that the origin of the paired spikelet occurred long before previously thought.

An alternative to the multiple reversions to the ancestral single spikelet trait hypothesis is that there may have been several derivations of single spikelet ontogeny that do not constitute atavistic traits. For instance, instead of a reversion to the ancestral single spikelet in species of Paniceae and Paspaleae with solitary mature spikelets, both spikelets may initially form but one may be suppressed early in development (Zanotti et al. 2010). Conversely, two spikelets may initially form but one spikelet of the pair may transition into an alternative structure, such as the "bristle" seen in the genus Setaria (Kellogg et al. 2013; Doust and Kellogg 2002). In these examples, a species ultimately classified as bearing single spikelets may actually first develop a spikelet pair meristem (SPM), a meristem that is thought to be unique to paired spikelet species. Therefore, developmental studies using techniques such as scanning electron microscopy should be utilized to determine if these species do, in fact, develop SPM.

Differences between two species in spikelet anatomy and inflorescence development can also result in both species being characterized as having paired spikelets, regardless of any difference in overall structure. For instance, the subfamily Pharoideae contains one genus, Pharus, which is considered the earliest-diverged grass lineage that develops a true spikelet (Sajo et al. 2007). While Pharus does technically develop spikelets in pairs, the resulting structures differ from many of the conventional paired spikelets in the Panicoideae subfamily (Figure 3-4, inverted spikelet marked by '?'). In Pharus species, the sessile spikelet is the first to initiate and is larger than the pedicellate spikelet which develops subsequently (Sajo et al. 2007). This developmental 
transition differs from many well-known paired spikelet species in Panicoideae (i.e., maize, sorghum) that first initiate the pedicellate then the sessile spikelet. Both spikelets begin as SMs that appear to differ in size. This is due to the developmental timing of the SPM-to-SM transition, but the sessile spikelet eventually grows to an equivalent size as the pedicellate spikelet. Additionally, the pedicellate spikelet in Pharus functions as a unisexual male floret, while the larger sessile spikelet forms the unisexual female floret (Sajo et al. 2007). This is in contrast to floral development in other paired spikelet species of the Panicoideae, which develop two bisexual florets per spikelet. There are, however, examples of paired spikelet species within the genus Brothriochloa (Panicoideae) that initiate spikelet development similar to Pharus, by developing the sessile spikelet before the pedicellate spikelet (Sajo et al. 2007; Le Roux and Kellogg 1999). These species do not, however, produce the unisexual florets seen in Pharus (Sajo et al. 2007; Le Roux and Kellogg 1999).

Clearly, further developmental analyses will be critical to determine the ontogeny of spikelet traits within Poaceae, and to further investigate the origin of the paired spikelet trait found in members of the Panicoideae subfamily. However, determining the origin of the paired spikelet trait in the grasses will first depend on whether species are classified based on their developmental progression versus mature morphology. If a trait is mapped without regard for the alterations in immature spikelet development, such as the change in floral zygomorphy typical of Pharus species, then the conclusion of this study that paired spikelets represent a derived trait in the grasses would need to be amended. Alternatively, the conclusions made in this study would also need to be amended if a future study aimed to map the paired spikelet trait based exclusively on the 
presence of paired SMs early in inflorescence development; in this case, species that develop one spikelet plus a "bristle" appendage may be included, despite the fact that it has one functional spikelet in the mature plant, as seen in Setaria. The current study categorized the paired spikelet trait based on adult morphology, and excluded Pharus from the conventional paired spikelet designation due to the asymmetrical spikelet development and dimorphic florets. Regardless of method of classification, however, this study has gathered significant evidence to show that paired spikelets have evolved multiple times during the evolution of the grasses.

The present study also highlighted the interesting and unexpected finding that triple spikelets are present in grass species outside of the Panicoideae. This trait appears to have evolved multiple times as well based on the appearance of triple spikelets in three grass subfamilies. Interestingly, when the genes in the ramosa pathway are mutated, outgrowth of branches occurs (Bortiri et al. 2006; Satoh-Nagasawa et al. 2006). Genes within this pathway ( $r a 1, r a 2$, and $r a 3$ ) are correlated with changes from branches in related grasses to paired spikelets in maize (Vollbrecht et al. 2005). Orthologs of the maize ral gene have been identified in other paired spikelet species throughout the Andropogoneae tribe, but are notably absent in rice, a species from the Ehrhartoideae subfamily which develops single spikelets (Vollbrecht et al. 2005; McSteen 2006). It would be interesting for future studies into the genetic basis behind spikelet traits to identify if orthologous genes of the $R A$ pathway are present in single or triple spikelet species, both within and outside of the Andropogoneae tribe. While components of this pathway have been lost in single spikelet species, the genes may have a more relaxed regulation of determinacy in species with triple spikelets. Regulation of orthologous 
RAMOSA genes may be responsible for the origin of paired and triple spikelets, as well as the repeated gains and losses of these traits throughout grass evolution.

Understanding spikelet morphology in the grasses is not only important in light of the evolution of the Poaceae family. Natural variation in the number and arrangement of spikelets has also been found to influence grain yield in wheat, rice, and maize (Wu et al. 2009; Miura et al. 2010; Boden et al. 2015; Je et al. 2016). Recent studies have shown that wheat - a grass that normally develops single spikelets - is genetically capable of producing paired spikelets (Boden et al. 2015). Therefore, it is critical to identify the genetic pathways involved in the development of paired spikelets, which could be translated into a strategy to increase yield in other economically important grass species that produce single spikelets. This research will also provide insight into the evolution and development of an agronomically important trait, which will be applicable to further studies in all grass species. 


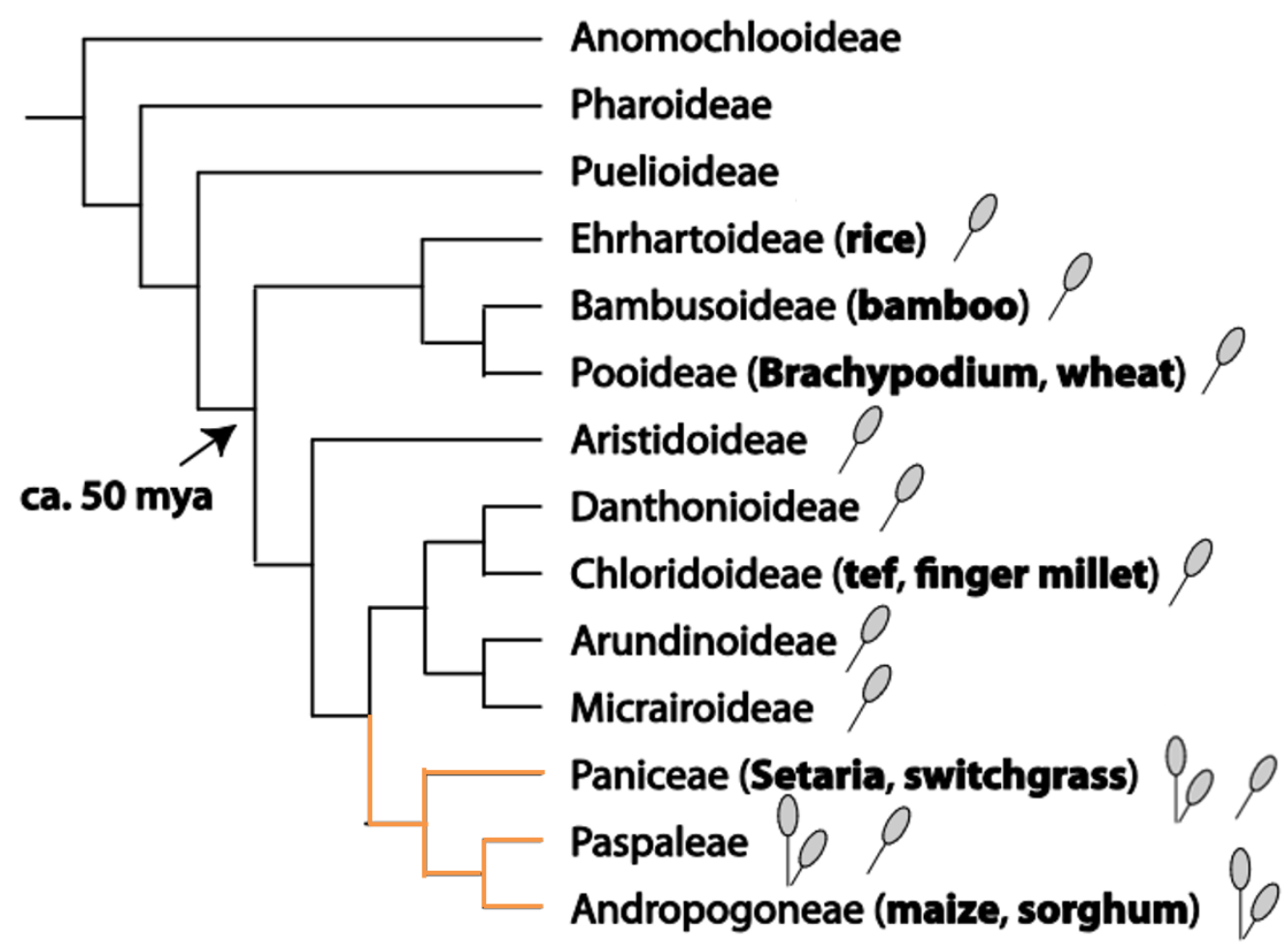

Figure 3-1. Phylogeny of the grasses showing the occurrence of paired spikelets within three grass tribes. This depiction suggests that paired spikelets only occur in three tribes within a single subfamily (Panicoideae). Additionally, it indicates the widely-held belief that the Andropogoneae tribe is the only grass lineage made up of exclusively paired spikelet species. Adapted from Grass Phylogeny Working Group, 2012. 


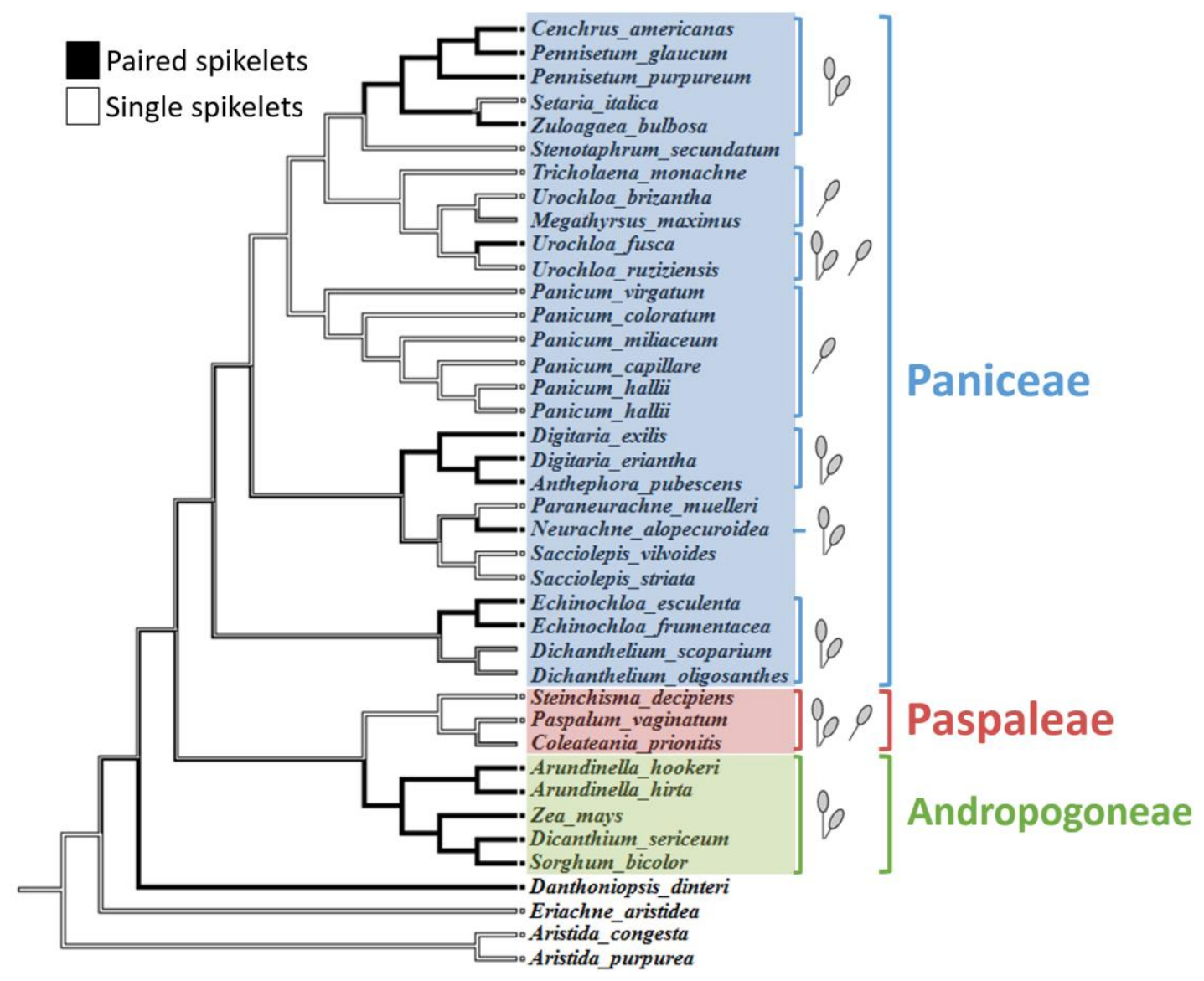

Figure 3-2. Mesquite ancestral character state reconstruction. Spikelet character reconstruction of 40 grass species. Andropogoneae is composed of species with paired spikelets (bolded black branches), and the Paniceae and Paspaleae tribes have a mixture of paired and single spikelet species. Grey branches indicate taxa with no information, and white branches indicate taxa with solitary spikelets. Phylogeny made with transcriptome data from Washburn et al. 2015. 


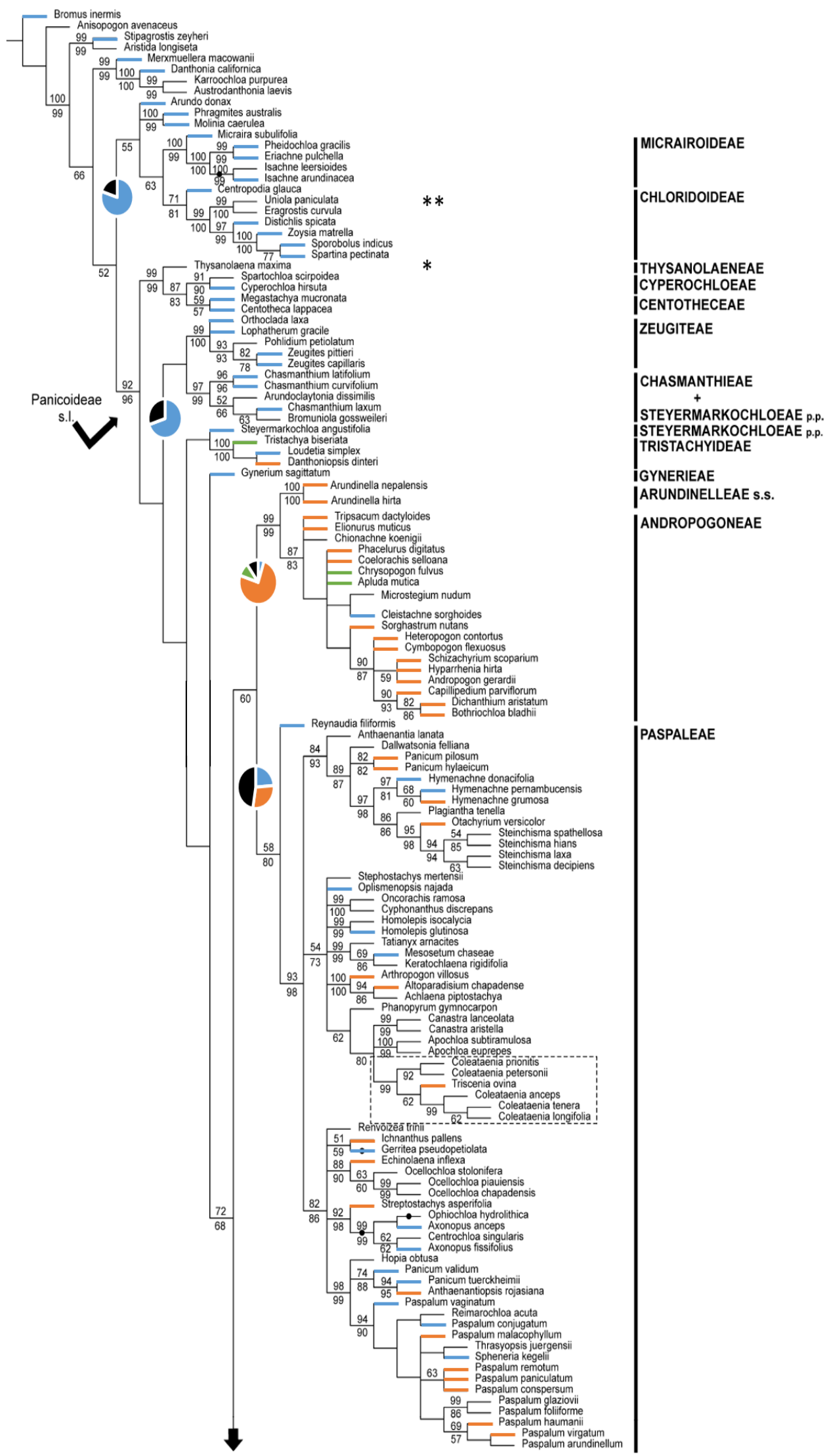

Page | 99 


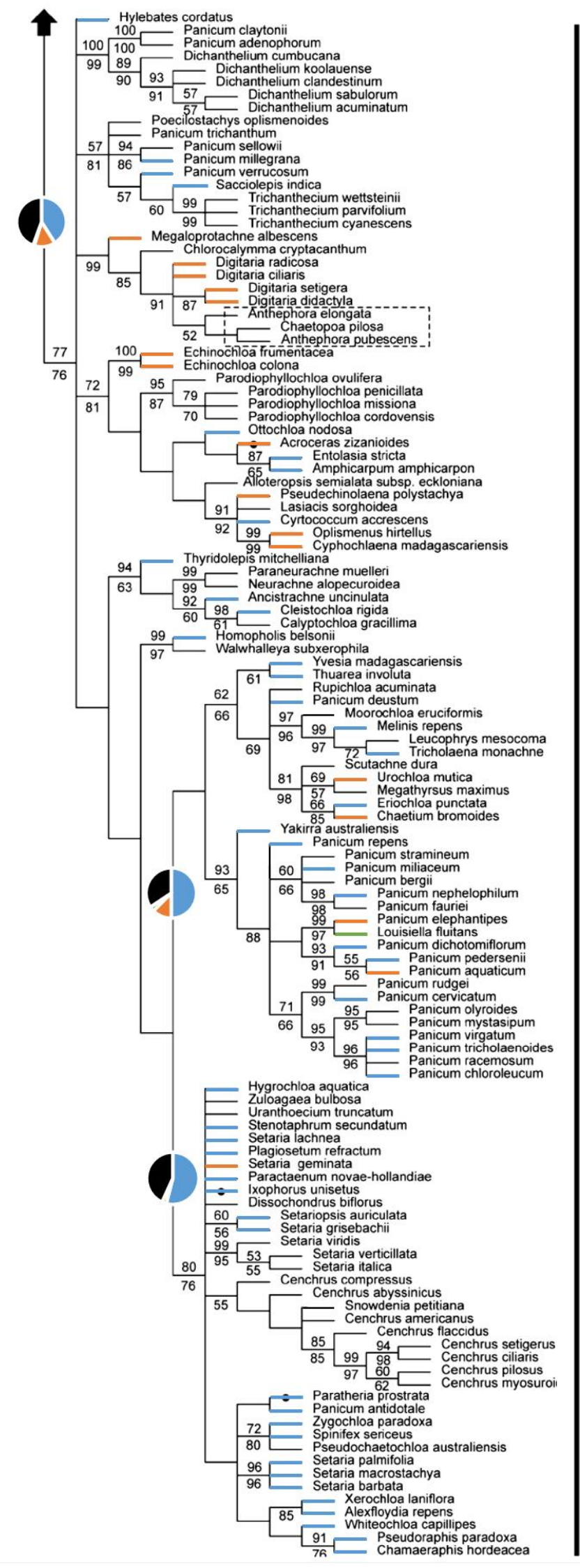

|PANICEAE

s.s.

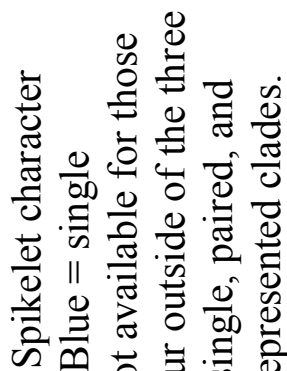

थल ๘

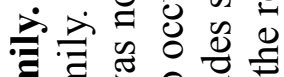

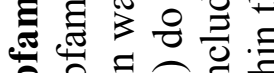

을

( $)$ 중

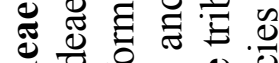

-응

.

ค

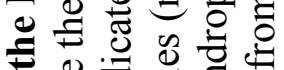

ఊ.

त. त्रिक की

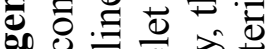

을 艺 늘

들 क की

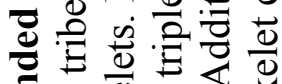

0 $0<1$

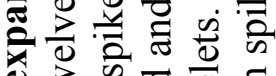

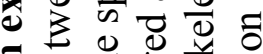

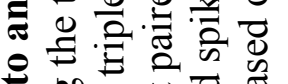

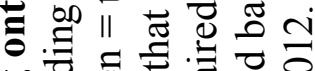

以응 Ð

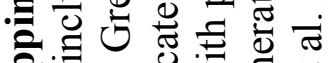

है

छ

ช ญ 잉

के के की ग

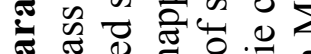

ฮ

율 Ð

ข

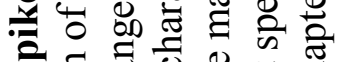

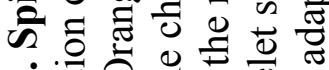

mं0

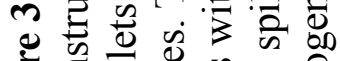

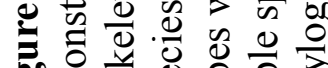

कo

Page | 100 


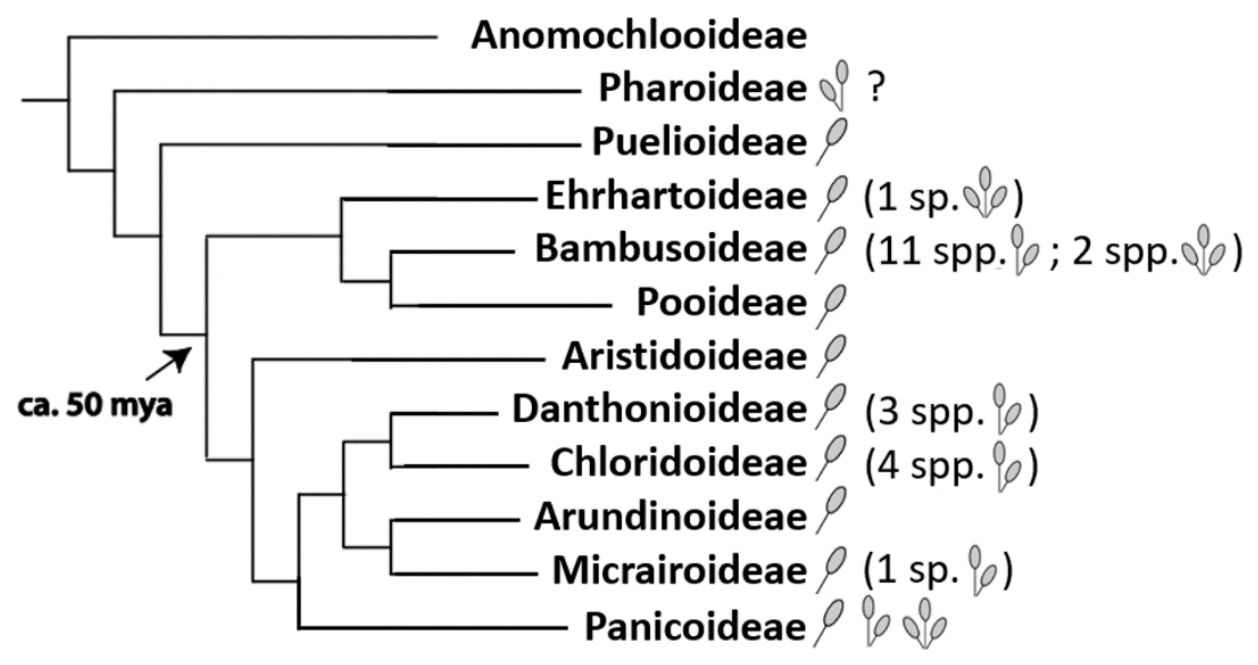

Figure 3-4. Phylogeny of the grass subfamilies indicating that paired spikelets species exist outside of the Panicoideae. This depiction suggests that paired spikelets occur in several subfamilies outside of the Panicoideae subfamily. Additionally, it indicates that even triple spikelets develop in several grass lineages. Adapted from Grass Phylogeny Working Group, 2012. 


\subsection{LITERATURE CITED}

Boden, S. A., C. Cavanagh, B. R. Cullis, K. Ramm, J. Greenwood, E. J. Finnegan, B. Trevaskis, AND S. M. Swain. 2015. Ppd-1 is a key regulator of inflorescence architecture and paired spikelet development in wheat. Nature Plants 1.

Bortiri, E., G. Chuck, E. Vollbrecht, T. Rocheford, R. Martienssen, AND S. Hake. 2006. ramosa 2 encodes a LATERAL ORGAN BOUNDARY domain protein that determines the fate of stem cells in branch meristems of maize. Plant Cell 18: $574-85$.

Bouchenak-Khelladi, Y., R. E. Onstein, Y. Xing, O. Schwery, AND H. P. Linder. 2015. On the complexity of triggering evolutionary radiations. New Phytologist 207: $313-26$.

Chuck, G., R. B. Meeley, AND S. Hake. 1998. The control of maize spikelet meristem fate by the APETALA2-like gene indeterminate spikelet1. Genes \& Development 12: $1145-54$

Doebley, J. 2004. The genetics of maize evolution. Annual Review of Genetics 38: 37-59.

Doust, A. N., AND E. A. Kellogg. 2002. Inflorescence diversification in the panicoid "bristle grass" clade (Paniceae, Poaceae): evidence from molecular phylogenies and developmental morphology. American Journal of Botany 89: 1203-22.

Grass Phylogeny Working Group, II. 2012. New grass phylogeny resolves deep evolutionary relationships and discovers C4 origins. New Phytologist 193: 30412.

Irish, E. E. 1998. Grass spikelets: a thorny problem. Bioessays 20: 789-93. 
Janssen, T., AND K. Bremer. 2004. The age of major monocot groups inferred from 800+ rbcL sequences. Botanical Journal of the Linnean Society 146: 385-98.

Je, B. I., J. Gruel, Y. K. Lee, P. Bommert, E. D. Arevalo, A. L. Eveland, Q. Wu, A. Goldshmidt, R. Meeley, M. Bartlett, M. Komatsu, H. Sakai, H. Jonsson, AND D. Jackson. 2016. Signaling from maize organ primordia via FASCIATED EAR3 regulates stem cell proliferation and yield traits. Nature Genetics 48: 785-91.

Kellogg, E. A. 2007. Floral displays: genetic control of grass inflorescences. Current Opinion in Plant Biology 10: 26-31.

Kellogg, E. A., P. E. A. S. Camara, P. J. Rudall, P. Ladd, S. T. Malcomber, C. J. Whipple, AND A. N. Doust. 2013. Early inflorescence development in the grasses (Poaceae). Frontiers in Plant Science 4.

Kellogg, E. A. 2001. Evolutionary history of the grasses. Plant Physiology. 125: 1198205.

Kellogg, E. A. 2000. The grasses: A case study in macroevolution. Annual Review of Ecology and Systematics 31: 217-38.

Kellogg, E. A., AND H. P. Linder. 1995. Phylogeny of Poales. Monocotyledons: systematics and evolution 2: 511-42.

Le Roux, L. G., AND E. A. Kellogg. 1999. Floral development and the formation of unisexual spikelets in the Andropogoneae (Poaceae). American Journal of Botany 86: 354-66.

McSteen, P. 2006. Branching Out: The ramosa pathway and the evolution of grass inflorescence morphology. The Plant Cell 18: 518-22. 
Miura, K., M. Ikeda, A. Matsubara, X. Song, M. Ito, K. Asano, M. Matsuoka, H. Kitano, AND M. Ashikari. 2010. OsSPL14 promotes panicle branching and higher grain productivity in rice. Nature Genetics 42: 545-49.

Morrone, O., L. Aagesen, M. A. Scataglini, D. L. Salariato, S. S. Denham, M. A. Chemisquy, S. M. Sede, L. M. Giussani, E. A. Kellogg, and F. O. Zuloaga. 2012. Phylogeny of the Paniceae (Poaceae: Panicoideae): integrating plastid DNA sequences and morphology into a new classification. Cladistics 28: 333-56.

Reinheimer, R., A. Amsler, AND A. C. Vegetti. 2013. Insights into panicoid inflorescence evolution. Organisms Diversity and Evolution 13: 97-110.

Sajo, M. G., H. Longhi-Wagner, AND P. J. Rudall. 2007. Floral development and embryology in the early-divergent grass Pharus. International Journal of Plant Sciences 168: 181-91.

Satoh-Nagasawa, N., N. Nagasawa, S. Malcomber, H. Sakai, AND D. Jackson. 2006. A trehalose metabolic enzyme controls inflorescence architecture in maize. Nature 441: 227-30.

Shantz, H. L. 1954. The place of grasslands in the Earth's cover. Ecology 35: 143-45.

Smith, R. 1983. Weeds of major economic importance in rice and yield losses due to weed competition (International Rice Research Institute: Laguna, Philippines).

Smith, R., W. Flinchum, AND D. Seaman. 1977. Weed control in U.S. rice production (U.S. Government Printing Office: Washington, D.C.).

Stevens, P. F. 2012. Angiosperm Phylogeny Website. http://www.mobot.org/MOBOT/research/APweb/. 
Tanaka, W., M. Pautler, D. Jackson, AND H. Y. Hirano. 2013. Grass meristems II: Inflorescence architecture, flower development and meristem fate. Plant and Cell Physiology 54: 313-24.

USDA. 2016. "Crop Production 2015 Summary." Edited by United States Department of Agriculture, 1-100. Washington, DC: National Agricultural Statistics Service.

Vollbrecht, E., P. S. Springer, L. Goh, E. S. Buckler, AND R. Martienssen. 2005. Architecture of floral branch systems in maize and related grasses. Nature 436: $1119-26$.

Vorontsova, M. S., D. Clayton, AND B. K. Simon. 2015. Grassroots e-floras in the Poaceae: growing GrassBase and Grass World. PhytoKeys 73.

Washburn, J. D., J. C. Schnable, G. Davidse, AND J. C. Pires. 2015. Phylogeny and photosynthesis of the grass tribe Paniceae. American Journal of Botany.

Wu, X., A. Skirpan, AND P. McSteen. 2009. Suppressor of sessile spikelets1 functions in the ramosa pathway controlling meristem determinacy in maize. Plant Physiology 149: 205-19.

Zanotti, C. A., R. Pozner, AND O. Morrone. 2010. Understanding spikelet orientation in Paniceae (Poaceae). American Journal of Botany 97: 717-29. 


\title{
CHAPTER FOUR \\ CONCLUSIONS AND FUTURE DIRECTIONS
}

\author{
Eden A. Johnson
}




\subsection{DISCUSSION AND CONCLUSIONS}

The maintenance and identity of grass meristems are an interesting area of research due to the numerous types of axillary meristems that specify many different structures (i.e., inflorescences, branches, and grass spikelets), while Arabidopsis transitions directly from the SAM to producing floral meristems. Mutations to the developmental programs that regulate the balance of stem cells within these meristems can cause alterations to the normal plant structure. For example, many meristem mutants in maize (i.e., thick tassel dwarf1, fasciated ear2, compact plant2) develop enlarged, fasciated inflorescences as a result of eliminating the regulatory functions of significant meristem maintenance pathway components. The first chapter of this thesis reviewed the regulatory pathways and mechanisms by which these pathways contribute to the initiation and maintenance of meristems.

This review revealed that, while much is known about the canonical CLAVATA pathway in Arabidopsis, there are still significant holes in our understanding. The ligandreceptor interactions are well-documented, but studies are still surfacing suggesting that even these well-researched interactions are more complex than once thought. For example, the kinase domain of CORYNE in Arabidopsis has been shown to be nonfunctional, and it has been proposed that CRN functions as more of a scaffold protein than functioning directly in signal transduction (Nimchuk et al. 2011). In addition, CLV1 was found to form tetradimers with the CLV2/CRN heterodimer at the plasma membrane, revealing a dynamic relationship between receptors in the CLV pathway to fine-tune WUS repression (Bleckmann et al. 2010). 
The orthologous CLV pathway in maize is also not completely understood. For example, the COMPACT PLANT2 G-protein $\alpha$-subunit was shown to mediate repression of ZmWUS through the FEA2 (ortholog of AtCLV2) receptor (Bommert et al. 2013). However, our current knowledge of this pathway is incomplete because a gene was recently identified with functional and sequence similarity to AtCRN, which also interacts with the FEA2 receptor (D. Jackson, personal communication; unpublished). In addition, there is preliminary evidence that the FEA2-CRN complex transmits repressive signals to ZmWUS via a different ligand than the FEA2-CT2 complex (personal communication). This result suggests that coordination not only occurs at the receptor level, but also may occur through formation of complexes that differentially respond to a variety of ligands.

One major conclusion from this thesis putatively identified one ligand of the CLV pathway in maize. Double mutants between the Suppressor of sessile spikelet1 (Sos1) mutant and components of the $C L V$ signaling pathway in maize, specifically thick tassel $d w a r f(t d 1)$, fasciated ear2 (fea2), and compact plant2 (ct2), revealed genetic evidence that ZmFON may function as a ligand through the TD1 branch of the CLV pathway. In addition, this study found that CT2 does not recognize or transmit signals from Sos1. A model for formation of different receptor complexes was proposed to reconcile the results of the intermediate phenotype observed in Sos 1;fea2 double mutants with the additive phenotype of Sosl;ct2 double mutants demonstrated in this study. Three receptor complexes were proposed: 1) TD1 homodimerizes at the plasma membrane; 2) FEA2 forms a heterodimer with CT2 to transmit regulatory signals to the meristem organizing center; and 3) TD1 forms a tetradimer with the FEA2 receptor. This model suggests that 
when FEA2 is not bound by CT2, it may recognize and bind the putative Sos 1 ligand to regulate meristem size through another, unknown kinase.

There is a possibility that Sos1 may also function through the FEA2 receptor independently of both TD1 and CT2. Future research should aim to determine, first, if the newly-discovered $Z m C R N$ gene functions as the intracellular component by interacting with FEA2, as it does in Arabidopsis. Next, if $Z m C R N$ does interact in a signaling complex with FEA2, further studies should test whether $Z m C R N$ recognizes Sos1. If Sos1 does signal through a FEA2/ZmCRN complex, we would expect Sos1;crn double mutants to exhibit a crn phenotype, as was seen in Sosl;tdl double mutants.

Further research should generate triple mutants between $\operatorname{Sos} 1, t d 1$, and fea 2 in order to determine if Sos 1 is also the ligand for the FEA2 branch of the CLV pathway. Triple mutants between the putative ligand and the receptors of the $C L V$ signaling pathway could elucidate the effect of a non-functional fea 2 receptor when Sos 1 is overexpressed and $t d l$ is unable to compensate. Additionally, to show that Sos 1 is indeed a ligand in the $C L V$ pathway in maize, future research should be aimed at testing for a physical interaction between the receptors (TD1 and FEA2) and Sos 1 using cell biology and biochemical approaches. For example, fluorescent protein fusion studies may be conducted to observe overlapping expression patterns of the ligand and receptor(s). Physical interactions may be analyzed using co-immunoprecipitation techniques, then observed in vivo by utilizing fluorescence resonance energy transfer (FRET).

The change from paired spikelets in normal plants to single spikelets in Sos 1 could also represent a change in determinacy of the spikelet pair meristem (SPM). Specifically, an SPM that gives rise to one instead of two SMs is said to have increased 
determinacy (McSteen 2006). SPM determinacy in maize is in part regulated by the RAMOSA (RA1, RA2, and RA3) genes (Vollbrecht et al. 2005; Bortiri et al. 2006; SatohNagasawa et al. 2006). In addition to roles in meristem determinacy, $R A l$ expression was also found to directly regulate branch outgrowth in paired spikelet species within the Andropogoneae grass tribe (Vollbrecht et al. 2005). This study compared ral expression in three economically important species - maize, sorghum, and Miscanthus - that develop inflorescences with differences in branching architecture. ral expression in both maize and Miscanthus indicated that expression was highest in the meristems that would produce the paired spikelets (SPM) (Vollbrecht et al. 2005). Expression then drastically declined in subsequent meristems forming from the SMs, such as floral meristems, which indicated that ral expression increased determinacy specifically to form the spikelet pairs (Vollbrecht et al. 2005). Expression of ral in sorghum inflorescences increased later in development than observed in maize and Miscanthus, which is consistent with the difference in branching architecture of sorghum (Vollbrecht et al. 2005). While sorghum produces a dense, highly branched inflorescence similar to the highly branched ral mutants (indicating the reduced determinacy in meristems before ral becomes highly expressed), maize and Miscanthus develop inflorescences with fewer, longer branches compared to sorghum. Results from this study implicate $R A 1$ in inflorescence architecture and the development of paired spikelets in the Andropogoneae tribe (Vollbrecht et al. 2005).

A previous study into the function of Sos 1 identified a potential interaction of Sos 1 with the RAMOSA pathway. Results from Sos 1;ral double mutants indicated that Sosl suppresses the ral phenotype (Wu et al. 2009). Notably, the mRNA levels of ral 
were increased in Sos1 mutants, while ra2 and ra3 levels remained unchanged (Wu et al. 2009). This result suggests that Sos 1 may also play a role in meristem determinacy through interactions with the RAMOSA pathway. Clearly both meristem maintenance and determinacy contribute to the overall structure of the resulting inflorescence. In order to test the interactions between meristem maintenance and meristem determinacy, future studies should generate double mutants between members of the CLAVATA and RAMOSA pathways. Further research into the molecular basis of the Sos 1 mutant is needed, which may also reveal that Sos1 represents a link that integrates two functions critical to normal plant development.

One compelling difference between grass species is that, while there are a significant number of species that produce paired spikelets, the majority of the approximately 12,000 taxa in the Poaceae family develop single spikelets. It is widely acknowledged that the subfamily Panicoideae includes many paired spikelet species, namely within three tribes that include significant crop species (i.e., maize, sorghum, setaria, and switchgrass). In fact, the Andropogoneae tribe specifically has been classified as the only lineage composed exclusively of paired spikelet species (Kellogg 2000; McSteen 2006; Wu, Skirpan, and McSteen 2009; Vollbrecht et al. 2005). Because the single spikelet trait is more prevalent in the grasses, and because the paired spikelet trait was assumed to be more or less restricted to the Panicoideae subfamily, several studies have referred to paired spikelets as a derived trait (McSteen 2006; Grass Phylogeny Working 2012; Kellogg 2001; Mathews et al. 2002). However, a thorough analysis of the prevalence of paired spikelet species throughout Poaceae had not yet been conducted. 
The third chapter of this thesis reports a thorough investigation of several grass subfamilies in order to determine the prevalence of paired spikelet species in the grasses. This study uncovered that species developing paired spikelets are prevalent in more grass lineages than previously shown, and do occur outside of the Panicoideae subfamily. This result indicated that paired spikelets first arose before the origin of Panicoideae. In addition, the analysis highlighted the fact that the Andropogoneae tribe, categorized as the only grass tribe made up of exclusively paired spikelet species, actually contains species that produce single, paired, and triple spikelets. Evidence from both character mapping analyses (i.e., paired and single spikelet species within one genus) suggests that this trait was lost and arose again multiple times independently.

Further research should aim to determine if there is a shared genetic mechanism underlying the paired and triple spikelet traits. For instance, it would be interesting for future studies into the genetic basis behind spikelet traits to identify if orthologs of $R A$ pathway genes are present in single or triple spikelet species both within and outside of the Andropogoneae tribe. Perhaps this pathway has been lost in single spikelet species, and has a more relaxed regulation of determinacy in species with triple spikelets. Thus, regulation of orthologous genes in this pathway may have been important for the origin of both paired and triple spikelets, as well as the repeated gains and losses of these traits throughout grass evolution. Therefore, it is critical to identify the genes and genetic pathways involved in the development of paired spikelets as a strategy to increase yield in other economically important grass species that produce single spikelets. 


\subsection{DIRECTIONS FOR FUTURE RESEARCH}

There are numerous future projects that would elaborate on the research presented in this thesis. First, it will be very important to determine the molecular basis of the Sos 1 mutation. While $\mathrm{ZmFON}$ is a promising candidate gene given its implication in the CLAVATA pathway, Sos 1 plants overexpress two additional candidate genes, ZmTPR and $\mathrm{ZmHYP}$. In order to understand the role of Sos 1 , research will need to determine whether the other candidate genes are also contributing to the mutant plant phenotypes, perhaps genetically through CRISPR experiments or through transgenic recapitulation. Furthermore, the high reversion rate of Sos 1 plants indicates that the mutation may be caused by a tandem duplication, a transposon insertion, or an epiallele. However, the Sos 1 revertant plants did not display a stable reversion (revertant plants regained an Sos 1 phenotype in subsequent generations), so further experiments will need to be done to determine the causative mutation. To determine whether Sos 1 may be an epiallele, the McSteen lab collaborated with Nathan Springer's lab to sequence the methylome of Sos 1 mutants compared to the W22 methylome. A following experiment may include bisulfite sequencing to provide additional evidence that there are differences in methylation patterns in the mutant compared to normal plants.

Another experiment that is in progress is the generation of Sos $1 ; t d 1 ; f e a 2$ triple mutants. These plants have been crossed in Missouri and selfed in Hawaii, so they may be preliminarily analyzed in the Missouri summer 2017 field season. Double mutants between $t d l$ and fea 2 have been shown to exhibit a synergistic interaction and result in fasciated, ball-shaped ears (Bommert et al. 2005). If Sos 1 is recognized by both $t d 1$ and 
$f e a 2$, the triple mutants may be expected to develop a similar inflorescence phenotype as the $t d 1$;fea 2 double mutants. Further experiments should also generate double mutants between $\operatorname{Sos} 1$ and the maize ortholog $Z m C R N$ to determine whether this putative intracellular kinase transmits signals from Sos 1 .

The final, critical experiment that is in progress is confocal microscopy of Sos 1 tassels expressing a ZmWUS-RFP transgene. Comparing normal and mutant tassels expressing this transgene will indicate whether the inflorescence meristems of Sos 1 mutants are smaller due to a reduction in ZmWUS expression. Images from the confocal microscopy experiment will provide further evidence that Sos 1 plays a role in the CLV signaling pathway in maize that ultimately regulates $Z m W U S$ expression in maize meristems.

To further study the evolution of the paired spikelet trait, experiments may expand on the character mapping analyses presented in this thesis by determining developmental differences between grasses that give rise to paired spikelets in the mature plants. For example, while species within the genus Pharus develop paired spikelets, the development of these structures is known to differ from that of species within the wellclassified Panicoideae subfamily. If developmental characterization asserts that the spikelet pair in Pharus is sufficiently different from other paired spikelet species, then the ancestral state in the present study may be re-classified as single spikelets, with Pharus representing a unique origin of paired spikelets that may have arisen via convergent evolution. Thus, classification of the paired spikelet character by utilizing developmental techniques, such as scanning electron microscopy, may further elucidate the evolution of the paired spikelets seen in agronomically significant grasses of the Panicoideae. In 
addition, the Mesquite analysis was based on a chloroplast phylogeny, and should be repeated with a published nuclear phylogeny of the same species to observe any differences in the pattern of spikelet character traits. Another alteration that should be made to the present study would be to analyze the expanded Panicoideae phylogeny within BayesTraits software, which takes into account branch lengths to further elucidate the likelihood of the mapped character states.

Furthermore, and perhaps the most economically interesting finding, wheat is a species that normally develops single spikelets, but has been shown to be capable of producing functional paired spikelets (Boden et al. 2015). This finding suggests that there is an underlying genetic basis, potentially shared by all conventional grasses, to the production of paired spikelets. Further research should aim to determine the genetic differences in gene expression between single and paired spikelet species, and should utilize this thesis to inform which species to compare. For example, other studies may use the expanded Panicoideae phylogeny in Chapter 3 to determine which species to use, including species within genera that contain both single and paired spikelet species (i.e., Urochloa, Paspalum).

It is my hope that the many conclusions drawn from the research described in this thesis enhances our understanding of an agronomically significant grass trait, as well as pathway functions within maize meristems. 


\subsection{LITERATURE CITED}

Bleckmann, A., S. Weidtkamp-Peters, C. A. M. Seidel, AND R. Simon. 2010. Stem cell signaling in Arabidopsis requires CRN to localize CLV2 to the plasma membrane. Plant Physiology 152: 166-76.

Boden, S. A., C. Cavanagh, B. R. Cullis, K. Ramm, J. Greenwood, E. J. Finnegan, B. Trevaskis, AND S. M. Swain. 2015. Ppd-1 is a key regulator of inflorescence architecture and paired spikelet development in wheat. Nature Plants 1.

Bommert, P., B. I. Je, A. Goldshmidt, AND D. Jackson. 2013. The maize G $\alpha$ gene COMPACT PLANT2 functions in CLAVATA signalling to control shoot meristem size. Nature 502: 555-58.

Bortiri, E., G. Chuck, E. Vollbrecht, T. Rocheford, R. Martienssen, AND S. Hake. 2006. ramosa 2 encodes a LATERAL ORGAN BOUNDARY domain protein that determines the fate of stem cells in branch meristems of maize. Plant Cell 18: $574-85$

Grass Phylogeny Working Group, II. 2012. New grass phylogeny resolves deep evolutionary relationships and discovers C4 origins. New Phytologist 193: 30412

Kellogg, E. A. 2001. Evolutionary history of the grasses. Plant Physiology. 125: 1198205.

Kellogg, E. A. 2000. The grasses: A case study in macroevolution. Annual Review of Ecology and Systematics 31: 217-38. 
Mathews, S., R. E. Spangler, R. J. Mason-Gamer, AND E. A. Kellogg. 2002. Phylogeny of Andropogoneae inferred from phytochrome B, GBSSI, and ndhF. International Journal of Plant Sciences 163: 441-50.

McSteen, P. 2006. Branching Out: The ramosa pathway and the evolution of grass inflorescence morphology. The Plant Cell 18: 518-22.

Nimchuk, Z. L., P. T. Tarr, AND E. M. Meyerowitz. 2011. An evolutionarily conserved pseudokinase mediates stem cell production in plants. The Plant Cell 23: 851-54.

Satoh-Nagasawa, N., N. Nagasawa, S. Malcomber, H. Sakai, AND D. Jackson. 2006. A trehalose metabolic enzyme controls inflorescence architecture in maize. Nature 441: 227-30.

Vollbrecht, E., P. S. Springer, L. Goh, E. S. Buckler, AND R. Martienssen. 2005. Architecture of floral branch systems in maize and related grasses. Nature 436: 1119-26.

Wu, X., A. Skirpan, AND P. McSteen. 2009. Suppressor of sessile spikelets1 functions in the ramosa pathway controlling meristem determinacy in maize. Plant Physiology 149: 205-19. 


\section{APPENDIX}

Additional data on the characterization of double mutants between Sos 1 and components of the maize CLAVATA signaling pathway 


\section{A.1 INTRODUCTION}

Data on the interaction between Sos1 and components of the CLAVATA signaling pathway in maize, namely thick tassel dwarf1, fasciated ear 2 , and compact plant2, were presented in Chapter 2 of this thesis. The main findings included genetic evidence that the putative ZmFON ligand, which is overexpressed in Sos1 mutants, may function through the TD1 branch of the CLV pathway. Signal from this putative ligand was not shown to be transmitted through the FEA2-CT2 receptor complex, which was indicated by the additive phenotype of Sos 1;ct2 double mutants. However, the intermediate phenotype of Sos 1;fea 2 double mutants provided the first genetic evidence that fea2 may also function independently of $c t 2$ in meristems of the maize inflorescences. Conclusions from Chapter 2 were drawn from measurements of plant height, tassel main spike length, number of paired and single spikelets, and the number of meristem initiations. Other tassel characteristics were measured but not included in the analyses presented in Chapter 2, including the average numbers of branches per tassel and the peduncle length. Finally, analyses also uncovered a potential "HET effect" of ct2 in Sos1;ct2 double mutants.

\section{A.2 RESULTS AND DISCUSSION}

\section{A.2.1 Additional measurements of Sos1;td1 double mutants}


Two additional measurements, average branch number and peduncle length, were gathered from each tassel that was analyzed for this study. Branch number was obtained by counting the total number of branches, then the average branch number was calculated for each genotypic category. The length of the peduncle, which is the stem subtending the inflorescence, was measured as the length from the node at which the flag leaf attaches to the stem, to the base of the main spike.

Results indicated that Sos 1 has significantly fewer branches $(\mathrm{p}<0.005)$ and shorter peduncles $(\mathrm{p}<0.04)$ than normal tassels, both of which could be due to the reduction in inflorescence meristem sizes in Sos 1 mutants. On the other hand, $t d 1$ mutants displayed no significant differences from normal tassels in branch number or peduncle length. Similar to what was found in the Chapter 2 analysis of double mutants, Sos 1; $t$ ll tassels had no differences from $t d 1$ in branch number $(\mathrm{p}=0.4)$ or peduncle length $(\mathrm{p}=0.12)$, but have significantly more branches than Sos1 tassels $(\mathrm{p}<0.006)$ (Figure A-1, A-2). The results are consistent with the interpretation that $t d 1$ is epistatic to Sos 1, indicating that the genes function within the same pathway. Furthermore, these measurements provide additional genetic evidence that $\mathrm{ZmFON}$ may be the ligand for the TD1 branch of the CLV pathway in maize.

\section{A.2.2 Additional measurements of Sos1;fea2 double mutants}

Every measurement described in Chapter 2 depicted intermediate phenotypes between Sos 1;fea2 and either single mutant, Sos 1 or fea2. However, the intermediate phenotypes are not reflected in average branch number or peduncle length. Specifically, 
Sos 1;fea 2 double mutants grow significantly more branches $(\mathrm{p}<0.001)$ and longer peduncles $(\mathrm{p}<0.002)$ than Sos 1 tassels, but do not differ from fea2 tassels in either measurement (Figure A-3, A-4). The fact that Sos1;fea2 double mutants do not display differences from $f e a 2$ mutants in either branch number or peduncle length further indicates that, unlike the additive phenotype of Sos $1 ; c t 2$ double mutants, fea 2 and Sos 1 do not interact additively, and instead may interact in the same pathway. Additionally, these analyses provide more evidence that fea 2 can function independently of $c t 2$ in maize inflorescences.

\section{A.2.3 Additional measurements of Sos1;ct2 double mutants}

The quantitative analyses in Chapter 2 indicated additive interactions between Sos 1 and $c t 2$ in mutant tassels. Further analyses indicated that Sos 1;ct2 double mutants have the same number of branches as $\operatorname{Sos} 1$ tassels $(\mathrm{p}=0.91)$, but have significantly fewer branches than $c t 2$ mutants ( $\mathrm{p}<0.006)($ Figure A-5). Contrastingly, Sosl; $c t 2$ double mutants show no differences from $c t 2$ tassels in peduncle length $(\mathrm{p}=0.07)$, but have significantly shorter peduncles than Sos 1 mutants $(\mathrm{p}<0.002)$ (Figure A-6). The fact that double mutant tassels have characteristics of both single mutants (i.e., branch numbers like Sos 1; peduncle length similar to $c t 2$ ) again indicates that $c t 2$ and Sos 1 interact additively and both contribute to the double mutant phenotype. An additive interaction provides genetic evidence that these genes do not function in the same pathway, indicating that signal from the putative ZmFON ligand is not transmitted by $c t 2$. 


\section{A.2.4 Analysis of Sos 1 ;ct2 double mutants revealed a possible "HET effect"}

Quantitative analyses of tassel spikelet compositions in Sos 1;ct2 double mutants elucidates a potential "HET effect". When Sos 1 single mutants are compared to Sos 1;ct2 double mutants, the only observable difference was in the number of meristem initiations (Table 2-4, page 72). However, when Sos 1 mutants are compared to Sos $1 /+; c t 2 /$ ct2 plants, the Sos 1 single mutant is found to develop significantly fewer single spikelets $(\mathrm{p}<$ 0.0009). Consistent with this finding, Sos 1/+;ct2/ct2 plants develop significantly more single spikelets than Sos $1 ;$ ct2 double mutants $(\mathrm{p}<0.03)$, which is the only significant difference between these genotypes. In addition, Sos 1/+ plants were found to develop significantly fewer paired spikelets $(\mathrm{p}<0.04)$ and meristem initiations $(\mathrm{p}<0.003)$ than Sos $1 /+; c t 2 /+$ plants, which we would expect to have a typical Sos $1 /+$ phenotype due to the recessive $c t 2$ mutation.

Along this line, Sos $1 /+$ plants and $c t 2 / c t 2$ mutants were compared to Sos $1 /+; c t 2 /$ ct 2 plants in order to further investigate the effects of an interaction between both single mutants. Quantitative analyses indicate that plants of genotype Sos $1 /+; c t 2 /$ ct 2 develop significantly fewer paired spikelets $(\mathrm{p}<0.001)$, more single spikelets $(\mathrm{p}<5.56 \mathrm{E}-08)$, and more meristem initiations $(\mathrm{p}<1.32 \mathrm{E}-09)$ than Sos $1 /+$. Furthermore, Sos $1 /+; c t 2 / c t 2$ plants develop significantly fewer paired spikelets (p < 2.5E-08) and more single spikelets ( $<$ 9.4E-09), but maintain a similar number of meristem initiations as $c t 2 / c t 2$ plants $(\mathrm{p}=0.84)$. While $c t 2 /+*$ plants, which should develop a normal phenotype due to the recessive mutation, show no quantitative differences compared to normal plants, Sos $1 /+$ plants compared to Sos $1 /+; c t 2 /+$ plants 
(should have a typical Sos 1 heterozygous phenotype) indicates that Sos $1 /+$ plants in fact develop significantly fewer paired spikelets $(p>0.04)$ and fewer meristem initiations $(p$ $>0.003)$. Interestingly, this indicates that $c t 2$ does have some effect as a heterozygote when interacting in an Sos $1 /+; c t 2 /+$ double mutant plant. One possibility is that the described effects may be due to a very limited sample size in $c t 2 /+$ plants $(\mathrm{N}=2$; Table 2-3, page 71), but this is unlikely considering only one line of evidence (marked with a *) compares $c t 2 /+$ plants with any other genotype.

Thus, these data suggest that $c t 2$ is functioning to determine the number of axillary meristems that are initiated in double mutants, while Sos 1 is responsible for the significant differences in numbers of single versus paired spikelets. Notably, the significant differences between paired and single spikelets are not observed when Sos 1 homozygotes are compared to Sos1;ct2 double mutants, indicating that there is a heterozygote effect in the double mutant. In addition, these interactions confirm that one gene is not masking the other, and instead they act in an additive manner, signifying that the $\operatorname{sos} 1$ gene functions in a different, but perhaps parallel, pathway than $c t 2$. 
Average Branch Number

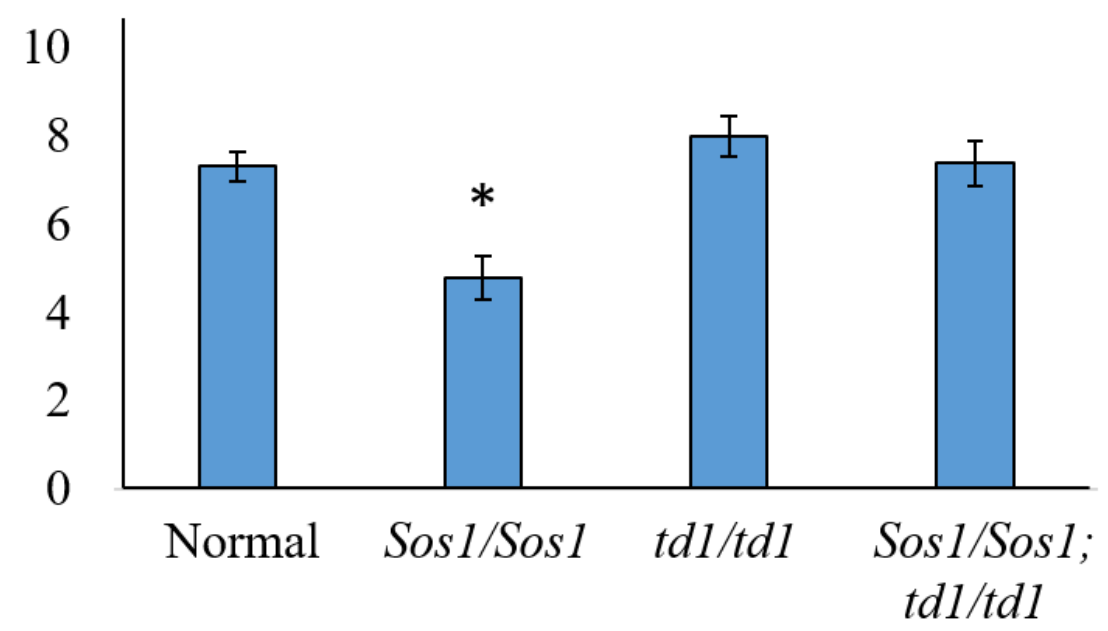

Figure A-1. Analysis of branch number in Sos1;td1 double mutants. Sos $1 ; t d 1$ double mutants develop the same number of branches as $t d l$ tassels, but more branches than Sos 1 mutants, indicated with a *. Error bars represent custom standard error values calculated for each category. 


\section{Peduncle length $(\mathrm{cm})$}

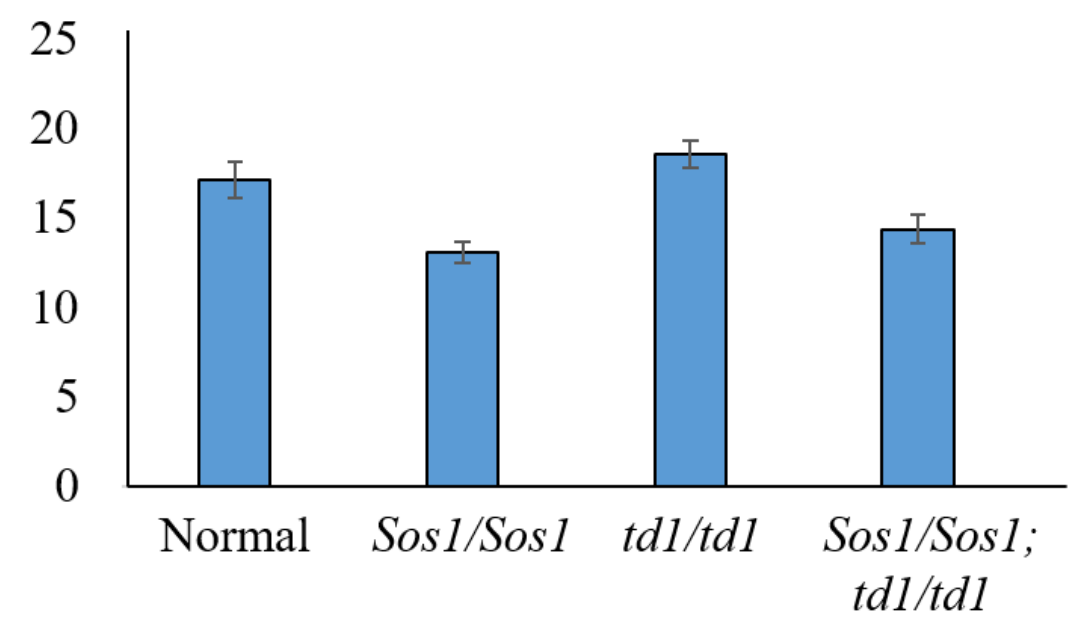

Figure A-2. Analysis of peduncle length in Sos1;td1 double mutants. Peduncle lengths in Sos 1;td1 double mutants do not differ from either Sos 1 or $t d 1$ tassels. Error bars represent custom standard error values calculated for each category. 


\section{Average Branch Number}

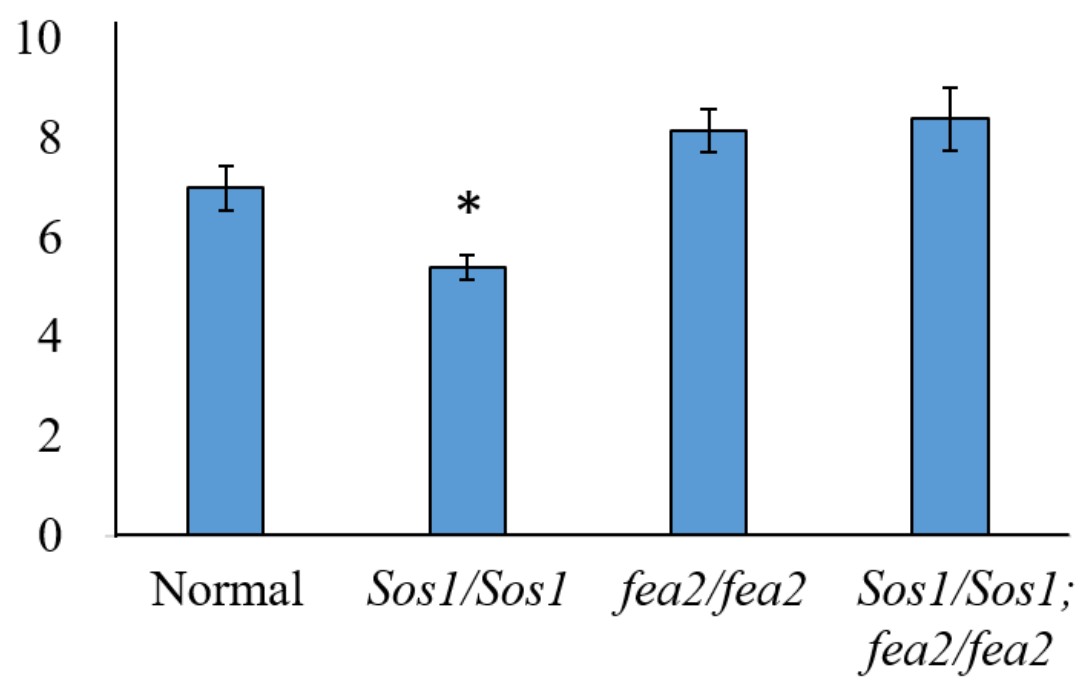

Figure A-3. Analysis of branch number in Sos1;fea2

double mutants. Sos 1;fea2 double mutants develop the same number of branches as fea 2 tassels, but more branches than Sos 1 mutants, indicated with a *. Error bars represent custom standard error values calculated for each category. 


\section{Peduncle length $(\mathrm{cm})$}

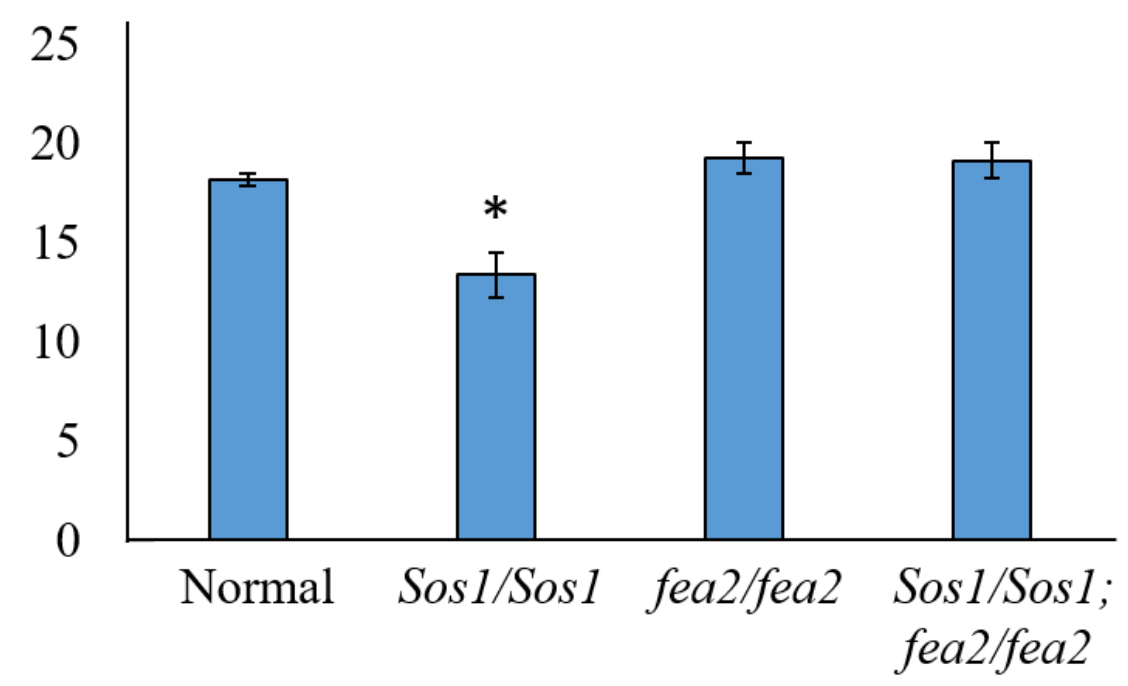

Figure A-4. Analysis of peduncle length in Sos1;fea2 double mutants. Peduncle lengths in Sos 1;fea2 double mutants do not differ from fea 2 tassels. However, double mutants have significantly longer peduncles than Sos 1 tassels, indicated by a *. Error bars represent custom standard error values calculated for each category. 


\section{Average Branch Number}

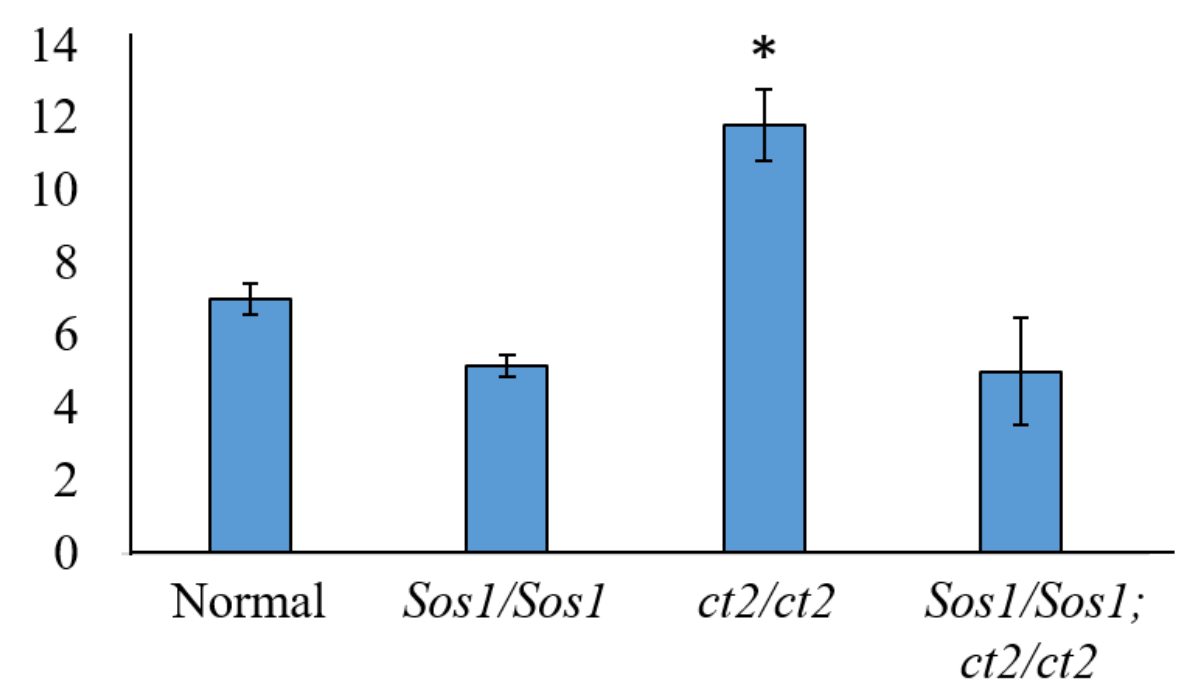

Figure A-5. Analysis of branch number in Sos 1;ct2 double mutants. Sos 1; ct 2 double mutants develop the same number of branches as Sos 1 tassels, but fewer branches than ct 2 mutants, indicated with a * Error bars represent custom standard error values calculated for each category. 


\section{Peduncle length $(\mathrm{cm})$}

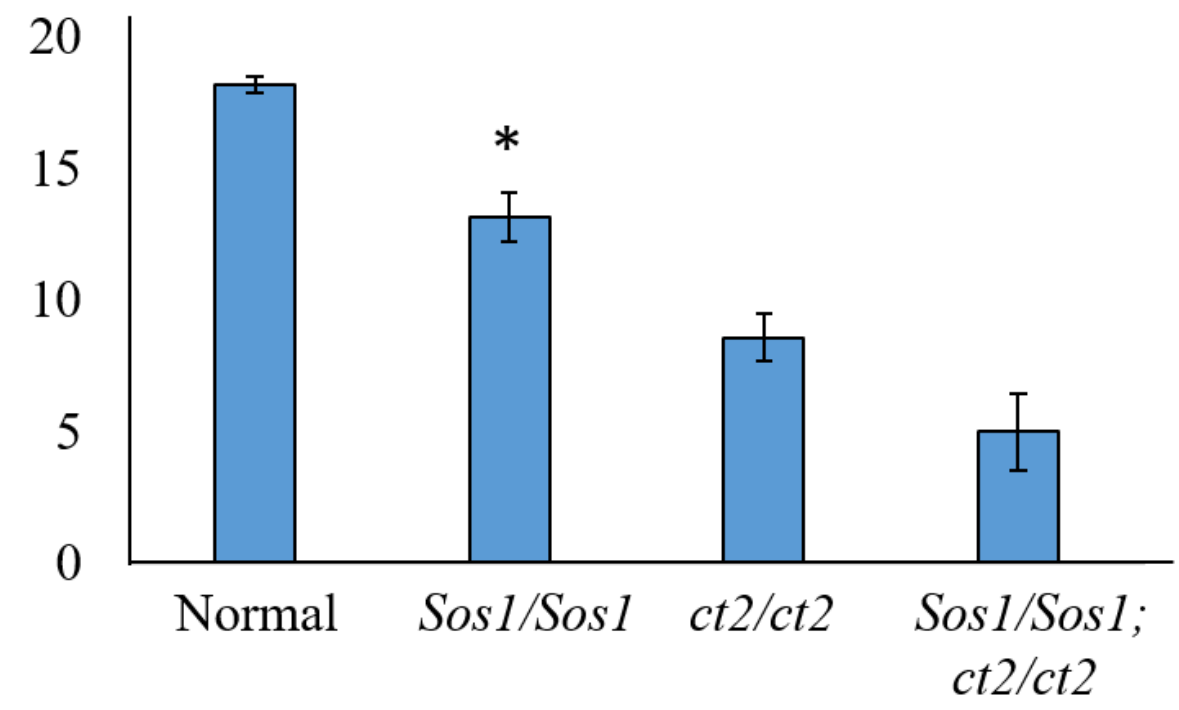

Figure A-6. Analysis of peduncle length in Sos1; 2 2 double mutants. Peduncle lengths in Sos 1; ct2 double mutants do not differ from $c t 2$ tassels. However, double mutants have significantly shorter peduncles than Sos 1 tassels, indicated by a *. Error bars represent custom standard error values calculated for each category. 